Southern Methodist University

SMU Scholar

Fall 12-15-2018

\title{
Dignity in Decision-Making: Modernity and Social Navigation among Rural French Polynesian Youth
}

\author{
Laura Jarvis \\ Southern Methodist University, Icjarvis@smu.edu
}

Follow this and additional works at: https://scholar.smu.edu/hum_sci_anthropology_etds

Part of the Polynesian Studies Commons, and the Social and Cultural Anthropology Commons

\section{Recommended Citation}

Jarvis, Laura, "Dignity in Decision-Making: Modernity and Social Navigation among Rural French Polynesian Youth" (2018). Anthropology Theses and Dissertations. DOI: https://doi.org/10.25172/td/ 13446839

https://scholar.smu.edu/hum_sci_anthropology_etds/5

This Dissertation is brought to you for free and open access by the Anthropology at SMU Scholar. It has been accepted for inclusion in Anthropology Theses and Dissertations by an authorized administrator of SMU Scholar. For more information, please visit http://digitalrepository.smu.edu. 


\section{DIGNITY IN DECISION-MAKING: MODERNITY}

\section{AND SOCIAL NAVIGATION AMONG \\ RURAL FRENCH POLYNESIAN}

YOUTH

Approved by:

Prof. Caroline Brettell

Professor of Anthropology

Prof. Carolyn Smith-Morris

Associate Professor of Anthropology

Prof. Sheri L. Kunovich

Associate Professor of Sociology

Prof. Nicolas Sternsdorff-Cisterna

Assistant Professor of Anthropology 
DIGNITY IN DECISION-MAKING: MODERNITY

AND SOCIAL NAVIGATION AMONG

RURAL FRENCH POLYNESIAN

YOUTH

A Dissertation Presented to the Graduate Faculty of
Dedman College
Southern Methodist University
in
for the degree of
Partial Fulfillment of the Requirements
Doctor of Philosophy
with a
Major in Anthropology
by
Laura Jarvis
M.A., Anthropology, Southern Methodist University, Dallas

December 15, 2018 
Copyright (2018)

Laura Jarvis

All Rights Reserved 


\section{ACKNOWLEDGMENTS}

Above all else, I would like to thank my families and friends on Tahiti and Rurutu, without whom this project and work would never have existed. The consistent hard work and understanding of those who I worked with made the project not only possible, but enjoyable.

There are a number of professors and peers who are deserving of praise and acknowledgment for their ongoing support. First and foremost, I would like to thank my late advisor, Dr. Victoria Lockwood, who gave me the resources and knowledge to get started on this path. I would also like to thank my current dissertation committee. Dr. Caroline Brettell became an invaluable lifeline when she took on the task of pushing me to the end, helping me find my voice and organize my often-rambling thoughts. Dr. Carolyn Smith-Morris has been a constant source of support and guidance throughout my career at Southern Methodist University. Even though he joined later in the process, Dr. Nicolas Sternsdorff-Cisterna never hesitated with encouragement and advice. Lastly, I would like to thank Dr. Sheri Kunovich, whose support and guidance was invaluable.

Furthermore, I send a gracious thank you my cohort in the Anthropology Department, especially my writing partners, Saira Mehmood and Afshan Kamrudin. Saira has been invaluable as a mentor and friend who has gone above and beyond in both reading and editing as well as providing constant entertainment when necessary. Afshan, with her SMART goals and weekly check-ins, may be the reason I made it this far. A heartfelt thank you also goes out to the 
numerous other graduate students in the Anthropology Department (cultural and archaeology) who were always willing to lend an ear or talk through a problem.

Of course, I cannot forget the immense love and support that I have received from my partner, Jake Seibert. He has picked me up and pushed me through when I could not see the light at the end of the tunnel. Recognition is deserved for my two best friends, Lauren O'Brien and Mary McMillan, as well as my sister, Aundrea Jarvis, for never giving up hope and always being there with support, feedback, or funny memes when it was necessary. And, of course, all the love and gratitude in my heart goes to my parents, Dorothy and Jack Jarvis, who have been nothing but supportive of their daughter who perceived the world as something to be studied as well as seen. I owe them everything. 
Dignity in Decision-Making: Modernity

And Social Navigation Among

Rural French Polynesian

Youth

Advisor: Professor Caroline Brettell

Doctor of Philosophy conferred December 15, 2018

Dissertation completed November 27, 2018

This research examines critical questions about the experiences of youth through the lenses of modernity, subjectivity, and the lifecourse. Growing up in a (post)colonial context of shifting definitions of adulthood, youth from the rural island of Rurutu, French Polynesia must navigate various decisions and transformations with little information to base their future aspirations on. This dissertation identifies dignity as the main motivating factor in youth decision-making, one that is constantly redefined as youth navigate shifting social fields. Dignity, as used here, is a target youth strive for in order to contest feelings of social precarity stemming from unaccommodating education systems and an unstable economic and political situation.

Conceptually, the research is framed by Johnson-Hanks' theory of vital conjunctures, which she defines as 'the zone of possibility that emerges around specific periods of potential transformation in a life or lives' $(2002,866)$. This research expands the examination of vital conjunctures through the use of what I will refer to as "vital conjuncture narratives." These narratives allow young people to reflect on the turning points they find most important, instead of relying on those established by the anthropologist, thus revealing the frequency and flow of 
decisions as well as the experiences of transformation. This way of examining youth allows for narrative agency and problematizes the historically linear lifecourse concept of transitioning into adulthood. These narratives show that youth seek dignity through connections to tradition, land, and family, upholding their ties to Rurutu as a foundation upon which to build their lives. 


\section{TABLE OF CONTENTS}

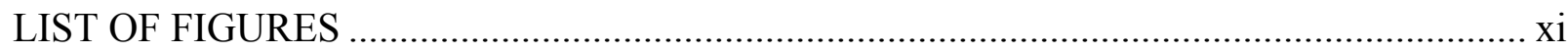

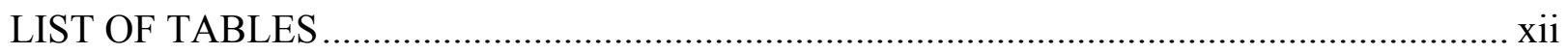

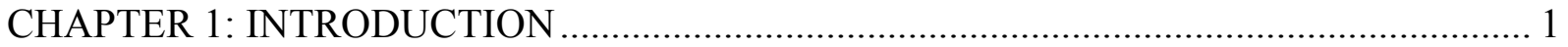

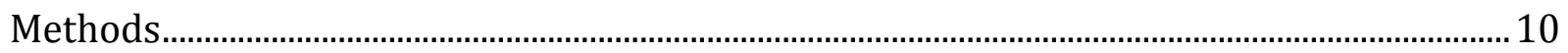

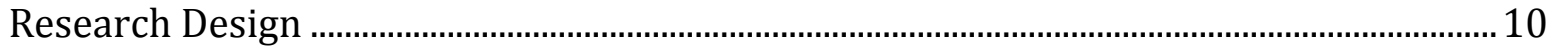

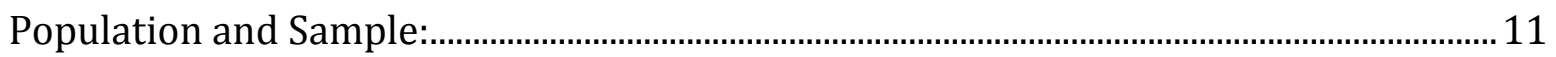

Participant Observation:........................................................................................................... 15

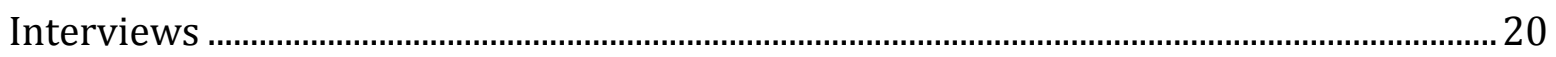

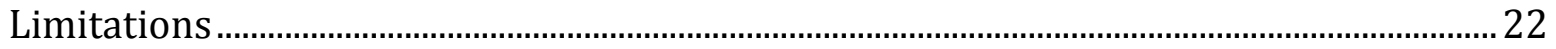

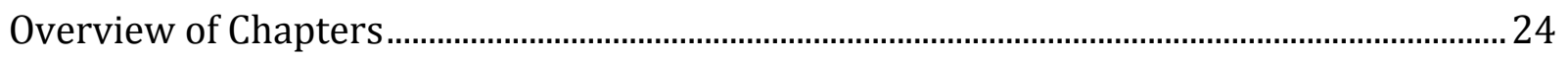

CHAPTER 2: THEORETICAL FRAMEWORK: THE ANTHROPOLOGY OF

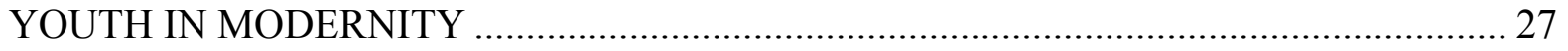

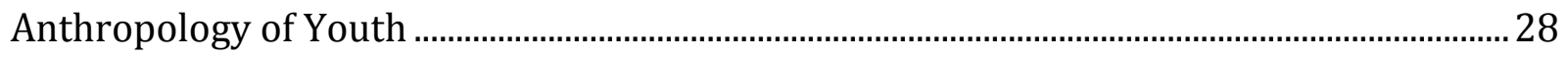

Identity, Subjectivity, and Social Navigation................................................................................. 44

Vital Conjunctures and Dignity ......................................................................................................... 47

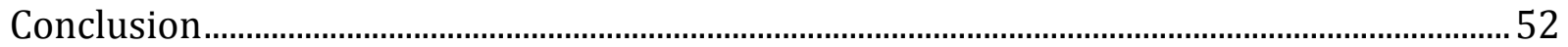

CHAPTER 3: RURUTU AND TAHITI: HISTORY AND ETHNOGRAPHIC

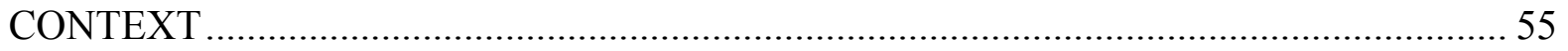

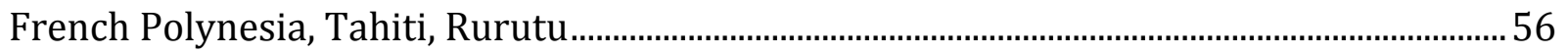

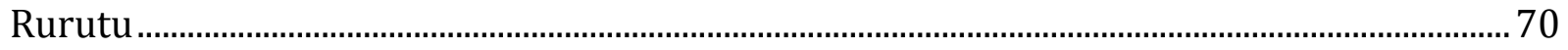

Education Policies in French Polynesia................................................................................. 81

The Life Course, Transformations, and Ambivalencies............................................................8

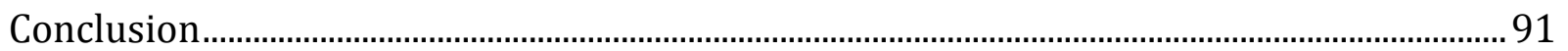


CHAPTER 4: TRANSFORMATIONS AND VITAL CONJUNCTURES:

A THEMATIC OVERVIEW

Coding Vital Conjunctures.

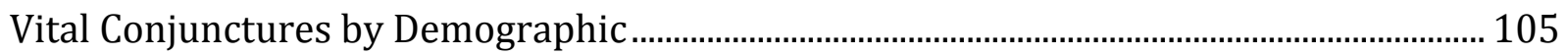

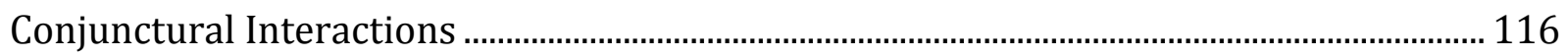

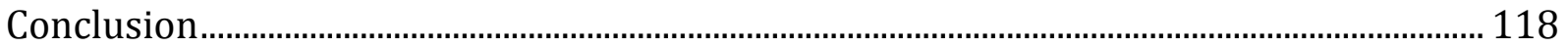

CHAPTER 5: JE SUIS FIU, TU ES CLASSE: EDUCATION AS

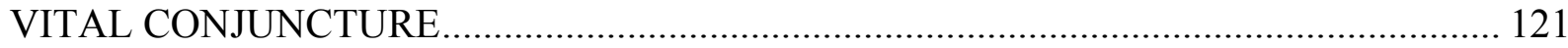

Experiences of Agency in Educational Decision-Making ..................................................... 127

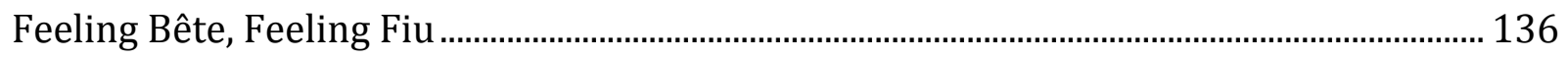

Classe

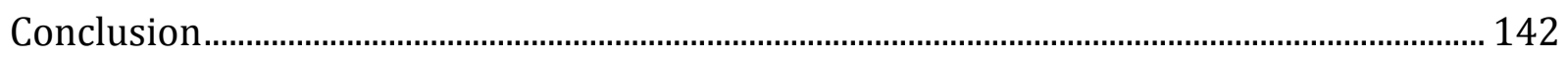

CHAPTER 6: AMBIGUOUS DIGNITY: NEGOTIATING PRESENT AND

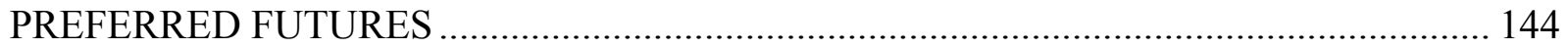

Conscious Liminality and Delayed Choices ............................................................................. 148

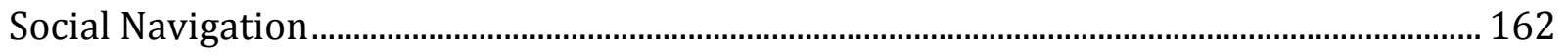

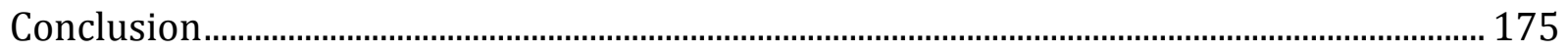

CHAPTER 7: JE SUIS RURUTU: CONNECTION AS DIGNITY ..................................... 179

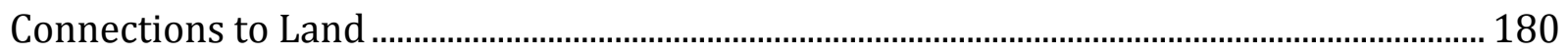

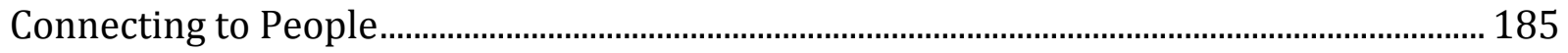

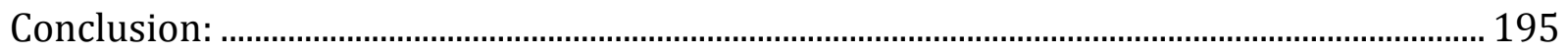

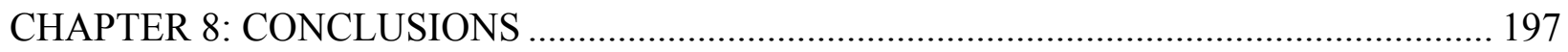

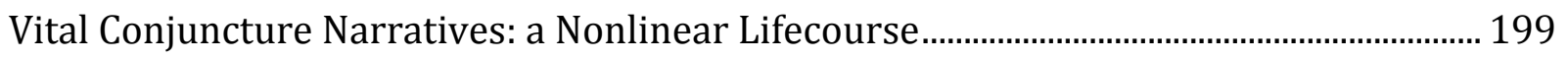

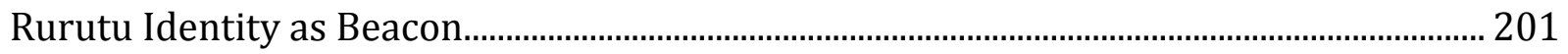

Dignity as Lodestone: Searching out dignity in everyday victories ..................................... 203 


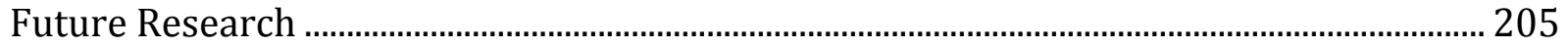

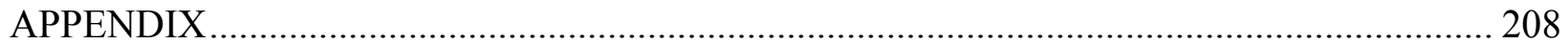

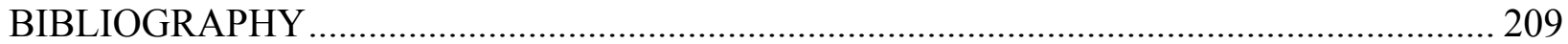




\section{LIST OF FIGURES}

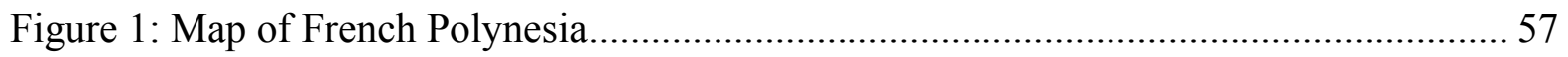

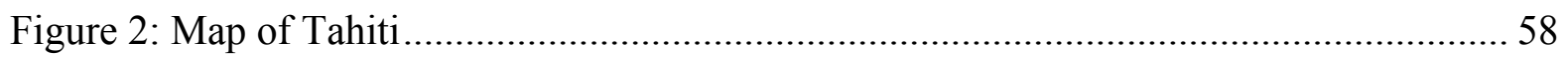

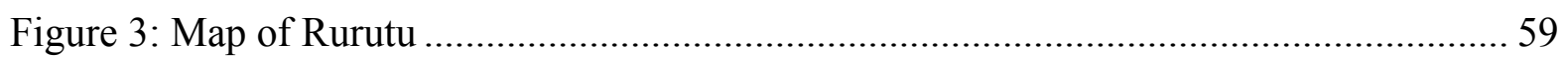

Figure 4: French School System in French Polynesia ............................................................ 83 


\section{LIST OF TABLES}

Table 1: Quotas for Interview Sample of Rurutu Youth..................................................... 13

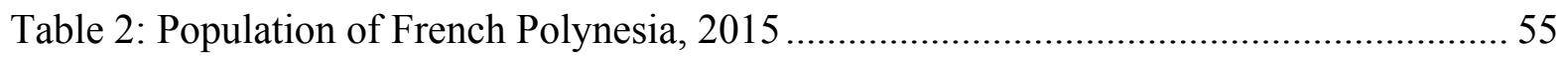

Table 3: Decision Count by Code ..................................................................................... 83

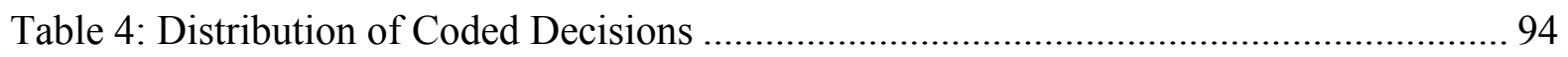

Table 5: Distribution of Youth per Vital Conjuncture ………………………………............... 96

Table 6: Distribution of Vital Conjuctures by Gender........................................................ 107

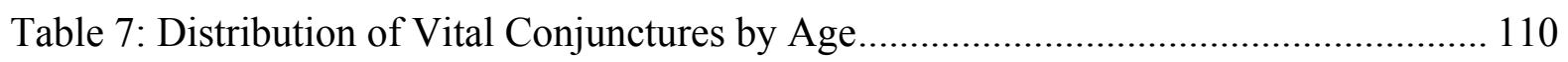

Table 8: Distribution of Vital Conjunctures by Town .................................................... 112

Table 9: Distribution of Vital Conjunctures by Level of Education.................................... 114

Table 10: Overlap of Coded Vital Conjunctures ……………........................................... 116

Table 11: Educational Outcomes and Agency in Decision-Making..................................... 127 


\section{CHAPTER 1 INTRODUCTION}

I was halfway through my field research on Rurutu, French Polynesia when I became fully aware of what it was that I was seeing in my research on decision-making. That day I had joined Manu (28) in his taro field. He had promised to show me the finer points of planting taro, and I was hoping to use the time to better understand his life story and current lifestyle. I knew that he was raised by his grandparents and had been extremely close to his grandfather before he passed. I knew his girlfriend came from the farthest of the Austral island group, Rapa, and that they had a baby together. I also knew that he had decided to quit school before receiving his baccalaureat, the equivalent of a high school diploma, because his grandfather fell ill and he was called in to be caretaker. We chatted about life on Rurutu, and how happy he was to lead a simple life of planting taro and living in a big home with his little family as well as 8 extended family members. At one point, while we were hammering handmade stakes into the ground to stabilize the mound where the taro would go, Manu's uncle approached. He spoke about the weather and the planting season, and then made a strange comment. He said to me, "See how Manu keeps his taro fields clean and clear of debris, but his lines are not quite straight? That means he is not yet there. You can tell a lot about a man by looking at his taro fields." At that, he meandered past us, leaving us to contemplate his proverb. So I asked Manu what he thought it meant. He replied:

"Well, you see, I think it means that I am coming along in my life, but I have not arrived. When you can get your taro straight, and your life straight, that's when you are respected. When I first came back to Rurutu to care for my grandfather 
and take over the tarodier, I was lost. I had left school and my girlfriend behind and was taking on so many responsibilities and I didn't know how to do it. But people were counting on me, so I learned to be respectable. I became diligent about cleaning my taro fields, I brought my girlfriend back here to live, and now we have a son. I have found my calling in planting taro, and I provide for my family when I can with the taro I plant. My life is clean, but my lines are still not quite straight. I have more to do, but I am responsible. I live well.

I then asked Manu at what point he thought he might "get there." He laughed and shrugged, and said, "I have no idea. But it's the trying that matters." At that moment, many of the narratives I had listened to from youth made sense. The decisions they made, as well as how they narrated them, were to show that they were growing and striving for some intangible thing. I have since labeled it dignity. From this idea of dignity, my research addresses several critical questions about the experiences of young people: first, what do young people see as the turning points in their lives; second, what do the transitions and decisions throughout their life courses reveal about their connections to society; third, how do changing global and local influences impact their definition of dignity?

In my rural field site of Rurutu, French Polynesia, youth grow up in a country that still depends on colonial assistance, but has been given autonomy in their local governance. France has kept control over education, health care, and media, but local governance, customs, and interactions show a certain authority of traditional practices. Thus, there is constant tension between revitalization and maintenance of local culture and acceptance of and desire for modern technologies and commodities. My research delves into how this history, and the current political-economic climate of the country, has affected Rurutuan youth. More specifically, I explore how colonial modernity impacts the motivations behind the decisions that youth make in relation to their hoped for futures and definitions of dignity, and how these decisions allow youth to navigate shifting social fields. 
I chose French Polynesia as my field site because, although many of the early research on youth took place in Oceania (Mead 1928, Herdt \& Leavitt 1998), there are few contemporary studies about youth from French Polynesia, especially the more rural areas. Rurutu and its neighboring islands avoided most large-scale development projects and thus were trapped between global influences and commodities and traditional subsistence living (Lockwood 2002). On my first trip to Rurutu, I witnessed an array of not-quite-modern but not-quitetraditional beliefs and actions. Specifically, I was struck by the hybrid nature of the Heiva festival, which celebrates Tahitian heritage during France's Bastille Day celebrations (a colonial complexity in and of itself). The young people took part in traditional dances and competitions, for which they won cash prizes they used to buy western clothing, shoes, and alcohol. The barracks, where the celebrations and other revelry took place, were covered in local plants, vines, and flowers, but inside they looked just like the arcades in the United States. This constant bombardment of contradiction, and the negotiation of it on the local level provided a perfect arena for a study of youth and identity.

I also chose Rurutu because of the leveling effect French colonialism has had on the local socio-economic sphere. French subsidies and communal land tenure, as I will discuss in chapter three, have kept income inequality to a minimum on the island. Also, while there is some cultural diversity, including French and Chinese influences as well as Tahitian, most youth on Rurutu have similar backgrounds - certainly more than in any middle or high school in the United States, or even on Tahiti. There is also an absence of serious water or air borne illnesses, and no political warfare or widespread violence, which can also have a serious effect on the life courses of young people (Langevang 2008, Lowe 1998, Masquelier 2005, McDade 2001). Therefore, I have been able to theorize that the decisions and transformations youth from 
Rurutu experience can be traced back to the interaction between internal forces and cultural factors such as one's ties to place and family, postcolonial structural obstacles like educational forces that do not align with local opportunities, and economic issues such as unemployment or overpopulation.

Although there is a high degree of homogeneity among the youth who grow up on Rurutu, there is still diversity of experiences and negotiated identities. Due to the colonial past and present, French Polynesia provides a fascinating dichotomy of autonomy but not sovereignty, which is useful for this type of research because it creates multiple national and local narratives that are directed daily at youth through media, education, and family. Oftentimes, the period I define as youth (aged 15-25) is marked with familial happiness and discontent, unplanned pregnancy, the ups and downs of living far from home, and such small victories such as volleyball tournaments, baccalaureat certificates, and blossoming relationships. Choices I originally considered anthropologically important, like those concerning school and future education, hardly registered as important in the grand scheme of some youths' life courses even though they have the power to set them on particular paths. So, instead, I set out to answer the question of what are really seen as important transformations. Therefore, this research is concerned with defining the most common vital conjunctures among French Polynesian youth, examining the individual and shared experiences of these vital conjunctures, and analyzing which cultural, social, economic, and political forces influence and impact these times of transformation.

Continued colonial presence is coupled with the rapid globalization in in the last 20-30 years that has altered the way of life for the youth who grow up in French Polynesia, and by extension Rurutu. Even between my first summer on Rurutu in 2011 and my 2015 research trip, 
the number of young people on Facebook, with Wi-Fi in their homes or the homes of family members, with iPhones and 4G cellular data tripled. Furthermore, there is an ongoing tension of identities experienced by youth: life on Rurutu is an anomalous mix of connections to traditional beliefs and land as well as connections to global consumption patterns and modernfacing lifeways revolving around advanced education and wage work. Not only does this struggle impact how youth live their lives, but these experiences can even shift depending on such demographic characteristics as age, gender, and town of residence. Thus, youths' selfdefined important decisions can be affected by numerous demographic variables.

Not only do young people negotiate complex identities, but they also transition to adulthood in diverse and complex ways as well. Conceptually, I find it most suitable to frame this in relation to Johnson-Hanks' (2002) formulation of vital conjunctures, which I discuss in more detail in Chapter 2. Johnson-Hanks defined a vital conjuncture as "the zone of possibility that emerges around specific periods of potential transformation in a life or lives" $(2002,866)$. Here, I define vital conjunctures as times youth have pinpointed in their lifecourse when an interaction of influences changed the direction of their path in life through either an important decision or an experienced transformation. Vital conjunctures are useful because they allow the researcher to shift focus from the destination to the journey of growing up, and because they afford consideration of aspirations and transformations instead of transitions historically associated with adolescence. This shift is important because while transitions generally denote a singular direction of change, studying youths' aspirations and transformations allows us to problematize the journey from childhood to adulthood, and to examine life-course events beyond whether they move an individual forward or backward on an arbitrarily linear path. 
Vital conjunctures also allow us to consider the agency of each youth while he or she negotiates tradition and modernity, thus providing a more nuanced examination of growing up.

This research furthers the examination of vital conjunctures through the use of what I will refer to as "vital conjuncture narratives." These narratives allow young people to reflect on the turning points they find most important, instead of relying on those established by the anthropologist, thus revealing the frequency and flow of decisions as well as the experiences of transformation. This way of examining youth allows for narrative agency and problematizes the historically linear lifecourse concept of transitioning into adulthood. When youth are allowed to pinpoint and then examine their experiences of important turning points, we can better understand how they navigate contradicting forces to define their present and future. Lastly, this research goes one step further in asking how youth utilize different identities and alliances to reveal what is important to them. The case studies that follow show that youth seek dignity through connections to tradition, land, and family, upholding their ties to Rurutu as a foundation upon which to build their lives.

Two further experiences during fieldwork revealed the ongoing hybridity of modern experiences and identities of the youth I worked with. Bhabha (1994) draws on the idea of hybridity to express the lack of discrimination between "mother culture" and "colonizer culture," instead seeing modern cultures as a condition of both. The following vignettes show how youth can utilize different spatial and social categories to claim modernity or claim the opposite as well as how they define Rurutu and being Rurutuan in diverse and contradictory ways. My very first experience with youth and modernity in the field was during an impromptu conversation with my housemate and key informant, Vania: "We are not modern!" Vania exclaimed, with an exasperated laugh, when I mentioned studying modernity on her island of 
Rurutu, French Polynesia. “Then what are you?” I asked her in response. Vania contemplated the question, and responded, “We are, I don't know what we are. We're Rurutu! Why do you say we're modern?" At the time I wanted to explain that I didn't mean "modern" in the way it came across - that I was studying modernity, their experiences of development and globalization, changing values and future prospects - but it was my sixth day in the field, so in my broken French I responded, "I don't know, your television, music, education, the laptop you use for Sunday mass, your email account?" Her answer to that, which only struck me later, was, "I suppose those things are modern, but I don't feel modern. I still eat the fish that [my boyfriend] catches, we still cook in the earth oven, and we can pick free fruit from the trees in the forest." At that time, Vania had quit school in her second to last year and was living on Rurutu with her boyfriend. She had registered for a yearlong apprenticeship to learn how to weave traditional hats, baskets, and mats in order to support herself. Two years later, Vania had broken up with her earth oven cooking boyfriend, had found a new boyfriend who was heading to university, and was living on Tahiti completing secondary school with plans to get a nursing certification.

Another two years later, in a different context, with different interlocutors, I had a much different conversation. I inadvertently started an argument about the pros and cons of rural development between my friend Loma and her boyfriend, Vavi when I mentioned how much I liked the new trading post at the quai in Moerai, the largest of the towns on Rurutu. Loma agreed with me, remarking that now the island was better able to sell local products to those who were passing through on the supply ships that came to Rurutu every two weeks. "And!

${ }^{1}$ Quai is the French term for a platform or wharf, and is the term they use to describe the small port in Moerai where the boats carrying supplies dock.

${ }^{2}$ In the French educational system, lycée is the second half of secondary school, which 
Now I have a place to peruse the latest styles of weaving before I buy anything." Vavi, on the other hand, was appalled that the government had sponsored the construction of a marketplace instead of supporting something that would be of use to them, such as new farm equipment for the local agricultural co-op. He also admonished the government for spending so much when there were so many young people who were not awarded any government-subsidized labor contracts that year. His friend, Tea, a student who was studying urban planning and engineering at the lycée $e^{2}$ on the main island, agreed that Rurutu should stay rural. "If it doesn't, I may be forced to move to a remote island to live out my days." When I asked him how he would put his credentials to use on a desert island, he merely smirked, shrugging his shoulders and taking another sip of rum. At first I was struck by the contradicting views on modernity, but it was really the ambivalence of Tea's view that impacted this research. He lauds rural development and increasing Rurutu's connection to the global market while studying engineering and urban planning. When I interviewed him later, he replied, "I know I will have to go elsewhere to utilize my education and talents, but Rurutu, my home, should not succumb. We love te fenua ${ }^{3}$ because it is simple."

Both the youth in my study and their social context are in a constant state of change. As I further analyze in Chapter 2, studies of modernity have problematized the traditional/modern transition, while youth studies have problematized the linear child/adult model. In both senses, the experience is more of a transformation. This is useful in seeing that there is no longer a singular destination of modern or adult. Originally, I was going to analyze how "modernity" impacted the vital conjunctures of youth as well - how the decisions of those who identified as

2 In the French educational system, lycée is the second half of secondary school, which directly follows collège and includes youth aged 14-20.

3 Te fenua is a Tahitian word for homeland or nation. 
modern and utilized "modern" materials would differ from youth who preferred to stay local and traditional. I wanted to see how the former would probably prefer a higher education to align with French ideals, while the latter might see the benefits of completing lower levels of education and moving home. In reality, my experiences on Rurutu problematized this dichotomy. Thus, this research instead adds to the body of work associated with youth and modernity by showing the impact of rapid technological advancements and shifting media on youths' social navigation. It also shows how modern influences can change or reify definitions of dignity while diversifying life courses and individualizing definitions of youth, adulthood, modern, and dignity.

Due to the historically non-linear nature of experiences during youth and adulthood, I have approached this research not to examine transitions into adulthood, but to examine the motivations and diverse decisions/transformations that youth experience. Tahiti has never really had a defined entrance into adulthood, so there is very little difference now on how to become adult, except that the ways in which individuals once gained responsibility and respect have become increasingly difficult due to the simultaneously opposing and coalescing expectations between global movements and local values. New opportunities such as higher education and challenges like the lack of adequate wage work and increasing cost of living can come up against ties to land and home. To best cope with these obstacles and call to the forefront the social and individual transformations youth from Rurutu experience, I will utilize the concept of dignity. As young people grow up, they are judged on their self-representation. Therefore, I define this struggle as striving for dignity. I am considering vital conjunctures in relation to a person's definition of dignity. Dignity, as a term, is something that can be strived for as well as something that can be taken away. Thus, to live with dignity, or protect one's 
dignity from being lost, there are priorities to which one must adhere. What are these priorities, and how do they relate to the contradictory influences youth must navigate?

Dignity, as an analytical concept, allows for fluidity in definition as well as action. As social positions and social fields shift, so can one's definition of dignity. Although my interlocutors never used dignity as a term, it describes the essence of what they were saying: the interaction of wants, needs, and expectations and the ways in which young people define their lives. For instance, in evaluating whether to pursue education or be loyal to family if a family member is sick, the only way to save one's dignity is to go home and care for one's family member. If they are experiencing impingement on their dignity and autonomy during their time in school on Tahiti, Rurutuan youth are more likely to quit school because maintaining dignity is more important than fulfilling western, colonial definitions of transitions to adulthood. The dichotomy between youth and adult, much like "modern" vs. "traditional, may no longer be meaningful except to problematize for study. Rather, we might speak of "adulting" which is living in a dignified way, and doing things that help an individual grow as a person. This is a subjective and personal process and dignity itself may be understood in different ways depending on individual situations and choices.

\section{Methods}

\section{Research Design}

This research took place in three separate phases. Phase one was a pilot study, in which I interviewed 94 people of all ages on their life histories and current lifestyles. This research was used to focus on key research questions. Phase two, in the summer of 2012, was aimed at refining my research methods, and determining the best ways to gather information on transitions, decisions, and the life course from diverse youth on Rurutu as well as Tahiti, as 
many who were born on Rurutu were living elsewhere, thus complicating the initial research goals. During the second phase, I also did research in schools and on the French Polynesian school system, including secondary and tertiary school attrition rates. The third and final phase was a 10-month-long trip, which consisted of four months on Tahiti and six months on Rurutu. The goal was 12 months in total, but an emergency forced me to cut the research short. During this third phase, I was a daily participant observer, interviewed 64 youth, six parents, and seven teachers and community leaders. The data presented in this dissertation is from the third phase. During 2015, I also performed household surveys as well as vital conjuncture histories, and gathered information on media, education, employment, and cultural revival.

This research focuses on the following objectives: to document different discourses and themes around aspirations and opportunities; to examine how demographic and household data correlate to the frequency of certain types of vital conjunctures; to define and record the experiences of youths' diverse vital conjunctures; to examine vital conjunctures for the motivations and priorities associated with them; to use the vital conjuncture narratives to examine social navigation and individual identity negotiation; and to use these navigations to problematize the correlations between modernity, the lifecourse, and adulthood.

\section{Population and Sample:}

\section{Interview Samples}

For the main phase of the research, that done between March and December, 2015, I adjusted the age range of the young people in my study to 18-30, as many of those in their late 20s were still not really considered "adult," as they had not attained certain status markers in the community. Furthermore, the older individuals in the sample, when compared to those who were younger, demonstrate how age plays a role not only in what vital conjunctures have so far 
occurred, but also in which experiences are deemed important (for instance, the choosing of a specialty in school would weigh heavier on the mind of a 19-year-old than a 27 -year-old).

While those who are younger can represent negotiations in identity or decisions about their futures through lifestyle choices such as clothing, television, or hobbies, those who are older often have settled into a way of life and created an internalized version of the events they experienced. The difference between those who have recently experienced vital conjunctures and those who are further detached from these times of vital conjuncture can tell us about how monologues can change over time, to represent who they have become.

The sample included young people who were raised in the three main towns of Rurutu (Moerai, Avera, and Auti) and currently living both on Rurutu and on the main island of Tahiti. This research required dual field sites because many youth live on Tahiti for extended periods for schooling, work, and internships, and some rarely return to Rurutu. To understand the spectrum of experiences of vital conjunctures, including those for residence, it was important to interview and spend time with youth on both islands. In the future, I would focus more on those living on Tahiti and in France, but the scope of this phase of research was smaller.

I attempted to fill a quota sample based on an equal representation of age, gender, level of education, and childhood residence on Rurutu. The quota sample represented youth from the three main towns of Rurutu, who were at the time living on Rurutu as well as o the main island of Tahiti. However, opportunities presented themselves in a pattern that is more representative of the population on the island. It is based on population distribution of Rurutu youth, so that the highest number of participants came from Moerai, the most populated town on Rurutu. The sample also skews in terms of level of education, with many more young people with their BAC than without. 


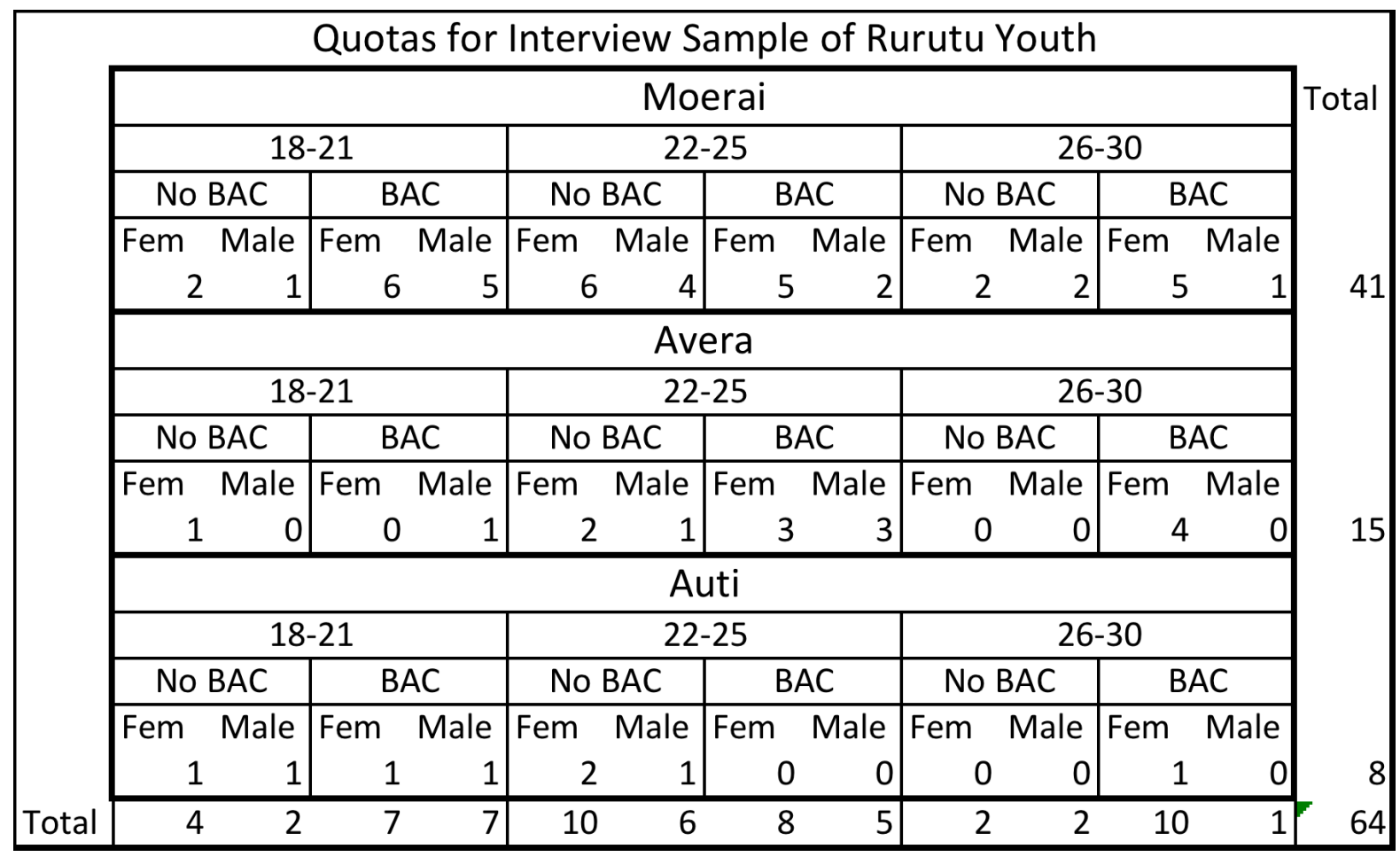

Table 1: Quotas for Interview Sample of Rurutu Youth

The youth in this sample who were living on Rurutu $(\mathrm{N}=58)$ were contacted via various connections, including three different local research assistants/key informants. I also connected to youth through my participation in sports, dance, and costume making, as well as through parents, friends, and sometimes just walking around town. It was significantly more difficult to get in touch with the youth who were on Tahiti $(\mathrm{N}=6)$ One of my interviews was actually done with a girl who was working at the hostel I was staying in. When she overheard me mention my research at breakfast, she insisted she should be interviewed. Otherwise, I connected with youth through mutual friends, research assistants, and at the universities and local secondary schools. 
This sample of youth ages 18-30 includes youth who are making decisions concerning their future education (or lack thereof), those who have quit or finished secondary school, those who may be in or have finished university, and those who have children and romantic partners, but are still living with parents and are still considered "youth." All youth in the sample also went through the portion of the French school system when they are counseled into making a decision about which track they prefer for secondary education. This allowed me to ask questions about the current process of educational decision-making as well outcomes up to ten years later.

In all, my sample included 64 interviews with 41 females and 23 males. Forty-one came from Moerai, 15 from Avera, and 8 from Auti. Six of these participants were living on Tahiti at the time of the interview, while the rest were interviewed on Rurutu. The interviews lasted between 45 minutes and 3 hours, depending on how loquacious each youth was. Due to time constraints and the limited reach of the social groups of my key informants, I occasionally had to interview individuals who I did not know well. While some of them were open (and actually became friends of mine) the majority of this portion of the sample chose not to continue on to the decision analysis or the participant observation. Therefore, most of those for whom I have extensive case study and participant observation data are mostly from the main village of Moerai, where I was living, or Avera where I also stayed for some time.

\section{Key Informants}

While on Rurutu I mostly lived with a key informant and her family - her little sister, the sister's boyfriend and daughter, the girls' mother, and occasionally her boyfriend. I also stayed for a while with her younger brother, his wife, and their infant son. On Tahiti, I stayed with her eldest brother and their father. She also lived there while she was in school. I also 
occasionally stayed at a hostel outside of Papeete on Tahiti. Luckily, the hostel was around the corner from my Rurutu friend Hotu's family home on Tahiti. Hotu and her sister-in-law were also willing to be key informants, and introduced me to their friends at the university and around town.

For the last month I was on Rurutu, I lived with a third family: My host's aunt, who I referred to as Tati (which means Auntie in Rurutu), as well as her college-aged son who was visiting from Tahiti where he was in school, and her elderly parents. At one point, her teenage niece also came to stay during Christmas vacation. The young people I lived with, as well as a good friend, Nat, were willing to also serve as research assistants. Although I was not able to pay them, all of my assistants were excited to help with my research; I made everyone dinner as reciprocity for their time and patience with me. My key informants also represented diverse socio-economic, education, age, and gender brackets, although all but one were from Moerai.

Throughout fieldwork, I had numerous other key informants who helped localize my questions, find other research participants, and with whom I spent a good deal of my time. It came to my attention fairly quickly that research on young people necessitates a higher level of rapport in order to attain useful data. Many were very shy at first and it took multiple meetings to develop a relationship of trust that permitted conversations about things that were happening in their lives. On the other hand, I was also occasionally surprised by how much they were willing to share, unprovoked, once I had crossed that line from researcher/stranger to researcher/friend.

\section{Participant Observation:}

For this research, participant observation was the most useful medium for gathering important data. According to Langevang, "Qualitative studies with young people require 
prolonged interaction with research participants, not only to understand their life worlds, but also to form relationships, build rapport and gain mutual trust” $(2007,2041)$. As was experienced during preliminary research, everyday interactions provide immense amounts of information. Holland et al. (1998) also argue that social positioning and intersubjective relations are best observed through everyday interactions. Therefore, time should be spent among groups of youth, as well as at their homes and schools.

This included following key informants (both on Rurutu and Tahiti) around during their days both at school, work, in the fields, or around the house to acquire knowledge of everyday routines, informal knowledge and practices, and other information that is not easily obtained through direct questioning. Participant observation allows for a better grasp on immediate reactions to events, how youth are treated in certain contexts and what is expected of them as well as what influential information is generated by the institutions they are closest to. It also offers a closer look at everyday lifestyles, including social networks, spending habits, and general feelings about their lifestyle. I kept notes about who we spoke to, what we did, and how much money we spent.

During my research on Tahiti, I periodically attended various classes at the local university (Université Polynésie Francaise: UPF) with my key informants from Rurutu. I also spent time with them at home, cooking, cleaning, and watching TV, as well as running errands in the city or around to visit local family members. There were occasional trips to the beach, or other leisurely opportunities. During these times, we would chat about plans for the near and far off future: from what to make for dinner, newest gossip in their siblings' lives, Facebook 
arguments, new and ruined relationships and friendships, to what to do if one of them got pregnant in the next year, or if their bourse $e^{4}$ was unavailable for the next year.

With Vania, I would follow her to class, lunch with friends from the university, grocery shopping for dinner, and around the kitchen while cooking. I discovered that university is a stressful experience because everything is online and most people do not have internet or even computers at home. If a student lacks internet access, they have to check in person every morning to make sure their class is not cancelled, or risk showing up for a cancelled class, which happens frequently. For the bigger lectures, we had to stand around for thirty minutes waiting for the doors to open to ensure good seats and space to write notes.

Vania and I also went on occasional morning workouts where we would take walks around our neighborhood, and spent evenings trying to teach her English and me Tahitian. We attended the Tahitian islands volleyball tournament to watch the team from Rurutu compete as well as a cultural heritage event at the university where dancers and orators from each archipelago represented the diverse cultures of French Polynesia. When Vania got pregnant, she also allowed me to attend her doctor's visits with her. Occasionally Vania's brother would order us pizza, or McDonalds, or they would make me attempt to fashion "American" food out of what was available in town. Their favorites were my "chili nachos" - made of Doritos, prefrozen hamburger patties, spices I had brought from home, and "cheeze" from New Zealand and my pommes de terre recuit, or twice-baked potatoes.

On Rurutu, I spent a lot of time around the house, observing everyday interactions and recording those who came to visit. Some days, we would spend the morning cleaning, setting

\footnotetext{
${ }^{4}$ Bourse is the term for the government funding for education, which pays tuition as well as a small stipend for living costs. Youth in French Polynesia are given the same support as those in mainland France, but the paperwork can be confusing, and not all families are diligent about turning it in to continue education.
} 
every single piece of bed linen out in the sun to banish the humidity, and drinking lemonade or grapefruit juice while snacking on mangoes and papayas from the trees in the yard. One of the first things I noticed during this participant observation is that housework is never finished on Rurutu. Vania claimed it was because she is a bit obsessive about the cleanliness of her house, but I also assumed she was battling boredom a lot of those days.

I also spent time in taro fields, toiling along with male interlocuters whom I had interviewed. The work was hot and backbreaking. We rarely spoke, other than to discuss the placement of the taro plots we were building, or the relative cleanliness of other families' fields. I also accompanied other interlocutors on expeditions to find tuna to prepare sashimi, as well as gutting freshly caught fish, preparing earthen ovens for special occasions, and during leisurely afternoons of playing petanque and volleyball on the road by our house.

Before I moved in with Tati, I spent a lot of time at her house. Since she was a wellknown local artisanat $^{5}$, her house was doubled as a trading post and local hangout for everyone aged five to eighty. She lived in the house with her son who was away for schooling as well as her elderly parents, and any number of cousins who decided to stay over or come to work on one of her many hand-woven rugs. I spent a lot of time sitting on the ground learning to weave and listening to the chatter of the older women about youth nowadays, and how they are having such a hard time because of the contradiction between the ways of the older generation and the dictated futures of the school system. I also listened as they judged the decisions made by younger people. Does it pay off to go to school? Should they take up farming and fishing like their fathers and grandfathers? Will that make them enough money to take advantage of

${ }^{5}$ Artisanat is the local word for anything made by hand, usually by local women. For instance, woven mats, baskets, hats, or decorative flowers would fall into this. Rurutu is well known for their artisanat women (Lockwood 1993), and this work garners them a living wage. 
everything out there? Is there a sort of respect in choosing to be an artisanat? But also, how good is your product? How trustworthy are you as a person?

In addition to these more intimate participant observations, I also attended church ceremonies - Catholic, Protestant, and Mormon - for Sunday mass as well as various local celebrations. I also witnessed three weddings ceremonies and receptions, of varying size from a grand Rurutu wedding in Moerai that hosted upwards of 1000 participants and lasted an entire week, to a day-long celebration in Avera, to a small gathering of a few hundred that included lunch and some dancing and disbanded at $8 \mathrm{pm}$. For the large ceremony, I was able to help with preparations including hosting family members from afar and hunting for locally produced baskets and garlands to gift the couple.

I also helped a participant to make her costume for the Heiva ${ }^{6}$ celebration, which is a very exhausting and very secretive process. I observed dance rehearsals, chorus rehearsals, and band rehearsals almost every weeknight from 7-9, and through the three phases of my research, attended three Heiva (Polynesian Heritage) celebrations on Rurutu. During these times I was also able to participate in many gatherings of youth from Rurutu, including social dances and parties, as well as less formal gatherings.

Altogether, I performed hundreds of hours of participant observation with at least 20 different youth as well as parents, community leaders, and other older people who fell into neither category. This extensive participant observation allowed me an intimate view of the

\footnotetext{
${ }^{6}$ The Heiva celebration is an annual French Polynesian celebration of Tahitian traditions and heritage, which dates back to 1881 and the annexation of French Polynesia by the French. Heiva is always celebrated around Bastille Day, but is full of Tahitian celebration, sports, competitions, and dances. For a more detailed examination, see: Kuwahara 2006; Stevenson 1990.
} 
perspectives of the influential people in the lives of my interlocutors, as well as youth whose lives I write about.

Interviews

\section{Youth Interviews}

My first step was to be seen with youth to establish myself as researcher. It was here that I would introduce myself and explain my research. Then I would ask if people were interested in working with me and participating in an interview. If they were, we would set up a time. Often it was difficult to find a private place to conduct interviews but once a time and place were established I would meet for the interview.

Prior to all interviews conducted for this project, participants were given a written consent document. A brief explanation was given, and then participants read the consent form and were given a chance to ask questions. All participants were required to sign the consent form before interviews and any private participant observation was performed. I found that the actual paper, instead of a verbal agreement and description made some of the young people second guess the purpose of the interview and the anonymity. It took some time to get them to open up, and I had to repeatedly explain that the interview would only be recorded verbally, and not with video. Once they understood that the recording was only audio, no one requested not to be recorded. Some refused to participate because they did not want to sign the paper and thus associate themselves in writing. Many were very nervous about anonymity, as they were discussing personal family matters, as well as situations and experiences that they did not want their parents or other important people to know about.

To get to the experiences of these vital conjunctures, and some of the influences on those decisions, I performed 64 semi-structured interviews that included sections on household, 
demographic, socio-economic, religious, and educational data. I asked about their families how many people did they grow up with, how many of them still lived on the island, what their parents/guardians do for work, what their levels of education are. I also asked questions about their lifestyles, including: how much TV they watched, their favorite shows and movies, whether they have Wi-Fi at home or where they go to use the internet, what, if any, social groups they are members of, and a brief network analysis. I probed for details on their relationships - both romantic and familial - their support networks and confidants, and their experiences at home and at school. Specifically, I asked each participant about the experience they had with choosing a specialization during the transition between the first and second parts of secondary school (college and lycée). This question was an etically designated vital conjuncture from my first two summers in the field, and proved an anthropologically useful facet of the life-course experiences of youth from Rurutu, which I will explain in Chapter 6. The last portion of the interview was to ask about the path their life has taken, and what they see as the three most defining moments of decision or transition. For the sake of this research, these moments are what I have termed "vital conjunctures".

\section{Vital Conjuncture Narratives}

For those who were willing to participate further, I then proceeded to delve into the descriptive accounts of these vital conjunctures $(\mathrm{N}=12)$ For many of the interviews, coaxing this information out of a participant was difficult. It took many different explanations and examples to even get to a point where we were talking about the same thing. It made the process seem authentic and natural, that as soon as they understood what I was asking there was a flood of information, anecdotes, and stories relating to these times in their lives.

In addition to the vital conjunctures the interlocutors detailed in their interviews, I also asked about certain times that I considered a vital conjuncture, including the decision of the 
track they would follow during secondary school and any decision to quit school that they had experienced. Therefore I have data for the rates of outcomes of these decisions as well as descriptive accounts.

\section{Parent and Community Leader Interviews}

Parents and community leaders were interviewed in order to understand what potential futures and what forms of dignity were being portrayed to youth. I was able to complete only six interviews with parents of youth in my study. Although these interviews began as structured interviews, they tended to be much longer and more open-ended than those with youth. The topics these interviews covered included: household and demographic information about their family, their childhood experiences, social changes they have experienced on the island and throughout French Polynesia, youth today, and specifically their thoughts on their own children.

I was also able to complete interviews with one priest on Tahiti, one pastor on Rurutu, two Tahitian-born teachers, two French-born principals, and one guidance counselor at the local college. These interviews were usually relatively short in comparison to the parent interviews. They covered such topics as: issues young people face nowadays, the differences they see between youth from Rurutu, youth from the outer islands in general, youth from Tahiti, and French expatriates, and their opinions on how best to lower attrition rates of outer-island youth.

\section{Limitations}

This research had both its strengths and weaknesses. One of the strengths lay in the amount of work done to establish a high level of trust and the characteristics of a good listener. This effort created a working environment in which participants were comfortable enough to open up and be frank in their discussion of their lives, experiences and decisions. My position as part of a local family facilitated this process as people on the island could more readily place me 
into their social networks. Another strength was my age. I felt as though I could relate better to the young people I was interviewing, because I am also going through the same sorts of decisions and vital conjunctures.

The research also had its share of challenges. The vital conjuncture narratives were not as lengthy as was originally planned for, and I did not have time to go back and ask follow-up questions. Future research would certainly involve a more in-depth examination of these experiences. Thankfully, I was able to complete extensive participant observation in diverse areas of social, familial, educational, and employment sectors, which helped round out much of my interview data. Though I would have loved to record many of these conversations, I can only pull from extensive field notes, as I found that attempting to record stilted most conversation.

I also ran into gendered issues while doing this research. The plan was to interview and spend participant observation time with both male and female participants; however, due to gossip, relationships, and a general lack of comfort between the genders in French Polynesia, my research sample skews toward females. This became even worse after I was accused of having a relationship with one of my research participants. Suddenly women didn't want their partners speaking to me or spending any time with me, and as a result I became more uncomfortable with my research.

Also, due to my own anxiety, I realize I may have often misinterpreted culturally influenced disinterest as apathy about my research or maltreatment of me as a researcher. Therefore, I did not push to get more interviews than from those who were outwardly excited to speak to me. For the first half of my time in the field I had trouble discerning the difference between Rurutuan hospitality and actual trust in me as a researcher and friend. 
As part of my original plan, I hoped to be able to interview many teachers in the secondary schools around Tahiti, but I generally found that these teachers were uninterested in participating in the project. I passed out a survey to teachers at three schools on the main island of Tahiti. The surveys covered such topics as their treatment and relationships with rural youth they were teaching. The survey did not go well. My first step was to go to the principal of the school and ask permission. He gave it, but told me he would not actually help me, as it was against the rules to show favoritism to my project. I then spent time in the teachers' lounge to meet them and request interviews. I was granted one interview during this time. On my next trip to the teacher's lounge one of the male French professors informed me I was not going about it well, and recommended requesting interviews by leaving my information and a brief overview of my research in each teacher's mailbox. This yielded two interested professors, only one of who was able to set up a time for an interview.

Next, I attempted to deliver surveys to the professors in the teachers' lounge. I handed some out in person and left a stack on a table in the lounge with instructions to fill them out anonymously and leave them in a designated area in the lounge. After only receiving a handful of completed surveys, I gave up on this endeavor as well. Some of the issue was that this was earlier on in my research and my grasp of the French language was not as strong as it was near the end, and I was not explaining my research as well as I could have. Eventually I was able to interview five educators of French and French Polynesian backgrounds, though four of them were from my own (very) extended social network.

\section{Overview of Chapters}

This dissertation is divided into eight chapters. Chapters 2 and 3 are devoted to a review of pertinent literature and an introduction of Rurutu and Tahiti as my two research sites. Chapter 
2 defines my theoretical parameters in relation to the Anthropology of Youth, and includes an analysis of the processes of modernity and the changing life-course. Additionally, I explain how the concepts of identity and subjectivity play an important role in understanding the experiences of youth and introduce the analytical concepts that particularly inform my own research as presented in this dissertation, including vital conjunctures and dignity. Chapter 3 details the historical and cultural context of French Polynesia, Tahiti, and Rurutu, especially the impact of (post)colonialism on the lives of youth.

In Chapter 4 I focus on a quantitative analysis of the vital conjunctures youth detailed during their interviews. I analyze the frequency of each type of decision as it relates to social and demographic data such as gender, age, town of birth, and level of education. In this chapter I will also examine the interactions between different types of vital conjunctures.

In Chapter 5, I examine of one important but etically defined vital conjuncture: the decision of which path to follow in lycée. This decision is important to note, as it has the ability to set the tone for an individual's life. Although ending up in a bad educational track, or quitting school does not mean a young person is destitute, it can have an impact on their identity and their dignity. This chapter is organized by two emic terms that are used by youth to talk about their secondary school experiences of moving to the main island: fiu and classe.

In Chapter 6, I concentrate on the ambiguities that are navigated during vital conjunctures through the retelling of case studies and life histories of my research participants. In this chapter, I present the concepts of "conscious liminality" and "social navigation" (Arnett 2000). These concepts revolve around the various ways in which youth adapt to social fields to preserve or strive for dignity. 
Chapter 7 is a continuation of the analysis of my qualitative data, linking identity negotiation and social navigation to social connections (such as to family, land, peers) and "Rurutuness." Here, I contend that youth move through their lives by grounding themselves in their Rurutu identity, which they claim through diverse connections to land and people.

Chapter 8, my conclusion, reviews the key arguments of the dissertation, the contributions made to the anthropologies of youth, modernity, subjectivity, Polynesia, as well as highlighting pathways for potential future research. 


\section{CHAPTER 2 \\ THEORETICAL FRAMEWORK: THE ANTHROPOLOGY OF YOUTH IN MODERNITY}

In this chapter I provide a rationale, as well as a theoretical foundation for my analysis of the transformations and decisions experienced by rural youth on the island of Rurutu. This research is grounded within three theoretical realms, all of which deal with the positioning, experience, and agency of young people: Anthropology of Youth, Subjective Identity Negotiation, and Vital Conjunctures. I use these theories to understand how young people think of themselves, their present situations and future endeavors, and how they use these perceptions to navigate changing social contexts.

In the first section, I briefly describe the origins and history of studying young people in anthropology as well as other disciplines including psychology, sociology, and human geography. Then I discuss how these disciplines have examined youth within the context of globalization and modernity, which include post-colonial influences, consumerism and liberal economics, media and imagination, and increasing social uncertainty. In later chapters I will explain how globalization has affected French Polynesia specifically, as well as how youth navigate and compromise within changing social contexts.

In the second section, I discuss research on adolescence and the life-course in general, offering a critical analysis of these perspectives and pointing to new theories on fluidity and the nonlinear life-course. This foundation is important for understanding the vital conjuncture narratives of the youth in my study, because the transition to adulthood, which has always 
lacked a specific rite of passage in Tahiti, is becoming increasingly fluid with new educational opportunities and global influences.

Finally, I will discuss theories of identity negotiation, to ground the examination of youth, modernity, and life course in a model that takes levels of influence into account when examining motivations behind youths' decisions in terms of their past, present, and future. I conclude the chapter by delineating the concepts that will be critical to my own analysis of the quantitative and qualitative data collected during my fieldwork.

\section{Anthropology of Youth}

Adolescence has been a subject of study in psychology since the early $20^{\text {th }}$ century (Hall 1907), when researchers were trying to explain the time of "storm and stress" experienced by (predominantly white male) young people who were unable to transition seamlessly from childhood to adulthood. Cohen (2009) argues, in recalling this time in the history of research on youth, that the obsession with the naturally turbulent progression between childhood and adulthood was used to gloss over political and economic conditions that affect these so-called natural adolescent behaviors. Anthropologist Margaret Mead responded to this with her research in Samoa, arguing that "storm and stress" was a sociocultural phenomenon, and not necessarily a naturally occurring experience of this transitional period (Mead 1928). Other than Mead's work, adolescence and youth was, for the most part, viewed in terms of what it wasn't (childhood or adulthood), or in terms of generations, age-grades, and life cycle rituals (Buckholtz 2002).

In the middle of the $20^{\text {th }}$ century, specifically after WWII, sociology picked up the thread of researching young people in their own right. Through the Chicago School (Cohen 1955) and the Birmingham School (Willis 1977), sociologists examined the subcultures of 
youth (predominantly white male); they focused particularly on the shared meanings of the alternative lifestyles that were popular among subcultures (Cohen, 1955). These sociologists focused on youth as resisters, and studied the cultures they created as a break from the hegemonic society. This research continues in the same sort of vein, in that as youth often find dignity in resisting hegemonic definitions of modernity and adulthood. I will discuss this further in later chapters.

A renewed (that is, after Mead) interest in young people as a focus of research in anthropology can be traced to the Harvard Adolescence Project of the 1980s, which examined adolescence within cultures beginning the transition into global societies (Burbank 1988; Condon 1990; Hollos \& Leis 1989). International development studies also played a large role in this outburst of research on youth. Development agencies have had trouble defining youth from adults because the definitions they use do not match standing biological definitions of adolescence. For instance, the median age of the developing world is 25 years old (Lloyd 2005), and the definition of adolescence ranges between 12-25, but developmental grants in Senegal and Ghana were targeting 50 year olds if they fit the definition of dependency and underemployment that is so often correlated to youth (Dijk, et al. 2011). In response to these questions about how to define youth and adolescence, a few works came out. In the late 1990s there was a psychological anthropology special issue edited by Schlegel (1995), which showed various cross-cultural constructions of youth. There was also a seminal work on adolescence in the Pacific (Herdt \& Leavitt 1998), which examined how biology, culture, and social change were affecting the experience of adolescence as well as youths' impact as agents of change. They argued that social change was affecting the ways in which youth were identifying themselves and experiencing life transitions. However, while many of these projects were new 
in that they looked at adolescence as a social/cultural construction of importance to understanding cultures, most of them still examined youth as a mere step on the way to adulthood.

After the turn of the $21^{\text {st }}$ century, a new era of research on young people, which was shaped in part by Buckholtz' review article (2002), called attention to an emphasis on youth as agents in emergent cultural formations. This research, Buckholtz argued, was "sparked by the stimuli of modernity and globalization and the ambivalent engagement of youth in local contexts" (Buckholtz 2002, 525). At the same time, Deborah Durham (2004) was declaring youth a "social shifter," and that research on this demographic was of utmost importance if we were to understand the future of our world. As young people are the next generation of public leaders and decision makers, this work is important, but these researchers also call for examination of youth in their own position within a larger cultural context.

The existing body of scholarship that examines young people is characterized by several important debates. The first debate revolves around a precise definition of "youth". Researchers have defined it by age, ritual, psychological development, economic success and class, social category, and biological maturity or lack thereof. Anthropological research on youth (AmitTalai and Wulff 1995; Condon 1990, 1995; Heinsohn 2006; Last 2005; Leichty 1995; Roche 2014; Schlegel and Barry 1991) contests that the definition of youth is constantly changing because it is defined in relation to other age groups, political discourses, and opportunities. The diverse ethnographic contexts in which youth are studied have led to a divergence of definition. This raises critical questions: at what point does a person go from being a child to being a youth or adolescent? What about from adolescent to adulthood? Researchers across disciplines argue that neoliberal economics and radical social change are making a precise definition of youth 
increasingly difficult to identify (Arnett 2000; Brown et al 2009; Cote \& Bynner 2008; Finn \& Oldfield 2015; Levine 2011; Sennott \& Mojola 2017). Many theorists are relying on the school to employment transition as the grounds for delineation (Mendoza-Denton \& Boum 2015; Punch 2002), which is problematic in its inability to take transformations outside of the economic transitions into account.

The second area of research and debate explores aspects of the position of youth to determine agency, how they negotiate contradicting influences, how they use space and positionality to interact with the world, and how they produce and reproduce unique versions of "self" and "culture" (Elliston 2004; Esson 2013; Evans 2007; Flanagan 2008; George \& Rodriguez 2009). For instance, Deborah Durham (2000) uses 'youth agency and power' to confront contradicting discourses on youth and development in Botswana. The national discourse urges youth to "pursue independence" while at the same time a cultural discourse urges them to continue being supported by family. This research adds complication to debates about whether youth, as they are positioned within a locally defined life-course, have agency, because most youth and their families in Botswana are interdependent. Thus, youth can have moments of agency and autonomy as well as moments of pure powerlessness.

The third debate centers around youth in terms of education, the usefulness of schooling, and how education is related to processes such as the construction of the self, cultural production, and subjectivity (Demerath 2003, Holland and Lave 2001, Jeffrey et al. 2004; Levinson et al. 1996; Worthman 2011). This research posits that education is often at the core of the construction of identity during youth. Demerath (2003), for example, argues that Western education (along with media, religious penetration, and neoliberal state ideologies) is a profound cause of the breakdown of "traditional" identity foundations and relationships. This 
breakdown causes rifts and contradictions for youth, some of whom react by creating counter narratives and identities in opposition to educational institutions. Demerath labels these youth “school leavers" (2003). This work connects to Willis' argument that youth find agency in resistance, and complicates the linear model of modernity through education.

The final area of debate is set in relation to modernity, neoliberal policies, and global capital: predictably constructed lifecourses no longer exist. Rather, predictability has been replaced by precarity of futures, drastic social change, and structural violence (Dyson 2008; Gable 2000; NRCIM 2015). There have been many attempts to explain this shift in the experience of young people, from arguing for an expansion of the ages typically considered youth (15-25), to the rebranding of late adolescence as "emergent adulthood". Youths' reactions to and experiences of precarity will be discussed in the next section, along with ways to move this discussion forward.

Youth can be seen as products of their environment and how they were raised, as well as social shifters who actively react to and remake culture (Durham 2004). Youth must be approached as a temporal social position steeped in power relations, with unique social productions (such as fashion, linguistic creations, and political ideas). The centrality of their identity, as well as how they position themselves and are positioned by others, can constrain or enable movement within differing social structures (Langevang 2009). Often this positionality entails ambiguous and contradictory local social engagements, but youth are endowed with agency, and they are, according to Willis, often the "ushers of social change" (1977).

\section{Youth and Modernity}

To understand youth in the context of modernity, we must first examine this concept. For the purpose of this dissertation, I will define modernity as a multitude of narratives, 
impacted by global flows of ideas and capital, which are seen as simultaneously attainable and inaccessible, and which structure the lives of people. Modernity is used as a lens through which to understand decisions in terms of levels of influence and motivations, and the kinds of lives people want to lead. In his seminal work on modernity - one which is still relevant although iPhones had not yet been invented - Appadurai (1996) has argued that imagination, at one time useful in its ability to "transcend and reframe ordinary social life," had been spurred by the modern rush of new information from global markets and thus "broken out" and "become a part of the quotidian mental work of ordinary people in many societies" $(1996,5)$. Imagination, as he defines it, is the ability to open oneself to experiences beyond the local sphere of influence, to new individual and social movements and new forms of agency. While originally this power was only granted to individuals in the space of art, myth, and religion, modernity makes it the work of everyday people. This global imagination, as well as enhanced global flows of goods and ideas, create a context in which the process of habitus -the integration of social structure and individual agency (Bourdieu 1976)- happens at a quicker pace: "[imaginations] move the glacial force of the habitus into the quickened beat of improvisation for large groups of people" $(1996,6)$. Appadurai also argues that the introduction of 'mediascapes' - defined as the imageand narrative-heavy medias produced by powerful states and which allow local cultures to produce imagined scripts and metaphors - expands the ability to improvise and think beyond what one has been taught through the cultural means of habitus. The individual frame of reference expands beyond what lived experiences and everyday institutions such as education and mass media have taught; categories of self and identity multiply into various 'possible lives' (Appadurai 1990, 9). These processes have only become stronger and more influential with the introduction of Facebook and other social media sites internationally. Now, it is not only 
imagination that allows young people to consider multiple possible futures, but the actual stories and posts of their friends who are, currently, living some of those multiple futures in other places across the globe.

Researchers have proposed that individuals activate imagination as they combine and negotiate the local and global (Appadurai 1996; LeBlanc, 2007), in order to create identities that articulate ambiguous and seemingly contradictory "modern" and "traditional" themes in complex ways (Stambach 2000). While there may be an exemplary narrative of modernity through state and media influences, individuals and groups still find ways to localize these narratives in eccentric and original ways. Those who are unable to "succeed" in the state narrative of modern identity may seek alternative values to define their personhood (Leichty 2005, Besnier 2012). In some cases, individuals and groups will even construct identities in direct contrast to hegemonic definitions of personhood (Demerath 1997, 2003). For instance, young men in Cameroon join community associations to gain status as adults when other social markers, such as steady employment, are unavailable (Fokwang 2008); in Kathmandu, youth emulate middle class consumption patterns to appear modern (Leichty 2003) while young Nigerian hip-hop artists combine traditional beats with western lyrics touting freedom, transitory values, and youth attitudes (Omoniyi 2009); and youth in Tonga recreate modern moralities using both local forms of morality and global media influences (Good 2012).

There are two prominent concerns in research on youth in the context of processes of modernity: 1) the dilemmas youth face in rapidly changing social environments, and 2) the ways in which youth respond to these contexts in innovative ways.

Modernity, especially in developing countries or marginalized areas, bring with them neoliberal economic policies, unstable post-colonial government powers, and the new global 
normal of instability and change. Modernity, and the contradictions between differing social institutions' definitions of "modern" also provide unstable aspirations and futures. What may work one year may not work the next. Dilemmas faced by youth in these contexts include: decreased economic prospects for educated youth (Camfield 2011; Jeffrey et al 2004; Morarji 2014; Roth-Gordon and Woronov 2009), generational disjunctions (Cole and Durham 2008; Durham 2000), changing morality and definitions of adulthood (Good 2012; Prowis 2016), and subsequent problematic social issues - such as depression, alcoholism, drug use, and suicide that arise (Dyson 2008; Flanagan 2008; Leichty 2003; Lowe 2003; McDade 2001).

It is also essential that youth and modernity in French Polynesia be viewed through a postcolonial lens. Good et al. (2008) define 'postcolonial' as not only an era in time, but also “a historical legacy of violence and appropriation, carried into the present as traumatic memory, inherited institutional structures, and often unexamined assumptions". The multitude of narratives I mentioned earlier is then further complicated by power inequalities in postcolonial areas. As Homi Bhabha argues, postcolonial modernity is the intervening of the social authority of local people in "those ideological discourses of modernity that attempt to give hegemonic 'normality' to the uneven development and differential, often disadvantaged, histories of peoples" $(1994,246)$. In terms of this research, and looking at decisions youth are making in contemporary times, it is important to frame my research in terms of inherited institutional structures and unexamined assumptions. Furthermore, Bhabha's concept of hybridity is essential to the study of youths' colonial social position on a remote island.

This argument has been shown in the Pacific island of Fiji by Brison (2003), who suggests that identity is defined within particular contexts as individuals trying to make sense of their life circumstances. She argues that within the rural areas of the Pacific there exists a 
conflict in values-- individuals are pulled between the community-centered "traditional" values and the individual autonomy that is the basis of modernization practices. Thus, at any given moment, the experience of modernity for young Fijian villagers can be an amalgamation of diverse and hybrid influences. This hybridity, and Hall's (1988) discursive articulation of cultural signs, shows the problematic practice of negotiating of values within colonial arenas where government discourse and local practices are incommensurable rather than pluralistic (Bhabha 1994, 253).

However, even though youth lack power in the global market, they are not acquiescent in the scheme of globalization. There have been numerous studies done on how young people react to uncertainty in new and imaginative cultural forms (Celentano 2002; Fokwang 2008; Miles 2000; Powis 2016; Van Maij1 2006). Youth have also been shown to demonstrate resilience in their ability to cope with unique situations through diverse innovations. Specifically, research has shown these innovations allow youth to balance opportunity and possibility with risk and inequity (Flanagan 2008), and mediate webs of responsibility with discourses about the "liberal possessive individual" (Durham 2008, Lamb 2007). Diverse concepts have been formulated to describe how youth in different cultural contexts deal in situations of precarity, including "making face" and "building body" (Leichty 2006), or “timepassing" (Jeffrey 2008 \& 2010) and "killing time" (Ralph 2008). While Leichty’s concepts examine the momentary adaptation to changing cultural patterns through personal aesthetics. Jeffrey and Ralph find that youth deal with precarity through adapting their life course to fit their experiences.

Particularly in the Pacific, research shows youth dealing with ambivalence due to "lifestyle incongruity" between familial/social expectations and globalized notions of individual 
monetary achievement (Herdt and Leavitt 1998; Levin 1978; McDade 2001). Many of these incongruities stem from the ongoing colonial power inequities between global economic colonization and indigenous lifeways (Thaman 2003; Tsing 2005). Ways in which youth negotiate these incongruities include valorizing traditional ways and rejecting education (Demerath 1997, 2003), utilizing liminal status as youth to invent new "moral frameworks; (Good 2012), or orchestrating hybrid identities (Holland et al. 1998). In research on Fijian youth, Brison found that anxiety and cognitive dissonance caused by contradicting values are mediated through narrative (2003). I will argue here that often times they are not mediated, but balanced through different decisions and lifestyles. This relates to Giddens' conception of 'lifestyle' as an 'integrated set of practices which an individual embraces, not only because such practices fulfill utilitarian needs, but because they give material form to a particular narrative of self-identity" (1991, 42 italics added). This idea of an embraced lifestyle, even one that may seem contradictory, came up many times in my discussions with Rurutuan youth about their experiences, decisions, and life histories.

Marie Leblanc's (2007) article on choosing education among Muslim women exemplifies a dichotomy of sociocultural mediated agency (the agency afforded women through everyday means, such as age and marriageability) and imaginative agency (agency that young women invent through their own actions). She argues that the act of continuing one's education in the face of potential exclusion from 'real' adult womanhood (gained mainly through marriage and motherhood) shows the ability to think and act beyond what is culturally sanctioned and taught. More interestingly, the imaginative agency transforms into sociocultural agency for many of them once they have finished school. Using their Islamic faith, educated women have 
started to negotiate their marriage participation through intensified religious devotion and community involvement.

These imaginative cultural forms stem from the idea that modernity includes multiple narratives. Giddens posits that "self-identity becomes problematic in modernity" $(1991,34)$ because modern global flows break down the linear organization of identity formation (seen throughout human psychological development and rites of passage), to replace it with a continually questioned and reformed 'reflexive self'. No longer is Bourdieu's habitus the learned, embodied intersection of self and society; now, the reflexive self must be "explored and constructed as part of a process of connecting personal and social change" (1991, 33).

Although modernity is a phenomenon wherein many contradictory narratives are thrust onto developing young people, it does not change the appeal of the concept in their definitions of their own lives and endeavors (Osella and Osella 2006), or its influence on people's perspectives. One issue, especially in the research on youth and globalization, is whether modernity is attained - as in one can be "successfully modern" (Osella and Osella 2006) - or negotiated (wherein there is no single narrative, but a social structure individuals interact with). This research, and my focus on dignity, stems from a compromise between these two perspectives - that while an overarching, or multiple overarching themes could declare certain individuals' "successfully modern," youth make decisions and resist other influences to negotiate a dignified modern identity.

The definition of 'modern identity', then, is an emic one: steeped in experience, cognition, and perception, and thus is a fluid term in itself. Leichty's research with rural youth in urban Kathmandu shows the disjuncture between the sentiments of state and consumer modernity that "coalesce to promote a logic that constructs modernity, and ultimately self, as 
quantifiable material conditions" $(1995,169)$, and the peripheral mentality of being from a "Least Developed Country". Due to this disconnect, anthropologists argue that the study of modernity must become increasingly experiential. It would seem, then, that adulthood and the study of youth would follow suit. This is the perspective I adopt in this dissertation. In the next section, I discuss life-course research and transitions as well as how they relate to my research.

\section{Life-course and Transitions}

In her annual review on youth and cultural practice, Buckholtz (2002) mentions another important factor in anthropology's perspective on young people as a subject of investigation: adolescence as life stage. In the years after Margaret Mead's Coming of Age in Samoa and as is evident in the Harvard Adolescence Project, anthropology took on research on adolescence from the psychological perspective (Fuchs 1976; Worthman 1987). This model posited that adolescence was a universal, albeit gender-specific life stage consisting of a time of transition and individuation. As mentioned above, adolescence in anthropology was, through the $20^{\text {th }}$ century, discussed in terms of life-cycle ceremonies and rites of passage. As late as 1991, Schlegel and Barry's edited inquiry into adolescence defines the stage in the life-course as a gender specific stage where adolescents are seen as preparing for adulthood and as productive members of society.

In the years since, adolescence as life stage and the life-course as a model have became subject to anthropological and sociological scrutiny (Brown et al. 2009; Bynner 2001 and 2005; Janssen 2009; Johnson-Hanks 2002; Punch 2002). The earlier assumptions of youth transitioning and arriving at the set destination of adulthood were called into question. Specifically, Punch argued that the rigidity of the life-course model does not allow for blurred boundaries between independence and dependence, continued interdependence even in adult 
practices, or a perspective-based approach that "highlights the meanings young people attach to opportunities and constraints" (Punch 2002, 124). Although many sociologists and anthropologists have problematized youth and "transitions" there are still myriad concepts that deal with the growing, "transitional" period.

Just as the examination of modernity has been critiqued for its linear fashion and focus on a forward-moving continuum, so too should the study of youth and adolescence be critiqued. As Maira and Soep (2005, xxiii) argue in their work on youthscapes, "processes of both youth and globalization need to be considered together, always with an effort to avoid the tendency to frame the two as stages or moments along a forward-moving continuum”. They also argue that societies are ambivalent about the agency of youth, because these young people are simultaneously seen as unfulfilled social agents or half citizens and fully capable agents of change. The literature addressing how youth attain adulthood is rich and has expanded in recent years in the context of studies of processes of modernity and global market changes.

Psychologists and psychological anthropologists have coined the term "emergent adulthood" (Arnett 2000, 2016; Brown, Rehkopf et.al. 2009; Brown, Hruschka, \& Worthman 2009) to describe the experience of the late teens and twenties, when young people have more freedom, but are still dependent due to economic status. This term tended to be focused specifically on American experiences, but has the ability to be useful in international anthropological studies of youth, globalization, and the life course (Mendoza-Denton and Boum 2015). According to Mendoza-Denton and Boum, there are a multitude of terms to problematize the historically defined "transitional phase" of youth and adolescence: delay (as well as waithood, arrested adulthood, or killing time) in the case of youth travel (Amit 2011) or un(der)employment (Lock and Te Lintelo 2012); hopscotching, when milestones such as 
marriage, education, or parenthood occur out of order (Cote \& Bynner 2008; Dole \& Csordas 2003; Johnson-Hanks 2005); and opting out, characterized by resisting structural norms of adulthood, such as in the case of the Arab Spring or Occupy Wall Street (Mendoza-Denton and Boum 2015). Although these concepts are useful because they promote a view of the life-course that is based on a problematized linear model, they are still only elongating or rearranging the standard linear chronology without breaking from it as a foundation of the research.

This literature has generated a number of analytical concepts and is collectively focused on a central question: how do young people navigate this time of wanting to grow up but not being able to because of a lack of economic prospects or capital and social and political upheaval that makes the very process uncertain? While the question is a useful first step in examining the interaction of global forces and the life-course, the story is more complex than the ways in which youth bide their time. My research adds to this literature in examining the ways young people organize the transformations and decisions they are faced with, and how they navigate these in the face of not only economic issues, but also ties to family and land. I argue that youth, in mediating and navigating so many contradicting forces must be allowed to consider their lives outside of a linear bounded timeline. We must take the uncertainty into account in their own social navigation during both small and big transformations and decisions.

In the life course, there are not only critical moments, but also sequences of moments one leading to another, and thus forming a process of change and identity formation over time. The three decisions given to me by individuals sometimes fit this path and other times seemed as though they were only distantly related to one another, and only really fit together in that they were part of the same life story. As Johnson-Hanks (2005) argues, it is the "judicious opportunism" - the incorporation of means-end rationality and momentary resourcefulness that 
is most important in making decisions in precarious and shifting contexts. The lifecourse is most useful when it is problematized as a cultural schema that is influential in how youth see themselves and make decisions about their future. The modern "western" schema of the lifecourse is education, marriage, children, but cultural schemas might contradict that - maybe women are having babies before finishing education or getting married, or education is becoming more available to older people. As I explain in more detail later, the concept of vital conjunctures (Johnson-Hanks 2002) allows for a non-linear lifecourse examination. For instance, research among young people trying to attain respectable adulthood in Accra, Ghana shows the importance of non-linearity. Langevang (2008) argues that young people's lives must be studied as "unfolding and continuously negotiated," since there is no way to tell when they become adults. It is not necessarily about adulthood anymore, but the action of seeking dignity and respect from others, having job security, being able to afford not only the necessities, but also a few extras. There are now a variety of life conditions, ambiguous positions, complex navigations, and uncertainty.

\section{Precarity}

Although modernity opens up the imagination and reveals various different life courses and selves available to a person, Giddens $(1991,201)$ also argues that modern reflexivity operates "not in a situation of greater and greater certainty, but in one of methodological doubt." Modernity, in addition to expanding possibilities of daily life, offers increased chances for failure, and fewer guidelines for the construction of identity or future selves. Brison $(2003,397)$ argues that this increased doubt is anxiety inducing: "if two different behaviors imply values that are fundamentally contradictory, then a person cannot regularly practice both without eventually recognizing the conflict in values, which may lead to a 'crisis of self'". 
The new global norm of instability and change is taking a toll on all generations, but particularly young people. With no one to guide them, in large part because the terms of living have changed so rapidly, they are constantly having to judge for themselves what will be the consequences of actions they take. Sennett's The Corrosion of Character may sum this up best: "Adjustment and change is woven through human history... But what is peculiar about uncertainty today is that it exists without any looming historical disaster; instead, it is woven into the everyday practices of a vigorous capitalism where instability is meant to be normal $(1996,31)$. The younger generation is trying to imagine futures in this context of global flows of knowledge and movement, a context in which they are constantly presented with the dilemma of not knowing. Older generation then have the compounded dilemma of not being able to help.

Thus, an important part of modernity, for youth, is precarity. Anthropologists define precarity as a longing for normal, or for a once-promised future (Allison 2012). Precarity is the condition of both an uncertain present and an insecure future, in which one's past experiences do not necessarily prepare her for what lies ahead, and the once-linear fashion of "growing up" becomes muddied, fluid, or non-existent. Thus, those in precarious situations are forced to wait (Melly 2011), or pass time (Jeffrey 2010) until an opportunity is revealed or uncovered. Precarity is a view of a "potential culture": one in the process of being generated, or emerging from an "assemblage of affects, routes, conditions, sensibilities, and habits" (Stewart 2012, 2). This view of precarity coincides with the experiences of youth, whose "culture" is often in flux - as their lives change, so do global influences, state powers, and social expectations.

I would add to this that there are two separate types of precarity. There is physical precarity, in which one may live on the edges of violence, or abject poverty, and thus one's decisions could be considered life or death (Vigh 2009). In this situation, every decision may be 
vital. There is also social precarity, where one's decisions may not be life or death, but the course of one's life, the ability to become a respected person, could be considered "on the line." The central challenge of living in precarious social situations is intense insecurity about the future (Locke \& Te Lintelo 2012; Masquelier 2005; Roth-Gordon \& Woronov 2009). According to Liversage $(2009,121)$, “actors' orientations to future horizons are often systematic; they are a limited, prioritized array of possible futures." Even in times of precarity, there are only so many available choices at any one time. For youth from Rurutu, social precarity is their main insecurity. They tend to deal with this by navigating contradictory identities and by making decisions that leave connection to their home identity open as a safety net. In the next section, I will present theories of how identity is constructed that connect modernity and vital conjunctures.

\section{Identity, Subjectivity, and Social Navigation}

Young people's experiences with globalization, modernity, and precarity vary significantly by context. While the plights of rural youth, such as those in my research, may seem similar, there is great subjective variety in the details of family and social lives, momentary reactions to certain events, opportunities and constraints, and definitions of dignity. Thus, it is important to "demonstrate the variety of young people's life conditions, the ambiguous positions they occupy, and the complex ways in which they navigate their way through" (Langevang 2008 2046). These different experiences throughout the years of transformation lead to diverse personal identities. In examining the individual juncture of personal, local, and global influences during these times of change and transformation, the motivations for decisions and thus the process of negotiating one's identity and future can be identified. 
To effectively study how youth construct meaningful lives in unpredictable circumstances (precarity), it is important to draw from the subjectivities of youth as individuals as well as members of social groups. Subjectivity most broadly refers to the personal lived experiences of individuals and how they relate to broader social structures. As Biehl, Good, and Kleinman argue, subjectivity "encounters the concrete constellation in which people forge and foreclose their lives around what is most at stake" $(2007,5)$. These authors go on to add, "examination of the complex ways in which people's inner states reflect lived experience within everyday worlds as well as within temporary spaces and transitions... can disturb and enlarge presumed understandings of what is socially possible and desirable" $(2007,7)$. Therefore, examining the ways individuals prioritize influences and find answers to difficult questions about their futures, as well as examining the narratives they tell about these transformations, can increase knowledge about how people go about creating their lives. This research analyzes how personal identity is subjectively formed by internal motivational structures and the roles, perceptions, and self-categorizations that provide social position and inform youths' decisions.

In addition to Bourdieu's "habitus" and Appadurai's “imagination," many contemporary anthropologists draw on Foucault's "making of the subject" (1988) and Bahktin's notion of the "authored self" $(1986,90)$ to conceptualize the development of selfhood. For instance, anthropologists studying the subjectivities of youth may speak of the "orchestration" of conflicting discourses (Holland et al. 1998), or "cultural innovation" (McRobbie 1994). But always, subjectivities are seen as multiple, and individuals are able to create hybrid, or "syncretic" identities, which combine contradictory themes in complex, multifaceted styles (Bhabha 1994; Comaroff 1996; Orta 1999; Riley 2007). In this dissertation, I will use transformations and vital conjunctures to conceptualize the ongoing construction of self. 
By examining individual interactions with global and state scripts about modern identity, incentives, and imagination, we as a discipline can get beneath the assumption that youth are on a linear path and see their own forms of agency, resistance, and acceptance of the world. As Johnson-Hanks argues: "Structures shape identities by providing the raw materials for their construction, but individuals are not merely the passive recipients of structurally-determined identities. Rather, individuals shape their own identities out of the schemas and materials available to them through their choices about courses of action" $(2011,14)$. Each action within a person's life history is a negotiation between structurally determined raw materials and internal motivations. Decisions people make are the visible portion of the deep-seeded production of self and identity that is happening at any given moment. At any time, if asked to make a decision, a youth is not simply considering consequences for future actions, but contemplating future versions of themselves. They are in a constant state of re-making, and thus their decisions during this time are even more important grounds for examination.

Particularly in the Pacific, anthropologists have found that although "traditional" identities are often constructed as resources to establish identity in cases of disparate power (Demerath 2003; Good 2012; Linnekin \& Poyer 1990), the actual relationships and cultural transactions that provided the basis for "traditional" ways of life have weakened (Leenhardt 1979; Levy 1973; Lockwood 1993). "Traditional," taken in this context to denote discourses steeped in relational selves and identities based around subsistence patterns, connections, and communal (re)production of culture, has been diminished in the face of western models of economic self-interest, commodity culture, and media intended for individual consumption. Thus, self-creation is becoming an increasingly individual practice, based more on personal choice than "traditional" prescriptions (Demerath 2003). 
As Langevang (2008) notes, when agents seek to move within social terrains while simultaneously being moved by it, there is interplay of agency and structure. Evans (2007) refers to this as "bounded agency," a socially situated process shaped by past experience, current available chances, and perceptions of possible futures. Vigh (2009) refers to this as social navigation, or a way of understanding movement within already moving realms and processes. He refers to navigation, a nautical term, as a nod to the seemingly endless movement of social fields much like navigating the waves of the ocean. Sommers (1994) also argues that identity is embedded in overlapping and shifting networks of relations between individuals, narratives, and institutions. In addition to theories of identity as the interaction between individuals and institutions, there are also theories that place identity in the interaction between different kinds of narratives. This model argues that identities contain both "little stories" momentary roles that shift and build upon each other - and "big stories" - stable identities that enable individuals to narrate their lives and move fluidly from one moment or context to another (Ahearn2001, Bamberg 2006; Gregg 2011). These theories, while placed in different levels of social interaction, make it clear that to understand identity formation, we must examine both the little stories, the big stories, and the institutions that lend importance and definition to both.

\section{Vital Conjunctures and Dignity}

Anthropologists have tried many different categorical terms to capture the inconsistencies in the previously assumed fixed stages of the lifecourse. However, these works fall short in assessing how and why youth make the decisions they do - in analyzing the experience of walking one path over another, or realizing there are no good options. They all assume that "adulthood" is the destination in the journey of life, arguing that one passes or kills 
time until he or she can become an adult. I argue that the destination of "adulthood" should be carefully considered, and that it may be a concept that is no longer deemed useful by those very individuals who "should be" searching for it.

My research stems from an increasing awareness that changing social contexts directly correlate to changing priorities among young people. As mentioned in the introduction, I will use the concept of vital conjunctures to best understand the non-linearity of choices and transitions from childhood to adulthood. In a call to create a new anthropology of the life course found in precarity instead of linearity, Johnson-Hanks defines the term as "negotiable" and ongoing life events that have become "variable in spacing and synchrony" $(2002,862)$. The term encapsulates her argument that we must move away from ordered, linear transition events of the life-course, and instead focus on multiple, unfixed, and extemporaneous aspirations. The term "vital conjuncture" is taken from Bourdieu's concept of the conjuncture, or the "context of action... in which habitus is made and its consequences are enacted" $(2002,871)$ and demography's vital event, or change in demographic status (birth, death, change in educational, residential, or marital status). Vital conjunctures are moments in the life-course when past experiences and future aspirations come together and a person must decide, or not decide, how to move forward.

By asking questions such as "under what circumstances does a young woman evaluate her current conjuncture in light of her hoped-for future as an honorable mother?” $(2002,872)$, Johnson-Hanks is able to better understand what/how structural and individual factors come into play during important life events. Continuing this line of questioning, Langevang argues that we must pay close attention to the "kinds of futures that young people are navigating toward and the constraints and possibilities they encounter in this process, emphasizing the importance of 
social relations" (Langevang, 2008, 2040). Vigh (2009) call this 'social navigation,' or the practice of moving within a moving environment. My research broadens this line of questioning to ask: what are the self-defined vital conjunctures in which external and internal influences coalesce, and what are the motivations behind each important transformation or decision throughout adolescence?

The analysis of vital conjunctures throughout young people's lives is a good lens through which to see how youth come to understand and act within their own society and in relation to their individual positionality. Jennifer Johnson-Hanks defines a vital conjuncture as "a socially structured zone of possibility that emerges around specific periods of potential transformation in a life or lives... a temporary configuration of possible change... uncertainty, and potential" $(2002,871)$. Vital conjunctures, thus, represent a point in time when one undergoes a conjunction of social institutions, symbols, expectations, and personal experiences, and the decision made or transformation experienced is a negotiation in and of itself.

Furthermore, these decisions are becoming increasingly important to analyze as they show the myriad ways in which the modern "imagination" is coming into contact with local and global structures, opportunities, and obstacles. The past notion of becoming an adult is being replaced by these imaginations, that there are people to be outside of just becoming an adult. One can actually now become oneself. This process of individuation that derives from the impact of globalization is what this research is trying to understand. By coupling ethnographic data with social theories of action, intention, and outcome, Johnson-Hanks et.al. (2011) made it possible to analyze and understand present action as it relates to future intentions. This research examines "action under uncertainty" (Johnson-Hanks 2005) by coupling life narratives 
revolving around the negotiation of internal and external influences during vital-conjunctures with social theories of subjectivity, globalization, and postcolonialism.

One theme that seems to run through my research on experiences of decision-making, transformation, or even examining one's path is that of dignity. Dignity is a concept that has been studied in other academic circles such as philosophy (Jackson 1997; Malpas \& Lickiss 2007) human rights, and sociology, but which has not often been taken up in anthropology. Although this is changing in medical anthropology (Jacobson 2012) and anthropology of morality (Zigon 2010), the idea of dignity is worthy of much greater attention. Dignity is an elusive concept, but one that is part of the Declaration of Human Rights as an "immutable concept in the treatment of human beings" (Sulmasy 2007). Dignity is often defined in the way people are treated, but can also be useful to examine the way people go about their lives. People, structural boundaries, and experienced obstacles can work to violate an individual's, or even a group's, dignity. Especially in areas where the historical violence of colonialism and the present inequality of capitalism exist, everyday life can work to dismantle one's dignity. However, in an anthropological sense, looking at dignity as a verb can be a way to show how individuals find a path forward during times of precarity. Willen refers to dignity as a "lodestone" or "vector", by which she means that it is something to be acted upon, or strived for (qtd in Dedios and Anderson 2014).

An anthropological perspective on dignity in the life course would present a concept for the negotiation of changing expectations. Although there is debate as to whether dignity can be used as an etic term in the case that it is not a word directly spoken by interlocutors, here I present the case for just that. The discussion of dignity does not have to be open or direct, because it encapsulates many different notions utilized by interlocutors, including respect or 
"living well" (Locke \& Te Lintello 2012). Dignity here is defined as socially situated and individually experienced; it is a community-based link between the individual and their political, social, and economic context. If we conceptualize dignity as a verb, and as a way to empower interlocutors in times of precarity, then it becomes the underlying motivation in the experience of making decisions of adapting to transformations. Striving for dignity is how youth show they are trying to fulfill their obligations to uphold expectations. It is one of the propellants that youth have when making decisions or living with outcomes of vital conjunctures over which they had little power. The search for "adulthood" is just that - a search for dignity, for respect. Many ethnographies focus on actions taken during times of precarity and uncertainty, when youth are unable to achieve adult status. As mentioned above, such research uses terms such as "killing time" (Jourdan 2002), "waiting" (Fokwang 2008) or "timepassing" (Jeffrey et al 2007). Those who kill time, or wait, or timepass are trying to find things that will bring them respectability when they are unable to reach socially constructed milestones in 'modern' life; thus, a search for dignity may be a useful way to frame and understand their actions.

The life course, even in its academic stage of disarray, is still a problematic notion because it strips away dignity by identifying winners (adults) and losers (older adolescents, emerging adults, unmarried people, those without children) in the "game" of life. Those who have been able to achieve a narrow definition of what it takes to be an adult are opposed to those who do not make the cut. I argue here that there are multiple modernities that can coincide with multiple adulthoods, and thus the idea of "adulthood" is no longer something to strive for; instead, youth are looking for dignity - they are looking for ways in which to define themselves and make a "life worth living" (Butler 2004). 
Vital conjunctures provide a means through which to bring together idiosyncratic experiences, individual aspirations, culturally inherited perspectives (scripts/schemas), historically provided opportunities/constraints, and momentary or enduring events in one's life. Johnson-Hanks argues further that the "dual focus on institutions and aspirations allows us to examine how and why certain life events cohere in given social systems and what happens when they don't' $(2002,878)$. For instance, during teen years and into one's twenties, aspirations to live near one's family or on one's island of birth clash with the colonial educational institutions' goals and expectations.

In addition to studying vital conjunctures as a theoretical model, I have also used vital conjunctures as method. Vital conjuncture narratives are yet another break from the linear life course, in that it allows youth to determine their own important times of decision-making and transformation. Much like how illness narratives are used to "negotiate the authority of experience versus the authority of expertise" (Wohlmann 2014, 19), vital conjuncture narratives put the authority in the hand of the youth themselves in deciding what experiences have affected them most during their lives. Thus, the vital conjunctures themselves become emic concepts.

\section{Conclusion}

Research that has adopted the concept of vital conjunctures has revealed the connection between seemingly contrary social structures in the lives of individuals, and how individuals process cultural discourses through decisions they make between options for the future (Johnson-Hanks 2005; Johnson-Hanks et al 2011; Langevang 2008).

With respect to the concept of modernity as an increased set of perceived possibilities, vital conjunctures provide invaluable analysis of how individuals respond to the same sets of decisions in diverse ways. Thus, if we are able to compare generally the same types of vital 
conjunctures, then we can analyze how diverse youth approach the same questions in diverse and unique ways. In studying this process, we can better understand how subjectivities are differentially influenced by gender roles, social expectations and categorizations, and values systems, and how youth use these processes to negotiate their futures.

This research will go a step further, a call made by Johnson-Hanks through her edited volume, A Theory of Conjunctural Action. In the conclusion, she called for social scientists to research the actual decisions, and not just the experience of making them. What brings about a time of vital decision-making? What decisions shape a person's life experience and their selfunderstanding? These decisions become a microcosm of sorts - a way to examine the intersection of the life course, globalization, and subjectivity. I have problematized this by asking young people to define their life's vital-conjunctures in emic fashion.

These strings of vital conjunctures all seemed to congregate around a central theme of dignity. The motivations behind certain decisions were to pursue, safeguard, or reclaim dignity. And those who were unhappy or having a hard time adjusting were those whose dignity seemed to be lost. Dignity, however, is not often theorized in anthropology. Sarah Willen, in a discussion on dignity, claims "the notion of dignity becomes ethnographically visible, and anthropologically meaningful, only in motion... we might think of it as a lodestar that guides the striving of individuals and groups within relational social fields that are gridded by constraint and fraught with indeterminacy" (qtd in Dedios and Anderson 2014).

If we consider dignity as a verb, instead of an object, we can think of it as a perspective of understanding subjectivity, experience, and personal identity negotiation. Coupled with analysis on decision-making and transformation during times of vital-conjunctures, dignity as something to be strived for, as a future self to construct (a dignified member of one's society), 
then the life-histories of youth come together in ways that are not disparate or haphazard. An adolescence spent striving for dignity is one well spent, whether "adulthood" is attained or not, and whether one's life resembles one definition of "modernity," or "success" or not. Dignity can also be seen as deeply personal and subjective. One's definition of dignity is constructed from diverse discourses and personal experiences of success, failure, and the ongoing judgment of others. 


\section{CHAPTER 3 RURUTU AND TAHITI: HISTORY AND ETHNOGRAPHIC CONTEXT}

The following chapter will introduce the historical, political, and economic background of my field sites. To understand the perspectives and experiences of youth from Rurutu, it is important to first view the connections between the country of French Polynesia and its colonizer, France. These ongoing relationships influence how French Polynesians (those throughout French Polynesia, including the Gambiers, Tuamotus, and Marquesas), Tahitians (meaning those who live on the main island of Tahiti) and Rurutuans (those who were born on Rurutu, and thus the subjects of my research) see their world, and what opportunities and obstacles exist for those growing up in this context. The chapter begins with a description of French Polynesia as a whole, including the geography, demography, and colonial history of the region. I then move into a comparison of the main island of Tahiti and the smaller outer island of Rurutu - both are sites of completed Populations in French Polynesia 2015 French Polynesia 275918

Tahiti 183650 Papeete/Faaa 56432 Austral Islands 6965 Rurutu 2466

fieldwork. From there, I discuss important social

Table 2: Populations in French Polynesia, changes that impact youth growing up on Rurutu. 2015

The first is the life-course as experienced in Tahiti, a subject studied to great length by Robert Levy (1977), which is changing with increased global flows of information and ease of travel 
and exploration. The second is an exploration of the ambivalent transformations that youth must go through between the ages of 15-30.

\section{French Polynesia, Tahiti, Rurutu}

French Polynesia is made up of five archipelagos (Society, Gambier, Tuamotus, Marquesas, and Australs), with a total population of roughly 275,918 people. However, the population growth rate for the country is declining $(0.6 \%$, down from $1.2 \%$ in 2007$)$, and the emigration rate has risen to 1500 per year. Of the current population, 183,650 live on the main island of Tahiti (mainly in the urban areas around the port of Papeete), while the others are spread over roughly 120 different islands that span the geographical distance of Europe, or four million square miles (2015 census). Rurutu, where I conducted my field research, is a small, rural island with a population of roughly 2450 , located approximately 150 miles from Tahiti. It is part of the Austral (Tubuai) Islands group, along with Tubuai, Rimatara, Raivavai, and Rapa. Please see the next page for a map of French Polynesia and its five archipelagos. Tahiti is located in the Iles du Vent chain of the Society Islands, and Rurutu is down in the Iles Tubuai. 


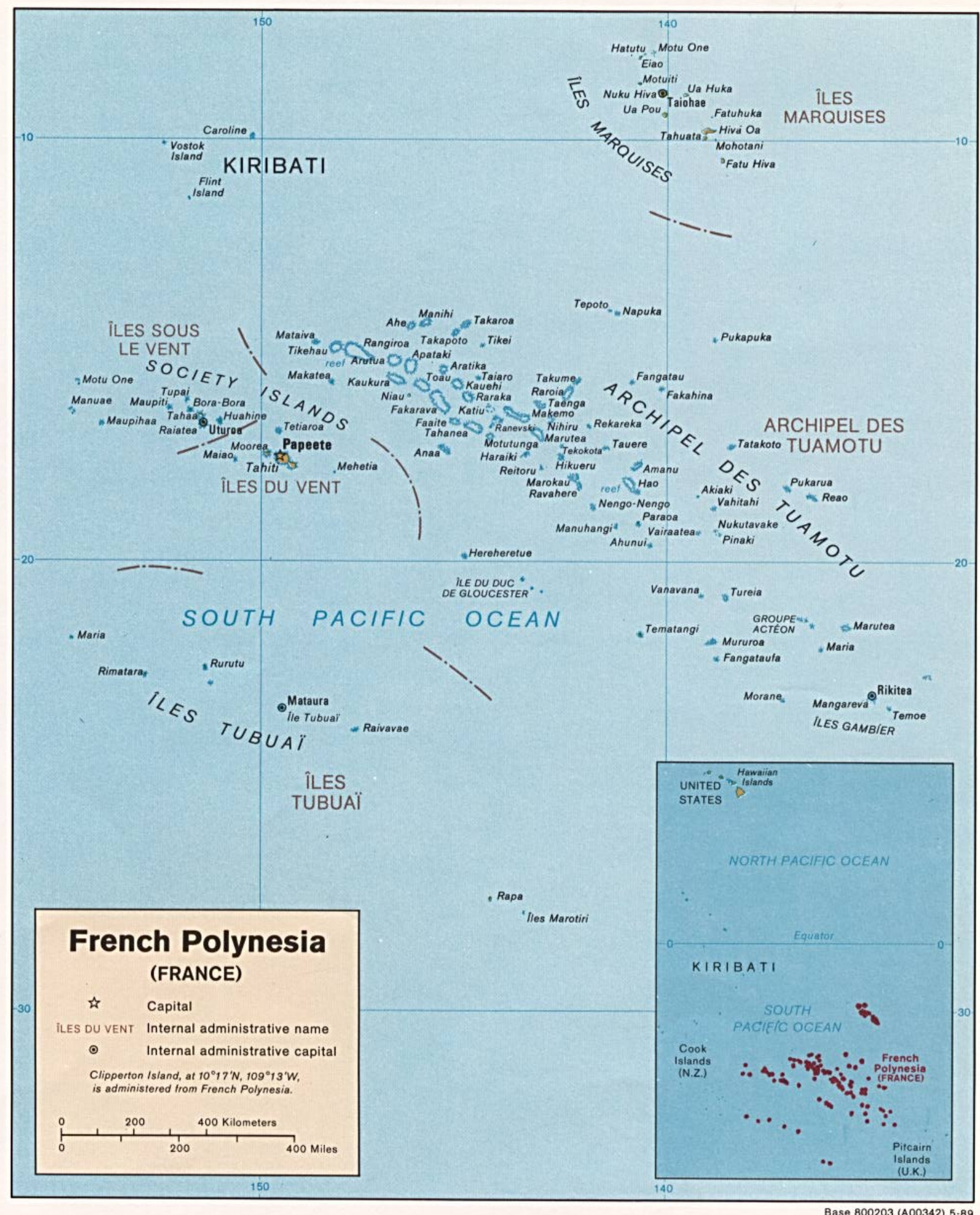

Figure 1: Map of French Polynesia 
As I mentioned in the last chapter, this research is dual sited - it took place on Rurutu as well as the main - and most urban - island of Tahiti. The research sites on Tahiti consisted of three communities: Papeete, the most urban area in French Polynesia, Faa'a, the closest and most populous suburb, and Pae'a, a less populated suburb on the south side of the island. One can see from the map of Tahiti, Faa'a and Papeete are quite close, and Paea is a bit further around the island. It is also visible on the map that there is only one set of roads on Tahiti, and they go around the outside of the island (as the middle is a volcanic mountain). Therefore, to get from Taravao, on the windward, or southeast side of the island, to Papeete, one must travel around the perimeter. This bus ride takes roughly $1.5-2$ hours.

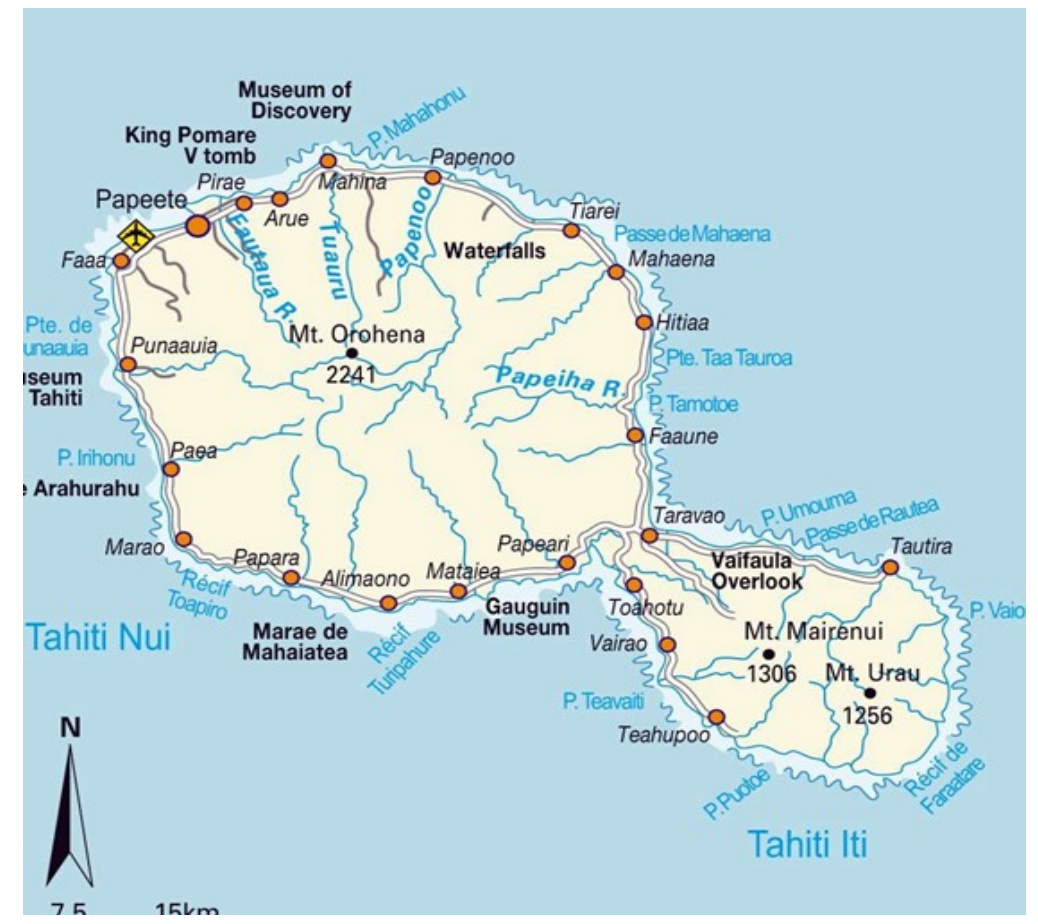

Figure 2: Map of Tahiti 
The second, rural field site is the island of Rurutu, in the Austral, or Tubuai archipelago 100 miles to the south of Tahiti. Rurutu is roughly three miles wide by 5 miles long. It has both a perimeter road as well as one road that travels over the interior mountains to cross from Moerai to Avera.

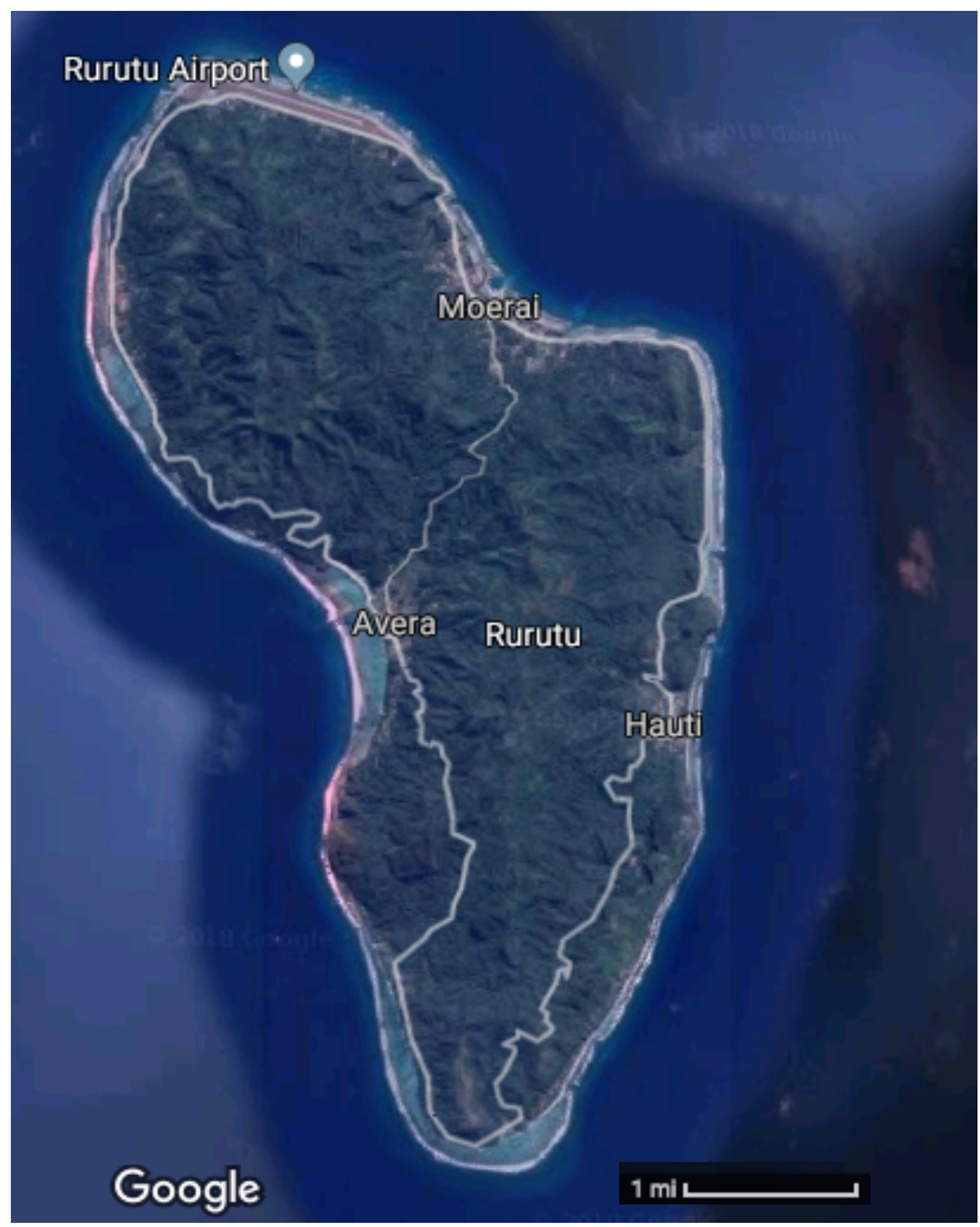

Figure 3: Map of Rurutu, from Google Maps 


\section{Colonial History}

French Polynesia has a complex historical relationship with France, which started in the late $19^{\text {th }}$ century when France made Tahiti and the Marquesas Islands French "protectorates" to keep them from British domination. Before that time, however - as early as 1796 - French and British traders and missionaries began arriving on the certain islands - specifically the Society and Tuamotu chains, but eventually the Marquesas and Australs as well. While colonization began with only traders and missionaries, soon enough French forces increased their colonial hand over the people of French Polynesia. Today, French Polynesia is referred to as a Pays d'Outre Mer, or semi-autonomous holding of France. The French Polynesian people still receive large stipends and government subsidies from France for building houses, starting businesses, and growing food. However, there is a growing degree of Tahitian autonomy, in which local government has control over certain decisions, including public works spending, social welfare issues, and local taxation.

French Polynesia has long been, and still to some extent is, a colonial territory. It was first "discovered" by Europeans in 1774, and Captain Cook wrote to his European compatriots about a people who were "delightfully well-meaning and open" (Kahn 2011). Based on Captain Cook's letters, the events of the mutiny on the Bounty, and other information disseminated during the $18^{\text {th }}$ and $19^{\text {th }}$ centuries, the predominant visual image of French Polynesia that emerged was of a paradise. The imagery of a "Garden of Eden" conceived by European travellers has shaped and been fostered by French Polynesia since the early days of colonialism until contemporary times (Kahn 2011).

While tourism blossomed in the $20^{\text {th }}$ century, it was really the missionaries who had the most important impact on Tahitian society, which in some cases included outer islands. During 
the late $18^{\text {th }}$ century, both the London Missionary Society and the French Catholics converted the majority of Tahitians to Christianity. The French Catholic missionaries were barred at first from establishing their church, and thus didn't acquire as firm a foothold until well into the $19^{\text {th }}$ century, when France had established Tahiti as a protectorate. According to Thomson and Adloff (1971), the merchants and traders changed the hierarchies and social structures among the local populations, but it was really the missionaries who reformed the social, cultural, and economic dealings of the islands. The large, extended family household structures that were the mainstay of Tahitian culture before European influence were replaced by nuclear family units that the Christian missionaries preferred.

Before the introduction of European influences, French Polynesia was split into different chiefdoms. At their largest, there was a monarchy in the Society Islands, conquered by Pomare I. There were large chiefdoms in the outer islands as well. However, they were, for the most part, separate areas with different dialects. These chiefdoms, and social life in general, were organized by the idea of mana. Mana is a sacred strength that comes from the gods, and is distributed disproportionately between individuals. For the most part, the eldest child receives the most, which decreases the farther down the family line one is. Thus, the first born of the first born would be considered most powerful. This system yielded chiefs, which in large areas such as the Society Islands (of which Tahiti is the center) became kings and queens. This system of social hierarchy, along with the communal land tenure system and the sacred maraes where Tahitians worshipped, were eradicated with the influx and acceptance of Christian conversion (Oliver 1974, 1981).

Once Pomare II, the king of Tahiti from 1782-1821, converted to Christianity and was baptized in 1819, it became the religion of the land, and conversion became even more popular. 
Due to traditional beliefs of mana or power, the Christian colonizers were seen as more powerful, which made their proselytizing even easier. According to the lore of Rurutu, curious chiefs actually ventured to neighboring Tubuai, where there was a missionary, in order to bring Christianity back to their people. Some think this may have been caused by the European illnesses wreaking havoc on the indigenous population, but the inhabitants of Rurutu took it upon themselves to be introduced to western religion (Walker 2002). The islanders took to Christianity whole-heartedly, and their traditions and beliefs became what Levy (1976) has termed "Neo Tahitian". Older social constructs and traditional beliefs in medicine, as well as modes of production did not change drastically, but the advent of Christianity altered gender roles, family and household structure, and relationships between individuals. The church is now central to life for most individuals living in French Polynesia. The church established by the London Missionary Society is now an autonomous Tahitian church known as the Eglise Protestante Ma'ohi (Ma'ohi being the local name of Tahitian descendants). Levy also shows that Polynesians do not see Christianity as having been imposed on them, but more a continuation or evolution of their own ways, bringing peace and good work to their lands (quoted in Saura 2015).

In addition to a shift in religion, French Polynesia has also experienced a shift in social hierarchy as a result of colonization. Whereas social hierarchy in the traditional sense was based on birth order and power bestowed by the gods, the new social hierarchy is based in colonial race relations. The most politically and economically influential people among those living in French Polynesia are the French expatriates, French descendants, and those they have termed demis, or people of mixed French and Tahitian heritage. The demis historically had the best of both worlds; they had the wealth from the French side, and access to land from the Tahitian 
side. This intersection of powers has allowed them to achieve a position among the upper echelon of Tahitian society. This power imbalance was first instated with the overthrow of Tahitian Queen Pomare IV and the treaty of protection that was signed in 1877. This protectorate put the government and everyday dealings under the consignment of France, while disallowing residency from Tahitians. Although Tahitians gained French citizenship as part of French extension after World War II, the historical construction of them as "lesser" has not passed from the minds of the French who are posted to the islands as nurses, teachers, principals, and doctors. My time in the French lycées on Tahiti showed that few French contract teachers show interest in the youth they teach, especially those from the outer islands. They are often seen as bête, or savage. The French professors are rarely seen at dances or Polynesian celebrations. This certainly has a negative effect on how youth view their traditions and culture, but also decreases the amount of respect the Rurutu students have for these teachers, and their motivation to get good grades. It also impacts how the students see themselves and their ability to succeed.

Although the colonial history of French Polynesia has instated some negative colonial policies and social institutions, the Tahitian (and by extension, Rurutuan) culture has also shifted to accommodate. As mentioned earlier in terms of religion, Levy termed these changes "Neo Tahitian." The Tahitian Way, although changed by colonization, still influences how young people grow up and view the world.

\section{The Tahitian Way}

The Tahitian Way revolves around Land, Family, and Church. As mentioned in the last chapter, postcolonialism is a "legacy of inherited institutional structures and often unexamined assumptions" (Good et al 2008). The Tahitian Way is the locally hybrid identity between the 
colonial French and Brittish social constructs and the traditional Tahitian ways of life. The Tahitian Way, as identitfied by Levy (1977) is already a modern identity. As part of this system of beliefs and constructs, Tahitian traditions are extremely closely tied to social networks and identity with the land. Bruno Saura $(2015,359)$ argues that while the other French colonial holdings, such as New Caledonia, have a more politically centered identity, French Polynesians tie theirs to upholding their land tenure, language, and cultural practices. As children, many youth help family members in the fields in order to learn about what land is theirs, and how they are tied to their land forever through the planting of their placentas in the ground (Kahn 2011). Food is often taken straight from the land or sea, tying them even further to the material world where they grew up. Even the land tenure system reflects the local hold over ties to land: until very recently, and even still in some rural islands, family groups communally own large parcels of land. It is neither bought, nor sold, nor passed down or inherited through nuclear family ties, such as from one's parents. All land belongs to an extended family network. Therefore, if a person wants to build a house on his/her family plot, he/she would be required to acquire the permission of the most elderly relatives. In urban areas, where families have sold off large parcels of land in order to raise funds, development of hotels, golf courses, and other touristcentered areas has boomed. However, in areas where land tenure has held firm, development has been slow, which has preserved traditions around land in the face of colonialism and global capitalism, but has slowed economic access for youth in rural areas. The government is slowly setting about to change these laws in order to acquire more land for development.

Another factor of the Tahitian Way is its relation to gender. Although there is a gendered division of roles (males tend to be responsible for farming and fishing, while artisanat trade is mostly women), there is also a social acceptance of individuals who do not wish to abide by 
these roles. With a few exceptions (I never heard of a woman being allowed to go out fishing in a boat) women can plant, feed the pigs and livestock, and take on more typical male roles. On the other hand, I did witness "male" individuals performing female roles such as weaving, cleaning, and cooking, but most of them also identified as feminine, or rere ${ }^{7}$.

Although there are certainly some rules and assumptions about gender roles, the Polynesian culture has always been relatively gender egalitarian (Lockwood 1993). This shows today in the treatments of males and females in the educational system. Neither gender is excluded from any type of education, vocational or otherwise (according to my observations). For the most part, young men mostly fill public works contracts while young women take secretarial positions, but I do not know if those are strict roles or a reflection of the applicants. In times of economic hardship, it seems that these roles become less rigid and more fluid. As I discuss further in Chapter 4, gender roles do seem to play some part in the priorities and vital conjunctures youth identified during interviews. In that case, it seems the western, Christian notion of men as breadwinners of the family and women as mothers is strong. However, motherhood as a particular identity may also be a coping mechanism to gain dignity in a precarious economic situation.

\section{Economy}

The imagery of a "Garden of Eden" for European travellers has shaped and been fostered by French Polynesia since the early days of colonialism until contemporary times (Kahn 2011). This characterization has made tourism the biggest industry in French Polynesia. Roughly 200,000 tourists per year visit the area. If young people want paid

\footnotetext{
${ }^{7}$ Rere is a term used in French Polynesia to denote third genders - males who take on permanently female personas and roles.
} 
jobs, they can often look to this industry, serving as guides, boat operators, or in hotels. Most of these jobs, however, are low paid unskilled labor.

While the missionaries and colonialism have taken their toll, it was really the advent of the Centre d'Experimentations du Pacific (CEP) that drastically changed the French Polynesian island from subsistence living and small enclaves to the consumerist "cash" culture they are today. Even though most nuclear testing was abandoned internationally in the 1970s, French continued their nuclear program well into the 1990s, finally ceasing in 1996 (Kahn 2011; Lockwood 1993). During the expansion of nuclear testing post-WWII, and after France lost Algeria to a long battle for independence (Kahn 2011), France moved their nuclear testing facilities to French Polynesia. Aside from the obvious health and ecological issues this caused ones France still has not properly apologized for (Saura 2015; Kahn 2011) - the CEP put an end to the truly "free" subsistence lifestyle that existed on the outer islands before the 1960s.

According to Thompson and Adloff (1971), the Tahitians were "passive, fatalistic, and ill-informed" of potential dangers, but were excited about new economic opportunities and increased living standards that came with CEP employment. Thousands of Tahitians, including many from the outer islands, flocked to the Tuamotus (islands to the northeast of Tahiti - see map) to find work with the French military that was building the nuclear testing outpost. These new contracts allowed families who were previously subsistence farmers and fishermen to buy luxury goods, imported foodstuffs, and increase their standard of living to meet the more metropolitan standards. This led to the cash economy that now exists on both Tahiti and Rurutu. Suddenly, outer island homes began to include imported food and merchandise. When electricity came to the island in 1980, so did TV. Bread and jam replaced taro and fish as the preferred breakfast foods of many Rurutu families. 
Job growth and global luxury items were not the only items brought by the growth of CEP. The changing import/export business brought with it inflation and a devaluation of the French Polynesian francs, and the increase in land bought and controlled by the government privatized much of the previously communally owned land (Lockwood 1993, 2002). This changed the land tenure system on the populated and affected islands, such as Tahiti, Moorea, and other Society and Tuamotu islands. Today, it is extremely difficult to buy a house or land on which to build near Papeete, making it harder for skilled and educated Rurutuans to carve out a life in the urban areas.

The eventual removal of the CEP in 1996 had just as drastic an impact on the people of French Polynesia. First, the number of available jobs severely decreased. Many of the migrants from such outer islands as Rurutu had to fend for their families without steady work. Also, the French government could no longer sustain the idea that French Polynesia was a necessary outpost (Lockwood 2003). While the nuclear testing was operational, it was easy to argue that continued support of the small island nations was beneficial to the mainland. Once that reasoning was gone, France declared that it was decreasing annual support to French Polynesia from 180 million USD to 100 million USD (Gonschor 2005). At that point, French Polynesia had extremely low tax rates, because it was not autonomous. The decrease in French aid led directly to a sharp increase in taxes placed on the local people. Taxes on exports and imports, as well as property taxes were implemented. These measures drastically altered the cost of living on both the urban and the rural islands. Many young people I talked to complained about how expensive it was to live on one's own as an adult. It has become increasingly difficult to acquire a house. Even with the small communal lands that are available and the inexpensive materials with which one can build a house, the regular payments one must make for taxes and electricity 
put a damper on plans to move out of the familial home. These taxes are only the baseline of modern life - they do not include gas to heat water for showers or cook on the stove, cars and the gas to run them, phone bills, and then, if one can afford the CFP 5,000-10,000 (\$50-100) per month, internet. Not to mention, if a young person wants access to the internet, that would be another CFP 10,000 (or \$100) per month out of their already small salaries.

One final pressure for the next generations of Rurutuans is over-population. The growing population on both the main island and the outer islands is turning the older, wellknown ways of maturing obsolete. In addition to dwindling economic prospects on Rurutu and Tahiti, which will cause more young people to emigrate to France and elsewhere, there is also the issue of division of land. As family size grows, the number of available plots of land for farming or house construction will continue to dwindle. This affects youth by limiting options on the home island, and thus limiting their ties to the Tahitian Way. If all young people moved back to Rurutu, it would be incredibly overcrowded, and the housing and agricultural markets would crumble. The population crunch has thus made it a precarious balance between striving for opportunities abroad, continuing to be connected to the homeland, and not augmenting the already critical population issue.

\section{Politics}

Starting with the fall of Pomare IV and the subsequent annexation as French protectorate, there has been tension in French Polynesian politics between those who support French rule (autonomy) and those who are pro-independence. This can be seen in the modern day political parties, represented as orange and blue, that support the two sides of this political and economic contest. Those who are pro-France, or support autonomy, believe that French Polynesia is better off staying under the political rule of France, and thus profiting from the 
social support and infrastructure provided by them. Autonomy has been granted, meaning that French Polynesia is in charge of some governing, and is given limited representation in the French Republic. The Pro-Independence party, on the other hand, has the goal of cutting off all ties to France and declaring a sovereign nation of Tahiti.

This difference of views was best seen during the time of CEP, when France was building nuclear testing sites in the Tuamotu islands. Local political parties grappled with the change in status and an inability to come to a compromise between the pro-independence party, which wanted to save the country from irradiation, and the UTD (Union Tahitienne Democratique) party, which was using CEP as a bargaining chip for increased ties to metropolitan French. The UTD, now the Tāhō‘ēra'a Huira'atira led by Gaston Flosse, was arguing for "autonomy" instead of independence, which they defined as a system of government wherein French Polynesia has a president and its own governing power as well as representatives in France's parliament. French Polynesia is allowed to decide how to tax its residents as well as how to allocate funding from France. The pro-independence party, which at the time of my research was headed by Oscar Temaru, has the mission of creating full independence for Tahiti. They also call on France to, upon their independence, pay reparations for the damage caused by unchecked nuclear testing.

Beyond the political tension that marked the introduction of the Centre d'Experimentation du Polynésie, political upheaval and uncertainty has been a key characteristic of French Polynesia, in the 50 years since the CEP came in being. Due to the way in which France organized the French Polynesian government, it is incredibly unstable, and one party can only seem to hold power for a short amount of time. During the years from 20002015, the office of the president changed hands more than 10 times (La Vie Quotidienne 2016). 
The ability to cast a vote of no confidence, coupled with the even divide between the group that calls for autonomy and that of the independence party, the French Polynesian government is unstable even in the current administration (Gonschor, 2015) ${ }^{8}$. Young people, although for the most part apolitical, are impacted by these upheavals, because the budgets put forth and the government aid for young people is often directly tied to whichever political party is in power (French Polynesia 2012). For instance, the Association of Youth and Sports, tied to the autonomy party, receives more funding to spend on annual sports tournaments and youthcentered events when the autonomy party's appointed leader is in power.

\section{Rurutu}

Rurutu, as opposed to Tahiti, is a small volcanic outer island of the southernmost Austral Island archipelago. It boasts the largest permanent population of all the Austral islands, at 2200. There is also a rotating population of approximately 600 people living on Tahiti and elsewhere. Rurutu was not marked for large-scale agricultural development by France due to its mountainous geography; many residents still rely heavily on small time agriculture, fishing, and female artisan work to pay for monthly electricity and water bills, yearly housing taxes, and imported foods and luxury items for which they depend heavily on shipments from Tahiti. Rurutu has a little-known tourist attraction revolving around the whales that come through from June to October, but the boats used for tourists are repurposed from those used for tuna fishing. Although the economic situation seems dire, "one is never poor or hungry on Rurutu" is a favorite line of the local people. It makes sense, because Rurutu is ripe with wild bananas, coconuts, and fruit trees. The winter lychee harvest alone could feed the entire island for at least a month. Tati, a 50-year-old woman I lived with, spent hours staring at her lychees, waiting for

${ }^{8}$ For further economic and political information on French Polynesia, see Gonschor 20022015, in The Contemporary Pacific. 
them to be exactly ripe enough to harvest and send to every single relative she knew.

The narrative always seems to revolve around Rurutu being a magical place because one does not have to pay for things, or if it proves necessary, there is always fish or taro to sell. However, the reality is not as pretty. People on Rurutu rely heavily on money from government subsidies, as well as their family members in Tahiti and France. Although Lockwood (1990, 1993) argues that there was very little in remittances between migrants and their outer island families, I found information in 2015 to the contrary. As the price of household bills and taxes has increased, so have remittances. Furthermore, these remittances are not only monetary family members on Tahiti often send commodities (cellphones, electronics, western-style clothing) to their familial counterparts on Rurutu. There is a strong but unspoken reliance on migration. Most of the families I spoke to have at least one family member who lives off of Rurutu - be it on another outer island, Tahiti, in France, or elsewhere. While this is normal for Polynesian cultures, especially in modern times, it is interesting that this interdependence is not talked about openly. Those who live elsewhere are spoken of as though they will be coming back soon, and the monetary assistance they provide is rarely brought up, or brought up only in terms of a reciprocal relationship between the family members on Rurutu and those abroad. One does not go hungry on Rurutu, but that is often because of money that is sent from overseas, and not necessarily because Rurutu is a paradise that provides everything a person might need for little to no cost.

The population is split into three districts - Moerai, the largest village, Avera, and Auti. Each one of these towns has - as my informants would say - a different "vibe" to it. Each has its own history and future that its inhabitants celebrate, as well as celebrating what makes everyone collectively Rurutu. The identities of the towns fall on a spectrum between the most 
"traditional" and the most "modernized." Auti, the most traditional, has one small general store, but no schools or other government buildings. Most of the families in Auti depend on agriculture, fishing, and artisanat work. The people who live in Auti hold tightly to the traditions of Rurutu. Alva, a 28-year-old mother of three who learned to weave instead of attending the secondary schools on Tahiti expressed her preference for life on the island: "I would prefer that my children learn to plant, fish, and live off the land. It is more important than school. I will teach my daughter to weave for herself, because it is our way and it will serve her well in the future." Avera is, meanwhile, considered to be the middle ground between traditional and modern. They have two relatively large general stores, one of the two primary schools on the island, and more people working in wage labor. Moerai is the most developed area on the island. This is where the post office, secondary school, and government offices for the island are located. Moerai also has the quai, where boats deliver goods from Tahiti.

I chose Rurutu for this research because of how it is viewed by its residents, those of the other Australs, and by Tahitians. Rurutu is the most populated of the islands in the Austral chain, but it is not the "most developed." Those who live in the Austral Islands consider Rurutu the perfect mix between modern and traditional. Many Rurutuans (and those from Tubuai, Rapa, and Rimatara that I spoke to) agree that the Austral Islands can be organized into a scale between "really traditional," or tupuna and "too modern," or classe - local people, specifically youth, utilize a French word to explain this phenomenon, which seems fitting. For example, Rapa does not have an airport, and only allows a supply ship in every two weeks. Therefore, there is little tourism to the island, and the inhabitants rarely make expeditions to Tahiti. Rimatara and Raivavai are slightly more modernized. Both have airstrips, but do not have regular flights to and from Tahiti. Rimatara has no secondary school, and their children must 
travel and stay on Rurutu for schooling. Also, to the amazement of those living on Rurutu, Rimatara only has one bakery on the entire island. On the other side, Tubuai is the "most developed" of the Austral Islands. Tubuai had extensive agricultural development programs (growing long lasting staple crops such as carrots and potatoes) throughout the 1950s and 1960s (Lockwood 1990). They export more crops than any of the other islands. They also have an outdoor mall on the island, and an increased level of consumption of western goods. The economics of Rurutu differs from that of Tahiti and the whole of French Polynesia as well. I will discuss this in the next section of this chapter.

\section{Economy}

The local economy of Rurutu includes four sectors: the public sector, including work at the mayor's office; public works on the island, the electricity plant or the post office; the private sector, in the few hostels located on the island, the well-established Chinese-owned general stores, the bank, or any entrepreneurial self-employment; and cooperative labor, such as the artisanat, fishing, and agricultural co-ops. The average monthly salary for a taro farmer or artisanat is roughly $\$ 300$ - $\$ 700$, depending on the season, amount of production, and demand. As Lockwood (2002) argues, capitalism promotes structural change in rural communities, so even though Rurutu is often seen by its inhabitants as a bastion of traditional values, it has not escaped being drawn into global capitalism. Although one cannot "go hungry" on Rurutu, there is not always enough disposable income to take part in the global commodity culture. Thus, there is a relative poverty on the island, but not abject poverty. Development and modernization have come to the island in disproportionate ways, but the mindset of those local to the area is that one is only poor because of moral setbacks such as laziness. Although families will do all they can to help those in need, there are still judgments. 
There is also socio-economic stratification on the island. It is not immediately apparent on a daily basis, due in large part to the French subsidies that are ever-present in people's lives, but it can be seen in subtle ways. For instance, the same people are always in charge of the town councils or committees, and those who run the island's cooperatives are always viewed with deference. Also, there is a difference between the teenagers who show up to festivals with new, clean clothes versus those who are wearing the same dirty jeans and tee shirt they wear to work in the fields. Having money, however, is not everything. It is also important to be well connected. Tuatini, one of my host brothers, recently opened his own garage out of his house. It is turning a nice profit, and because he is now a proprietor, he is allowed to offer one government subsidized 6-month internship contract. The young men who have been accepted to this position come from his own group of friends and acquaintances.

I met young people who were employed across the board. While it is not easy to start one's own business, as there are multiple forms and permissions that must be attained from the government, it is certainly a venture that some youth are willing to accept. Throughout my time on Rurutu, there were four new businesses that opened, both on the legal market and the black market: Treatini's garage, Panu's bakery and pizza delivery service, Tefi's snack bar, and Luna's marijuana start up. There are well-established small businesses as well, such as the bakery in Moerai, but these are run by older Rurutuans who plan to pass them down to their children. Young people are also able to sign up for a program called Compte Personnel d'Activité (CPA), which is a government-funded apprenticeship program that provides three month to two year paid contracts with local businesses and public sector jobs. However, due to French bureaucracy and lack of funding, only roughly 80 contracts of 800 registrants per year are assigned. These jobs are generally shared between individuals over time, and thus are not 
appropriate for older youth looking to build houses or start families. Furthermore, they are only for individuals without educational degrees. For instance, if a young person has graduated lycée and passed their BAC exam, they are thus ineligible to register or participate in the program.

Since these jobs are hard to come by, many young people find themselves carrying on the subsistence farming and artisan crafting of their parents and grandparents. Many times they describe this work as "for the family" or something to do while they await a new job. Most find that this sort of work affords them enough to survive, but not enough to save for the future. Unlike the youth of India (Jeffrey 2008, 2010), Nepal (Snellinger 2016), or Ghana (Langevang 2008), where the underemployment tends to be part time or inconsistent wage work due to neoliberal policies, for youth on Rurutu this work garners social capital through connections to the family while providing some monetary gain. The next section discusses this in more detail.

\section{Family Trade and Socio-Economics on Rurutu}

Young people tend to live with their parents, grandparents, or other extended family members, or with their beau famille (which is the extended family of their significant other) well into their 20 s and 30 s, and even occasionally after they are married. Often this is due to a lack of available housing or land on which to build a house, or to a lack of funds to support a family on one's own. Furthermore, families on Rurutu are extremely close to one another. Thus, by contrast with middle class families in the United States, there is not the need to be independent. Many of the young people who lived at home found it easier and cheaper to stay close to family. For the most part, every household on Rurutu has at least one wage-earning member. Others subsidize this through fishing, agriculture, and artisan craft businesses. The average household size of the youth I interviewed is six, but households range from two members to 12 . 
Family and family connections are essential to life on Rurutu. In the previous section, I showed how the familial property is handled, and the process one must go through to acquire land on Rurutu. This, in addition to the rocky and uneven geography of the island, has been useful in keeping larger, multinational corporations from setting up plantations and overdeveloping the islands. However, for youth it also means that land on which to build a home is not easy to come by. The towns are already developing further and further up into the mountains, as there is little space left near the coast. Thus, as people mature and decide to settle down, connections to one's family are increasingly important, particularly if one intends to come back after education or work elsewhere. These connections are the key to land ownership. For instance, Maruia, a 25-year-old mother of one who lives with her mother, daughter, and copain in Moerai, has been trying for five years to clear the family-owned land behind her current house and build her own home there. However, she requires permission from extended family members on both sides of her mother's lineage who are scattered across French Polynesia and are undecided on whether to grant her the land. Until they sign off, the area lays fallow. Thus, connections to family have economic as well as psychological impacts on young people.

Much like the intergenerational migration patterns studied by Smith-Morris (2007), One's "Rurutu-ness" is also connected to family. There is a certain amount of dignity associated with putting family above all else. These connections carry people through their lives. For instance, many of the unemployed youth I interviewed live at home to care for sick or elderly family members or the children of their siblings and cousins. This connection to family gives them a purpose. Those who live abroad do their part as well, sending commodities as well as keeping in touch via Skype, Facebook, and phone calls. 
For instance, Mairau spoke fondly of her very large, dispersed family: "In my family there are ten of us; five boys and five girls. The two oldest live in Papeete with their copains/copines and children. Two live in France; one is in the army and the other has a baby. One brother is in the Tuamotus, but has no kids, one is in Papeete, because she is still in school, and there are three left here on Rurutu - two in Moerai and one in Avera with her boyfriend." Mairau's description clearly shows that the dispersal of family members is an accepted part of life. Earlier in her interview, Mairau spoke of how she never wants to leave Rurutu because "things [on Rurutu] are free, and you never go hungry," but in a later conversation she showed me the new dress and shoes her brother in Papeete had sent her. This unwillingness of Rurutu's population to admit to the existence of outside support stems from the ongoing trope of Rurutu as a magical place where no one is poor or hungry. Any proof otherwise is not highlighted, because even when having to depend on people, those who live there still think it's better than anywhere else.

The other aspect of this web of international relationships is the amount of goods that get shipped out of Rurutu. During the time that I lived with Tati, we shipped over 300 kilograms (660 lbs.) of lychees in one day, destined for family members far and wide. Clearly, the money sent home by those who live elsewhere does not go unappreciated. Those who live on Rurutu are, however, occasionally acutely aware of the negative experiences of family members who live elsewhere. Rona, a 23-year-old female who grew up on Rurutu with her grandparents described the dispersal of her family to me in response to my asking who she currently lived with. As she puts it, "My entire family is elsewhere. My brother is in the army in France, my sisters are on Tahiti, and I'm the only one left on the island. My family in Tahiti does not like it there, they think it is too expensive, but their work is in Tahiti. My sister and brother-in-law 
there finished their studies so they could get good jobs in Tahiti, but they really don't like it there." Rona knows that those who live on Tahiti make sacrifices for monetary gain, and maybe that life in French Polynesia comes down to the choice of living on Rurutu while having to depend on others sometimes to support one's lifestyle, or living on Tahiti, where it is busy and dirty, but at least one has the ability to support a family and the growing expenses that come with it.

Even within the family on Rurutu, there is a good deal of exchange that goes on. As Alva, a 28-year-old mother of two who lives with her significant other and their children explained, "[our family has] a very good relationship. My brothers bring me fish when they fish, and we share everything - taro, fish, and any money I bring in with my crafts. I also help my parents with their bills. It's the bills that are hard. They are too expensive, so we must budget. It's also why everyone is always looking for work." Much like poor families around the world, there is a constant scramble to pay what bills are necessary. Sometimes young people go without schooling, or family members go without medical care (Brison 2003, Camfield 2011). Although the scramble here does not preclude health and education (due to French subsidies) this shows that the issues of consumption and tax-sponsored infrastructure have an effect on daily life. In summary, as the expenses of the increasingly global commodity-driven life on Rurutu grow, dependence on family abroad as well as on the island increases.

In terms of support of family, labor is also exchanged. Many youth on Rurutu work directly for their families. Sara (19) and her brothers all work the fields for their father, and Tereata (21) and Shi'o (23) work in the restaurant and hostel that their father owns. Manu (28) works his father's fields, as he passed away a few years ago. Also, many of the young women act as nounous, or nannies for the children of other family members who are employed in wage 
work or busy farming and fishing. This work is generally unpaid, but is an incredibly important social construct connected to living on the island.

\section{Celebrations as Group Social Navigation}

Rurutu is a place of celebrations - both Tahitian and Christian. Holidays of both natures are experienced in a uniquely Rurutu way, with a lot of local and regional flair. There is the Fête de Mai, the Heiva, New Years, Christmas, All Saints Day, and a host of other smaller scale celebrations. These are times to show one's devotion to the cultural representations popular on Rurutu. The Fête de Mai consists of opening one's house to the procession of members of the Protestant church parish and public in order to raise money for repairs to the church. Every June one will find young people harvesting plants, rocks, and shells to help make their costumes for the Heiva festival, a festival of Polynesian heritage that takes place around Bastille Day every year. The dancers practice for three hours every night to learn the dances to match that year's theme, while their family members assist in making costumes, feeding the hungry dancers and chorus, or help build the sets that will be transported to the festival grounds for the dances. New Years is brought in with a week- long celebration that culminates in a trip around the island where the next generation of orators learn the intricacies of the history of Rurutu, and the local strong men and women compete in stone lifting competitions. All Saints Day, on November $1^{\text {st }}$, is the celebration of those who have been lost. It is a beautiful time when the entire cemetery is lit up with lights and candles, and many families hold vigils at gravesites of their relatives. However, not all celebrations are steeped in Tahitian traditions - there are also two walks per year to raise money and awareness for AIDS and cancer. These, I'm sure, are holdovers from the push to gain international recognition for AIDS. 
The way of life on Rurutu is interesting in its paradoxes. Rurutuans are proud of the absence of serious "development" on the island, meaning they have little in the way of plantations and large stores, but they lament the lack of constant funds to pay for their wifi internet that has become so popular. The older generation celebrates the ongoing labor to grow taro and other crops and tend to the tree crops that grow all over the island. The youth also refer to Rurutu as a paradise where one really can't go hungry because there is always food available. Conversely, they much prefer French bread to Rurutu breadfruit for breakfast.

During the day, girls will get together and have a snack on the beach or at one another's houses, where they bake snacks or make food for the family. On days when many family and friends are due to leave Rurutu or to come back home, such as at the beginning and end of longer vacations, young women can be found picking flowers and sitting around making the traditional courronnes to don and give to their travelling mates. The older boys often get together to fish, work in taro fields, or help one another around the house, or with repairs. However, they are not always so driven. They can also often be found playing Kikiri, the local gambling dice game, while drinking heavily under the cover of an abandoned house or restaurant. Furthermore, both young men and women compete in various sports throughout the year. There are 5 different sports teams on the island, two in Moerai, one in Avera, Auti, and the smaller town of Vitaria. The sports include futsal (indoor soccer), volleyball, $v a$ 'a (canoe racing), and outdoor soccer. The teams are very adversarial, and often will get into arguments during games.

The airport is always buzzing on the days when the students come back for vacations or leave to resume school. A large portion of life on the island revolves around the airport and the supply ship when it arrives. Most residents have some family on Tahiti or other islands, and it is 
a standard practice to send boxes and coolers of items and foods that are cheaper on the island in exchange for food and other items from the main island that are harder to acquire on Rurutu. Many young people await their new vacation clothing that arrives from the mainland by plane or boat just in time for the Heiva festival, while simultaneously working on their costume for the dance competition, which must be made solely of local natural materials (save, of course, for the fishing line and Velcro used to fasten everything together).

\section{Education Policies in French Polynesia}

The impacts of colonialism in French Polynesia extend beyond monetary issues, religious conversions, and shifting land tenure systems that break down social connections. Due to the colonial present of French Polynesia, the educational system is tied closely to the French system, and is run mainly by French educators who are on two-year contracts to work in the islands. Many of the teachers at the secondary schools on Tahiti, as well as on the outer islands, are French, and stay only as long as their contract states. These teachers know little about the way of life on outer islands of French Polynesia like Rurutu. And they know even less about the perils of leaving one's home island to continue education on Tahiti.

In the French education system, once a child has completed primary school, they move on to the first portion of secondary school, from the ages of 13-15. These years are labeled in descending numerical order $\left(6^{\text {th }}, 5^{\text {th }}, 4^{\text {th }}, 3^{\text {rd }}\right)$. At the end of $3^{\text {rd }}$ year, youth take the Diplome National du Brevet (DNB) test. If they pass, they are allowed to continue on to the second portion of secondary school, and must then choose a branche, or course of study. The choices boil down to language, math/science, business, or vocational curriculum. Those who choose a vocational track - Brevet du Professionelles (BEP), Certificat d'Authorisation Professionel (CAP), or a Baccalauréat Professionel (BACPRO) - can stay in school between two and six 
extra years, depending on the vocation they choose, how much training it requires, and what level they would like to attain.

For those who want to continue in a more traditional Western education, they would choose the bacallauréat tracks, and would get their BAC. Figure 2 shows the complexities of the French school system that the youth from Rurutu must navigate. For those who do not pass their DNB exam, or who were having trouble in college, there is also the choice to continue into the Maison Familial Rural (MFR) program. This is an educational program that exists on a few different islands of French Polynesia, including Rurutu, and has classes devoted to studies that are helpful in rural areas, such as farming, fishing, weaving, and cooking. The MFR program's only certification is the CAP in agriculture, which is not useful outside of individual or cooperative agricultural endeavors on the island.

The issue with choices presented during $3^{\text {rd }}$ year is that most people do not quite understand what they are choosing. The process, as far as I understood from the youth I interviewed, revolves around an interview with one's primary teacher about his/her grades, which then reveals what schools they might be able to attend, and what track they can choose from. A student then chooses his/her top three school programs (one can choose one school but three different programs, as polyvalent schools offer multiple programs, or three different schools). Once a student has taken his/her DNB tests and received the scores, the top three schools decide whether to admit or not. At this point, the student chooses from those offers, applies for a bourse, or government aid, and makes plans for housing and transport. 


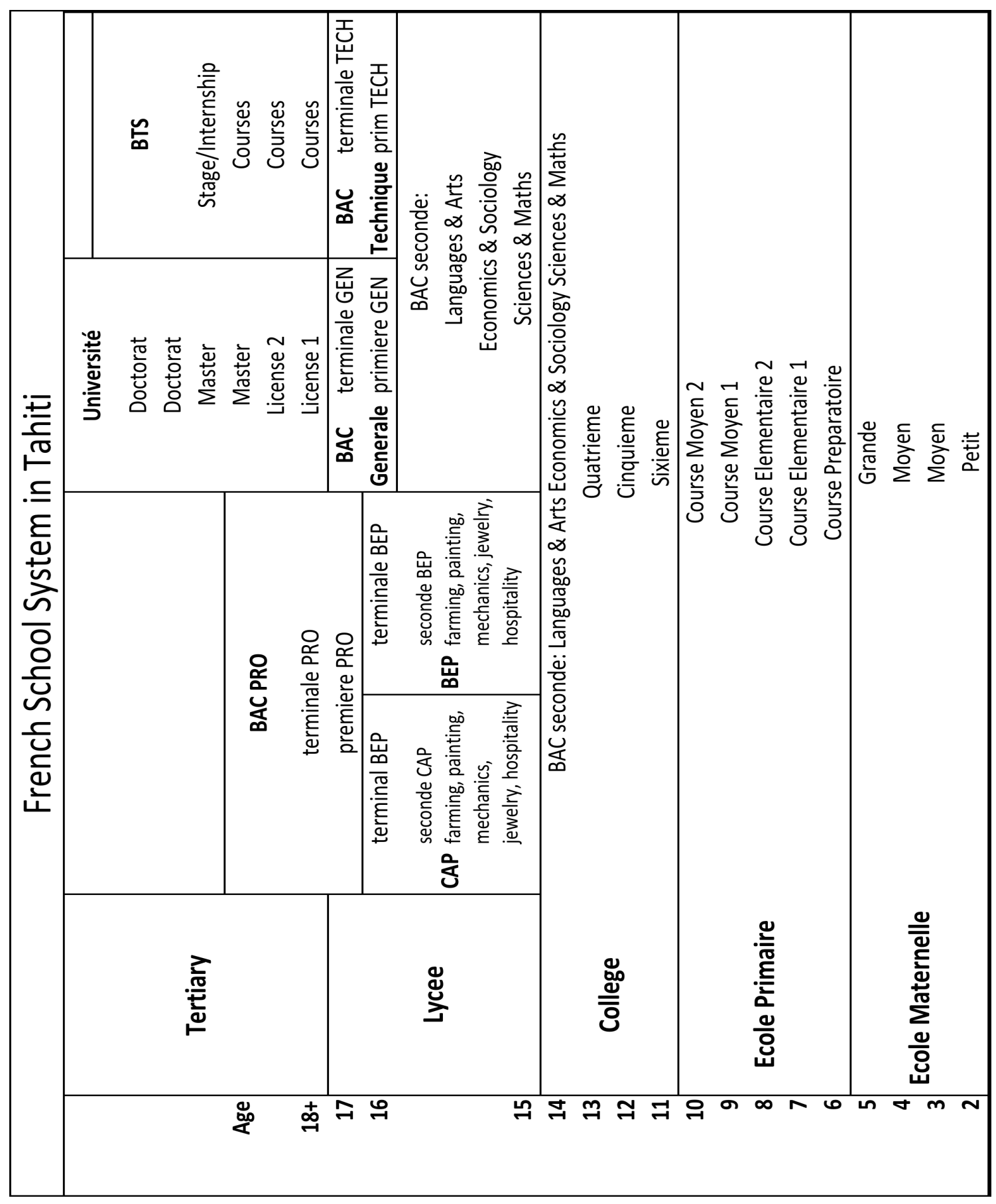

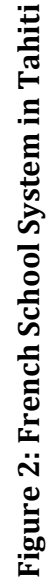


The teachers and guidance counselors helping Rurutu youth choose often do not take their real life future into consideration. The market for accountants in Tahiti is very low, but a managerial position at McDonalds requires a certification of $\mathrm{BAC}+2$, so they have to go to university or continue their education after receiving their BAC, even for lower level jobs. For those with credentials who choose to return to Rurutu, there is short-term contract work at the mayor's office or public works, but the department that assigns these contracts gets hundreds of applications for a handful of jobs and the CPJS (Centre Polynesien des Jeunes en Services) office is constantly overwhelmed and understaffed.

Issues that youths and their families take into consideration when signing up for schools include proximity to extended family, available programs, cost, availability of scholarship/bourse, and number of friends who also attend that school. There are some secondary schools that include space for youth who "board", and others that can only handle day students. Youth who board must have a place to go on the weekends, as the dormitories close on Saturday and Sunday. Many youth have problems with the family they stay with on the main island. Often the family is extended aunts and uncles, or cousins they have only met a few times. Occasionally there is a bourse that the student receives to pay for room and board during weeks and weekends, and often this goes to the famille d'acceuil on the main island, but the young person does not always reap these benefits. They are instead seen as free household labor, because they are staying for a long time and must "pay their share." These families also occasionally gossip about the individuals staying with them, and can cause drama back home on Rurutu because they share what goes on with family back home. Most of the youth I interviewed experienced problems with their host family. Sometimes it was resolved or they were able to find other lodging in the area. Other times, the drama caused them to quit school 
without their credentials and return home. These youth also often had to rely on family

members to reregister for federal support each year. Families who did not have experience with education often did not understand the process or forgot, thus forcing the student to give up their education and return home.

Other issues and decisions that affect Rurutu youth and cause vital conjunctures include availability of work, relationships, cultural practices, and family. Availability of paid employment has proven to be a formidable problem for Rurutu youth. Oftentimes when a new political party comes to power, the distribution of government support shifts. This means that certain contracts that were available on the outer islands may no longer be available, and while the scholarships that keep them in school are rarely if ever under negotiation, the prospects upon graduation, or upon moving home might change.

Furthermore, these issues occur simultaneously with other potential problems such as the illness or death of a close relative. Often young people from Rurutu will have to choose between continuing on a path to finish their education or caring for a loved one. There is often no long-term care facility available, and if there were, using it would bring great shame to the family. Young people often take responsibility for ailing relatives, as they do not have jobs, but this then derails their plans to find employment through education or apprenticeship. The next section of the chapter will speak more to how these conflicting priorities have changed the structure of potential life courses for youth on Tahiti.

\section{The Life Course, Transformations, and Ambivalencies}

As for Tahitians in particular, one can take from Levy's extensive research on the islands of Piri and Huahine, although their beliefs differ slightly from those of Rurutu. Tahitians believe that people mature in autonomous ways, by inner forces rather than instruction. And one 
knows they have matured when they are able to support themselves or their family, and put away the irresponsible ways of their taure'are' $a$, or youth. Identity, accordingly, is the "product of the relation between internalized personal forms and social definitions and realities. When it all works properly, and developmental and contextual social conditions are right, public forms make the inner world seem coherent, and the inner world gives vitality to public form" (Levy 2005). When it does not work properly, there are often symptoms, such as overconsumption of alcohol, depression, general unhappiness in relationships, partner violence, or even suicide (Kirkpatrick 1987).

"Tahitians experience themselves as unique and solid individuals who are different from others in the village. They and I are not of the same measurements. Their nature, the way they do their work, their thinking, the decisions they make, those are different from mine. Self is solid and given, not problematic" (Levy 2005, 451). Therefore, the understanding is that those of Rurutu see their individuality as unchanging, and their decisions are, for the most part, their own. However, they are not without doubts, and they often do not think of themselves first.

Robert Levy (1977) did extensive research on the Tahitian life course during the 60s, $70 \mathrm{~s}$, and $80 \mathrm{~s}$. He found it to be both rigid and fluid. Rigid in that there were very few pathways to follow - especially on the outer islands - and fluid in that there were no highlighted rites of passage to illustrate a transition between childhood, adolescence, and adulthood. Although he completed his research on the Society Islands of Huahine and Tahiti, his conclusions about the different stages of the life course, from child to taure'are' $a^{9}$ to adult to elder are apparent in the life courses of older generations on Rurutu as well. According to the local elders, in their time, when a woman bore children and a man could provide for his stable family, or when they got

${ }^{9}$ The Tahitian term for adolescents, especially young men. 
married, they were considered adult. These were gender-based markers of having put away the carefree lifestyle of adolescence and taken on the responsibility and lifestyle of adulthood (Kirkpatrick 1987; Levy 1977).

Now, however, this linear progression to maturity is breaking down, and contemporary young adults often ignore this passage. Contemporary youth see life less as a defined and progressive course and more as a series of choices and progressions, both forward and backward. Adulthood is less of a destination for them, and more of a process. The decisions they mentioned as important ranged from education and economic issues, to relationships and family planning, family problems, and residence. The priorities of each young person changed depending on the individual. While family, land, and church are still most important, changes within the ways of life on Rurutu and Tahiti have made certain dreams and lifestyles more difficult to attain. The ways in which youth are judged often still center around older traditions; for example, how one treats one's family or manages one's crops reflect one's own personality. But there are now many new obstacles in the way of being seen as a responsible adult.

This traditional linear life course has given way to more potential futures, but also new uncertainties. These are spurred by new economic processes, including hourly and salaried wage work instead of subsistence farming, extended years of education, easier travel and international opportunities, and new gender norms that are no longer based on the combined Tahitian/Christian values of men who support the household and women who bear children. Although these social systems have been changing over the past 40-60 years, they are only increasing with the installation of wifi and $4 \mathrm{G}$ on the islands. Now, young people can download American and Japanese popular culture as well as the French broadcasts. The adults portrayed in Beyoncé's and Rihanna's popular songs, or shows such as Glee and Empire are vastly 
different than those of the still loved but less ubiquitous Spanish soap operas. Rurutu youth see kids on television going to college, being single, being independent from their families, and it has bearing on their hopes for the future.

As children, Rurutu youth are given a lot of freedom and responsibility for themselves. Teens and older children care for their younger siblings while parents are busy working, and are sometimes tasked with buying food for dinners. They can ride their bicycles all over town. Young boys (and sometimes girls, if they show the inclination) are brought to the fields or work with their fathers. They participate in sports, dances, and household chores. This is largely unchanged from the time of Levy's visit in the 1970s. Adolescents, however, have to deal with making far more decisions than their parents ever did. Research from my previous summer trips showed that although life course options are limited, there is diversity in how youth attain and react to the life courses they find themselves on at any given time. Many of the adults and parents I spoke with did not know how to help their teens in this modern life, and often worried they would not be able to make good decisions without proper role models.

Due to the changing colonial history of French Polynesia, there are many paradoxes within life in French Polynesia. France only partially developed the rural outer islands, but introduced cash economy and consumerism to the islands. The continuing curtailment of aid from France has caught French Polynesia, in particular rural areas, between subsistence living and international trade and consumption. While it is natural to attach the former with the past and the latter to the future, the truth is that they exist simultaneously in the present of Rurutu and Tahiti, and it is this contradiction that the youth must deal with. My friend Niau asked for new soccer sneakers as 'compensation' for teaching me how to plant taro. When I asked for help picking a color he liked, he asked me to send pictures to him via Facebook Messenger so 
he could pick the ones he wanted. We danced together at the festival too - remixing traditional Tahitian dances to fit the hip-hop coming from the speakers. This is how I perceived "Tahitian ambivalence," something at the core of many of the interviews I conducted and the behaviors I witnessed. There is no sure way to negotiate such contrasting lifestyles, but Rurutuan youth seem to do the best they can with what is available, whether by keeping in touch with family through the computer, keeping up their Rurutu identity through memes and pictures on Facebook, or utilizing social media to keep up with friends from other areas while they continue their family's work planting taro or weaving artisan pieces.

In contrast to Levy's portrayal, the youth I came to know do not see the linear life plans that existed before or they do not care to. Their paths seem to be more focused on the negotiation between finding work, living a respectable existence, and not being labeled as having lost their Rurutu identity. Those who are seen as embracing the modern urban lifestyle too strongly - those who are classe - are no longer regarded as truly Rurutu. It is shameful, or honte, to have lost one's islander identity. Continuing to employ the idea of being "Rurutu" through lifestyle or keeping within cultural representations of personhood while outside the island is of utmost importance, and can be attained in various ways, such as through romantic relationships, residence, dance, continued consumer relationships with family on Rurutu, returning to the island, or even social media presence that shows one's ties to the island culture. Young people put special effort into the latter. Furthermore, land is held cooperatively with family, and thus it is important to keep this connection strong, and not be seen as having put aside one's Rurutu identity.

Therefore, in French Polynesia, although education is well organized, mostly free, and valued by many, the majority of people (even those under 25) do not have a BAC degree, and 
some have not finished compulsory education to the age of 16 (INPES 2009). Additionally, there are high rates of unemployment, and few opportunities for individuals to progress. However, many people do not consider lack of education a failure, so long as they are able to care for their family (whether through wage labor or agriculture). To gain status in rural Tahitian communities, individuals are expected to be hard working, involved in the church, and have their own household. An available piece of land for a house and arable gardens can be just as important as education and regular wage work.

Relationships, too, can conflict with family, jobs, education, and residential preferences. Most young people meet their romantic partners at the Heiva or New Year's celebrations when the young man asks the young woman to dance. They might also meet at school if one of them is not from Rurutu. This happens more and more now, because youth on Rurutu see others of the island more as family. Therefore, partners must choose between one island or the other, or give up family proximity to take a job near their significant other. Anita, who is a guard at the post office in a town on Tahiti, left Rurutu to follow her then boyfriend to Tahiti. Although they are no longer together, she stays on the main island because her job allows her to care for her child. Her family understands this sacrifice, and she will likely never move back. In another blow to the traditional life course of Tahiti, young people now wait well into their thirties or even later in order to get married. Weddings on Rurutu are a very important celebration, and the pastor often speaks of putting away childish desires and accepting their responsibility toward each other and their family. Nowadays, however, weddings are extremely expensive, and it is very difficult to find a time for the entire extended family to be able to visit

These historical and contemporary colonial and postcolonial experiences have concocted a particular set of scripts and lifestyle choices for rural youth in French Polynesia. 


\section{Conclusion}

Throughout this chapter, I have explained the various ways of life that effect young people from Rurutu. The continuing political upheaval and discord, coupled with the politics of job growth has deepened the issue of finding jobs that youth experience on Rurutu. On the other hand, the ability to lean on one's family for support (even while striving to become adult) makes it less necessary to find a salaried position. The connection to family can detract from certain paths, but also opens other ways to strive for dignity. Although Rurutu is seen as the basdtion of traditions, the island is itself an amalgamation of tradition and modern. Those youth for whom academic credentials come easily have more opportunities to find wage labor, but also have more opportunities to discover obstacles within the contradicting impulses to find careers and live close to family on Rurutu. There are few paths forward in the select specialties that do not include living on Tahiti or elsewhere in the world.

The context of Rurutu's (post)colonialism, where the French school system is constructed in opposition to many of the actual opportunities young people have creates a context in which each vital conjuncture can be shown to prioritize certain social institutions and cultural influences over others. However, in the face of globalization and (post)colonial problems, and ambivalent aspirations, young people utilize family connections to navigate changing contexts and life goals.

The next chapter will use quantitative analysis to better understand the ambivalent nature of modern scripts, and examine whether individually defined vital conjunctures can be used to analyze motivations in times of conflicting influences. 


\section{CHAPTER 4 \\ TRANSFORMATIONS AND VITAL CONJUNCTURES: A THEMATIC OVERVIEW}

In this chapter, I will discuss the distribution of vital conjunctures over the course of Rurutuan youths' lives. This chapter will include analysis of vital conjunctures by demographic categories, as well as among all youth. When I asked each participant about the important decisions and transformations in their lives, I made sure not to specify an order. When asked for examples, I gave mine out of chronological order as well. Thus, although some vital conjuncture narratives were organized chronologically, my hope is that those mentioned first would be considered most important, and those mentioned third could be considered less important.

Due to the collection of both quantitative and qualitative data, this research will allow me to answer questions of decision-making in two ways: the first would be whether certain demographic characteristics lead to certain vital conjunctures. For instance: Are youth with higher levels of education narrating their important transformations in terms of education? Is age a factor in which vital conjunctures are seen as most important? How does level of education affect opportunities? The second would be whether there is a pattern to how differing external influences relate to each other and individuals during vital conjunctures. For example, are family and education always in opposition?

As I mentioned in the discussion of my methods, I asked each youth I interviewed to describe three vital conjunctures they had previously or were currently experiencing. I then aggregated these vital conjunctures and coded them according to themes that emerged from the 
text. The reason for coding and counting vital conjunctures is to arrive at an overall picture of how youth from Rurutu view and narrate their lives. In the qualitative analysis chapters that follow, I have chosen to limit the number of case studies presented in order to reveal the diversity and complexity of vital conjunctures even within a single youth's life. In this chapter, I offer an overview of the larger dataset in order to show the bigger picture of how demographic characteristics can influence the appearance or experience of different vital conjunctures.

The nature of the diverse decisions youth complete necessitates that the analysis of each decision be as unique as the experience of it. However, the quantitative analysis did allow me to discover a few themes relating to their process of making decisions. These themes included family, quality of education, relationships, residence, family planning, and work issues. Much of the anthropological literature on vital conjunctures examines certain demographic or cultural phenomena, such as childbirth, the education-work transition, or finding sport as vital conjunctures (Esson, 2013; Johnson-Hanks, 2005; Langevang 2008; Liversage, 2009). I wanted to understand the full span of these experiences throughout the time in which most life change happens. Decisions, in terms of their influence on the life course, are multifaceted, and no one decision, transformation, or life event should be weighted above all others. The examination of vital conjuncture narratives reveals the factors that come together within each vital conjuncture, the different priorities that went into each decision, and the effects of those decisions on the rest of the life course.

During this research I asked very generally about vital conjunctures: "Can you please name three times in your life where your life changed course - for instance, you made an important decision, or you experienced an event that shifted your direction to lead you to where 
you are today?" The question itself took some explanation, some examples, or some cajoling, but eventually most of my research participants answered.

\section{Coding Vital Conjunctures}

I coded the vital

conjunctures mentioned in each interview by what seemed most important in the decision: either the motivating factor or the factor that was decided on. As

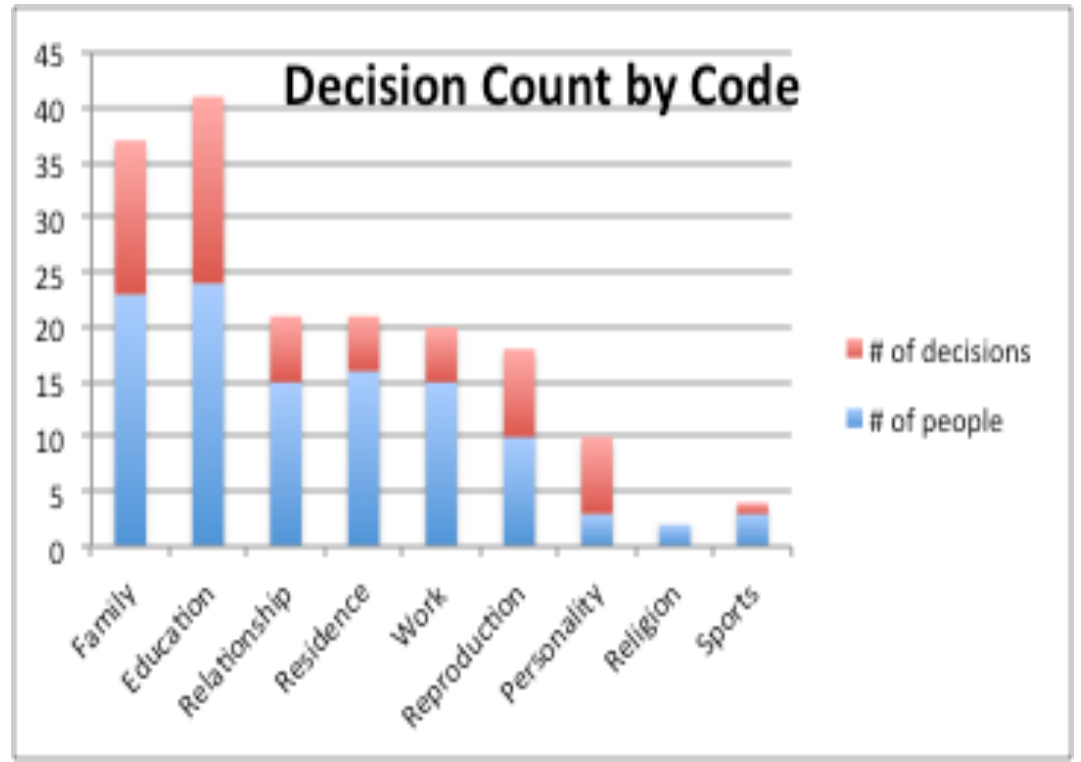

Sommers (1994) argues, identity is

Table 3: Decision Count by Code about the "big stories", or ongoing stable identities that allow for continuance, and the "little stories", which are the momentary roles and decisions youth navigate. To understand the big stories, we must also examine the small ones. Goffman (1974) argues that all decisions are political, and they show who a person is. I also argue that all decisions involve prioritizing one aspect of self over another. If there is not part of oneself in the decision, then it is not a vital one.

The data on vital conjunctures coalesced around nine major themes: family, education, relationships, residence, employment, reproduction, personality growth, religion, and sports. These themes emerged from the answers to broad questions, and were not conceived of beforehand. Of the 64 interviewees who were willing to participate in this portion of my research, only 54 responded to prompts about vital conjunctures they have experienced during their lives. Since I asked them to name more than one event or vital conjuncture, there are 
actually 133 different decisions that could be analyzed. Some youth made more than one decision that coded for the same theme; thus there are 109 different decision codes when weighted to take that into consideration. The chart above shows this distribution of vital conjunctures, with the red layer showing which codes had the most redundancy in youths' narratives. Family and education were the themes of the young Rurutuans narratives that were the most likely to come up twice within one narrative

\begin{tabular}{|c|c|c|c|c|}
\hline \multicolumn{6}{|c|}{ Distribution of Coded Decisions by Youth from } \\
Rurutu \\
\hline Code & Decision 1 & Decision 2 & Decision 3 & Total \\
\hline family & 15 & 9 & 5 & 29 \\
\hline education & 14 & 9 & 4 & 27 \\
\hline relationships & 5 & 9 & 8 & 22 \\
\hline residence & 7 & 2 & 2 & 11 \\
\hline work & 6 & 5 & 3 & 14 \\
\hline birth & 2 & 7 & 7 & 16 \\
\hline personality & 3 & 4 & 1 & 8 \\
\hline religion & 1 & 1 & 0 & 2 \\
\hline sports & 1 & 2 & 1 & 4 \\
\hline Total & 54 & 48 & 31 & 133 \\
\hline
\end{tabular}

Table 4: Distribution of Coded Decisions

This table shows that while family and education often came up first in these narratives, such topics as births or relationships tended to be secondary in importance (or chronology). Most of the residence-related vital conjunctures that were mentioned first were transitions to Tahiti during school, while those mentioned later tended to be marital residence changes. 
Although these seem to follow a chronological order, many of the vital conjunctures concerning family were non-chronological. Educational decisions did not follow a specific pattern of chronological vs. importance-related.

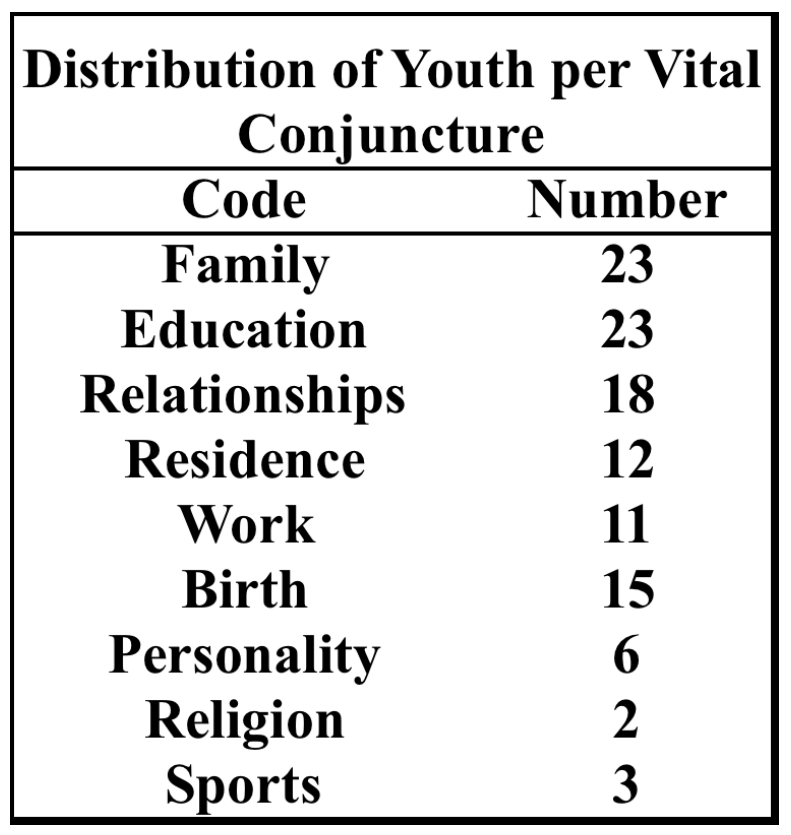

Table 5: Distribution of Youth per Vital Conjuncture

This table shows the distribution and frequency of the 54 youth who provided at least one vital conjuncture in their responses. Thus, although family received more recognition in the narrative than education, the same number of individuals within my sample named a conjuncture that was related to education as they did family.

Family

Family is quite clearly very important in the life narratives and social identities of Rurutu youth. Twenty-three percent of decisions made by the youth interviewed related to nuclear, extended, or beau (in-law or host) family. This does not, however, include vital 
conjunctures related to pregnancy or romantic relationships. These decisions stuck closely to a few main premises: the sickness or death of a parent, grandparent, or other close relative that often led to early cessation of studies; strife within one's beau famille (in-laws) or famille d'acceuille (host family during one's studies); unwanted expectations from one's birth or childhood family; and experiencing separation from family members. Eight participants included the illness or death of a parent, guardian, or grandparent as a vital conjuncture. Seven of the eight mentioned this first in their narrative, even if it happened later in life. This could mean, as Evans (2014) argues, that familial death is a vital conjuncture because it upsets social relations and positions within the family. Deaths are also seen as transformative, and often lead to youth making secondary decisions in the wake of that person's death.

Manu, for instance, had to quit school when his father fell ill, as he would not allow anyone else to care for him. Manu, who is now 28 with a child and a copine, does not see this change in his young life as a choice, or negatively. His family brought him home and he did what he had to do. He has now moved on from it and found a successful life with his copine, and their son. He continues his father's legacy through farming his father's taro fields.

Choosing family over everything else is not the only experience identified. Several youth from the study brought up terrible experiences with their in-laws or host families on the main island, especially during high school. While this vital conjuncture did not always lead to cessation of education, it is seen as a time of displeasure and reconsideration of the importance of school. For instance, Tamatoa, a 19-year-old university student, had to take his BAC exam twice due to issues with his host family on Tahiti. He was convinced the aunt he was living with had put a hex on him, and thus he had to decide if it was worth it to stay and finish his studies. He lived another six months with her, not knowing whether and/or why she hated him. In the 
end, he managed to pass his BAC exams and at the time of our interview was starting his second year. When Tamatoa experienced so much angst with his host family that he failed his BAC exam, he had to decide whether to quit and return to Rurutu or try again. He was constantly living with the question of whether and why she hated him so much. As he told me this story, he seemed visibly shaken. He was thankful that he was able to acquire on-campus housing for university.

Bad experiences around family also included, experiencing separation from family members. This was also seen as a turning point in one's life. For Reva and Nat, two siblings who are 26 and 19 respectively, their separation and subsequent reunification were times of transition in both their lives. For Reva, leaving home made her grow up and take responsibility, since she no longer had Nat's support. Eventually, Reva decided to return home to Rurutu. While Reva narrated this transformation as a final chapter in an adventurous time in her life, Nat narrated the vital conjuncture of Reva's return home as a catalyst for accepting his identity as a rere (third gendered person) and a homosexual. She had been the only one in the family with whom he felt comfortable enough to be himself, and her reappearance was helpful to his wellbeing.

Family-centered vital conjunctures were the most common transforming experiences youth revealed. This follows the Rurutu identity and lifeway of family above all else. However, the second most popular theme I coded for is education. Globalization has made the completion of one's BAC ever more important. Thus, decisions to stay in school or terminate early are often seen as transformative. This dichotomy adds to literature on the contradictory forces of home and education. Although Demerath (1994) and Leichty (2007) argue that education as an 
institutional influence often wins out over family in modernizing or developing societies, among those in my research sample it seems evenly split.

\section{Education}

Equal in frequency to family-related vital conjunctures, education was cited in 32 percent of the decisions tracked ( $60 \%$ of young people interviewed mentioned education). Originally, I assumed that the decision of which track to follow during lycée would be considered a vital conjuncture. One's specialization, more than any other singular characteristic, can open or shut doors and hence access to diverse future paths. Although only two young people listed the specific experience of finding a secondary school specialty as a vital conjuncture narrative, the stories of trying to choose a branche for lycée were often full of problems and challenges. Many were turned away from the programs they wanted, or had overbearing parents who did not take their talents into consideration. For those who did not end up liking or succeeding in their track, the two choices were to change (which is relatively easy, save for the mountain of paperwork) or quit early. I will cover the case studies of these experiences in the next chapter.

Outside of the experience of choosing a branche, school was still full of experiences of transformtions and vital conjunctures. Many of the youth interviewed cited the continuation of their education as a vital conjuncture. While some of these youth had eventually quit without the certification they were striving for by the time my research ended, it was still an important step at that time. For many, the decision to quit early was cited in conjunction with other themes, such as family illness or strife, relationship troubles, or pregnancy. There were also two young women who cited the decision to return to school after time away as an important factor in their life histories. Education, as can be expected in the modern world, interacted with many 
other codes because education is often seen in relation to a different aspect of life; young people who choose education do so by giving up some other aspect of their lives - choosing the life of education over relationships, proximity to family, and even parenthood.

Education can be seen as a pathway to active participation in the global economy, and diplomas carry with them a certain amount of dignity. However, education, and especially Rurutu youths' experiences of it, can also be degrading and useless. The interaction with colonial forces, racism, prejudice of teachers, not to mention terrible living situations, can work to strip youth of their dignity among other indecencies. The decisions about school show that France is not providing an appropriate degree program in French Polynesia that focuses on the things a small island nation might need.

\section{Relationships}

The next most prevalent vital conjuncture theme I found within my interviews was romantic relationships. This too was contradictory. On one hand, there is a sense of pride in finding a good partner. On the other hand, three separate young women mentioned lack of significant other as a point of pride. For this latter group, it seems as though choosing not to have a relationship becomes something of a defining moment in their lives. Heinari, a 19 year old first year university student, cited her lack of a copain as a vital conjuncture. She "understand $[\mathrm{s}]$ how tempting it can be to put a boyfriend above all else, so in order to succeed in school," she opted out. On the other hand, many young women chose their relationship over education. Rui's boyfriend wanted her to move home to Rurutu, live with him, and start a family. Thus she quit school to pursue her future as a mother and a wife. They are now married and have two children. 
For others, a significant other cheating on them, or strained relationships and breakups may lead to significant life changes. Three of my participants (one male, two female) mentioned a break up as a defining moment in their lives. Haina told the story of leaving her boyfriend after finding out he was cheating on her. She was with her boyfriend for many years, but he was occasionally violent or abusive. However, she finally left when he cheated on her with a girl from his class. This was a major turning point in her life, and one she looks back on with mixed feelings. She had made the decision that her life would be better on her own than in the relationship and set out to start over. She now has a daughter with her newest boyfriend, who she claims is nothing but nice and loyal, and she is considering going back to school. Others have found themselves through a certain relationship with someone of the opposite sex. Those whose relationship did not conflict with an educational trajectory nevertheless talked about how relationships had changed or improved their outlook. For Haina, her new boyfriend had given her the confidence to try to go back to school. When I last saw her, she was researching how to sign up for online courses to finish her BAC exams.

Relationships are important to people across cultures, thus viewing them as transformations in the same capacity as illness or education allows for a complete picture of the experiences of youth. Although not all relationships last forever, it is important to take their lasting effects into account when analyzing life course transformations. Break ups and new relationships often signal new chapters for people. It is interesting to note how many narratives included relationship-related vital conjunctures: transformative new relationships, breakups and the subsequent fall out, or the lack of relationships because young women are beginning to prioritize their education. All of these were seen as important pieces of youths' current paths and identities. 


\section{Residence}

Residency changes and events were also mentioned as an important theme. Most youth saw the transition to Tahiti from life on the much smaller island of Rurutu as transformative. Although residence does not play as big a part in their life course histories as family or education, it is still incredibly important, and the ways in which youth talk about residence patterns as vital conjunctures are also telling. For many of the other vital conjunctures, it is an outside force acting upon the youth that impacts their life course. For instance, school becomes exhausting, or they experience trouble within their family, or they find a relationship that changes their outlook.

While a living situation seems like an external vital conjuncture, most of the youth I interviewed mentioned it in the context of a personal transformation. Transitions from Rurutu to Tahiti changed their priorities, or made them more extroverted. Turi, a 24 year old BTS graduate spoke of the changes he experienced on Rurutu: "Being away from home was scary at first... You're not, you know, chez toi. My teachers were different, and I moved into the dorm and had to stay with my cousins on the weekends. I don't know. But now I like it. There's freedom. I know how to make my own decisions."

These transitions were often seen as growing experiences, more than decisions. In this case, even negative emotional reactions or disagreements within the host family were seen in a more positive light. Decisions about residence also came up in tandem with family decisions. For instance, the decision to leave one's birth family and live with a beau famille, or finding and financing one's own home were seen as vital conjunctures for six young people within the survey. Nakita, a 27-year-old mother of two who lives with her husband and kids in a cabin on the hill outside Moerai expressed the "terrifying transformation" of running her own home for 
the first time, especially, in her case, when the house has yet to be hooked into the electricity grid.

Work

The stories about important work decisions often centered around quitting one's job, finding a great new job, or having trouble finding a job. Many of the youth who had trouble finding work joined the army, as it provides a stable paycheck and a chance to travel outside of Rurutu and Tahiti. For those Rurutu youth I interviewed who were living on Tahiti posteducation, finding work was an important event in their lives. For many of them, it is the reason they remain on the main island instead of their home island.

For those who are living on Rurutu, trying to find a job is important. The lack of posts, of having to make money where they can, is a vital conjuncture that shows how economic changes can have huge effects on lifeways and social navigation. Although there are jobs to be had on Rurutu, finding and keeping long term contracts is not easy. Moana, a 30-year-old woman who has two degrees and lives with her parents on Rurutu, remarked: "My transformation is happening right now. I finally have all my certifications. Did you know there are four administrative jobs coming up due to retirement on Rurutu just this year? Yes. Two jobs are opening at the mayor's office, one at the post office, and one at the college. This is a big year for retirement. I keep a running list of which jobs I can apply for with my certifications." Thus, getting a job on Rurutu takes time and perseverance, but young people are prepared to make those choices. 
Birth

Ten different young people chose the birth of their child for one of their vital conjunctures. Seven of these were female and three were male. The women generally spoke of this transformation in terms of putting all else to the side for the baby. Males used this as a catalyst to become a responsible person. For instance, Teva, a 23-yaer-old father of one who takes care of his baby while his copine works at the dispensary, explained that having a baby made him realize how irresponsible he used to be, and he strives to be better for his family.

Birth and reproduction were the subject for Johnson-Hanks' original theory about the non-linearity of the lifecourse. This makes sense in this context, as birth makes individual's more responsible, but a lack of economic opportunities make independence difficult to obtain.

\section{Personality/Religion/Sports}

Personality change was one vital conjuncture I was not expecting to find. Youth who experienced changes in character often narrated it in relation to other events in their lives. There were some youth who cited internal changes as defining moments in their lives. For instance, Maruya was very introverted and quiet growing up, but during lycée she made a decision to become more of an extrovert, open up to people, and make friends. Of the 54 youths who listed vital conjunctures, six mentioned this as a vital conjuncture. While the number may not be statistically significant, it is an interesting point to understand that sometimes a person can change without an external force working upon them.

Two other vital conjunctures that I coded for, but that were not as common as the others, were religious conversion and conjunctures related to sports. Both were cited by male and female youth, but only two or three times each. Religion, as a familial and community space of 
connection, is still very much a part of the Tahitian or Rurutu way. Although participation can very, identifying with a religion is almost expected as youth grow up. Therefore, the two instances of religion as vital conjuncture were both based around conversion. For Raitu it was his conversion to Protestantism for his girlfriend, and for Himene it was her conversion to Jehova's Witness that spurred huge transformations in her life. For most youth, however, religion is not a basis for change but the stable foundation upon which they build their lives.

Sports were also mentioned as a decision or event that changed youths' life courses. For one young man, it was the loss of the dream to play professional soccer that made him realize working hard in school was no longer a choice. A young woman, on the other hand, chose her education over her future as a ping-pong player. There was a marked difference in the agency felt during these two events, but sports have remained a passion for both as they have grown. Additionally, as I will examine in Chapter 7, sports, along with religion is really a way of connecting and forming foundational bonds within the community. Therefore, changing sports is seen as a vital conjuncture, but playing sports is not necessarily transformative.

\section{Vital Conjunctures by Demographic}

In the last section, I described and explained the frequencies with which certain themes emerged in general discussions about vital conjunctures with my research participants. In this section, I will analyze these vital conjunctures in terms of how demographic characteristics affect them. For instance, how do gender identities and socialized gender roles impact the experience or narration of vital conjunctures? The demographic characteristics I will use in this

analysis correlate to the quotas I used for my interviews: age, gender, town of birth, and level of education. 
Due to imbalances in representation for each demographic, the comparisons of frequency of each vital conjuncture are measured in the percentage of that demographic category that narrated at least one vital conjuncture matching that code. Of those who answered questions about important decisions, the demographics break down is as follows:

GENDER: female $(\mathrm{N}=35)$, male $(\mathrm{N}=19)$;

AGE: 18-21 $(\mathrm{N}=16), 22-25(\mathrm{~N}=19)$, and 26-30 $(\mathrm{N}=11)$;

LEVEL OF EDUCATION higher education (BAC or higher: $\mathrm{N}=31$ ), and lower education (other types of certification, or dropping out before reaching certification: $\mathrm{N}=15$ );

TOWN OF ORIGIN Avera and Auti $(\mathrm{N}=17)$ and the larger town of Moerai $(\mathrm{N}=29)$.

Although the levels of education and towns could be separated out further, I chose to condense them into two categories for multiple reasons. In terms of education, although receiving a vocational degree (CAP/BEP) shows one's certification, for the youth from Rurutu the number of jobs available to CAP holders is roughly the same as those who dropped out of higher level BAC programs. Additionally, the cutoff for the ability to receive governmentfunded apprenticeship contracts ends at the attainment of a BAC certificate. Thus the most important educational distinction for rural youth is whether or not they have a BAC.

In terms of the amalgamation of two towns, Avera and Auti are seen as the more traditional of the towns on Rurutu, whereas Moerai is quite clearly the most modern and largest by far. Coupled with the lack of youth I interviewed from Auti, it seems that the differences between Auti and Avera are much less dramatic than the differences between both those towns and the larger one of Moerai. 


\section{Gender}

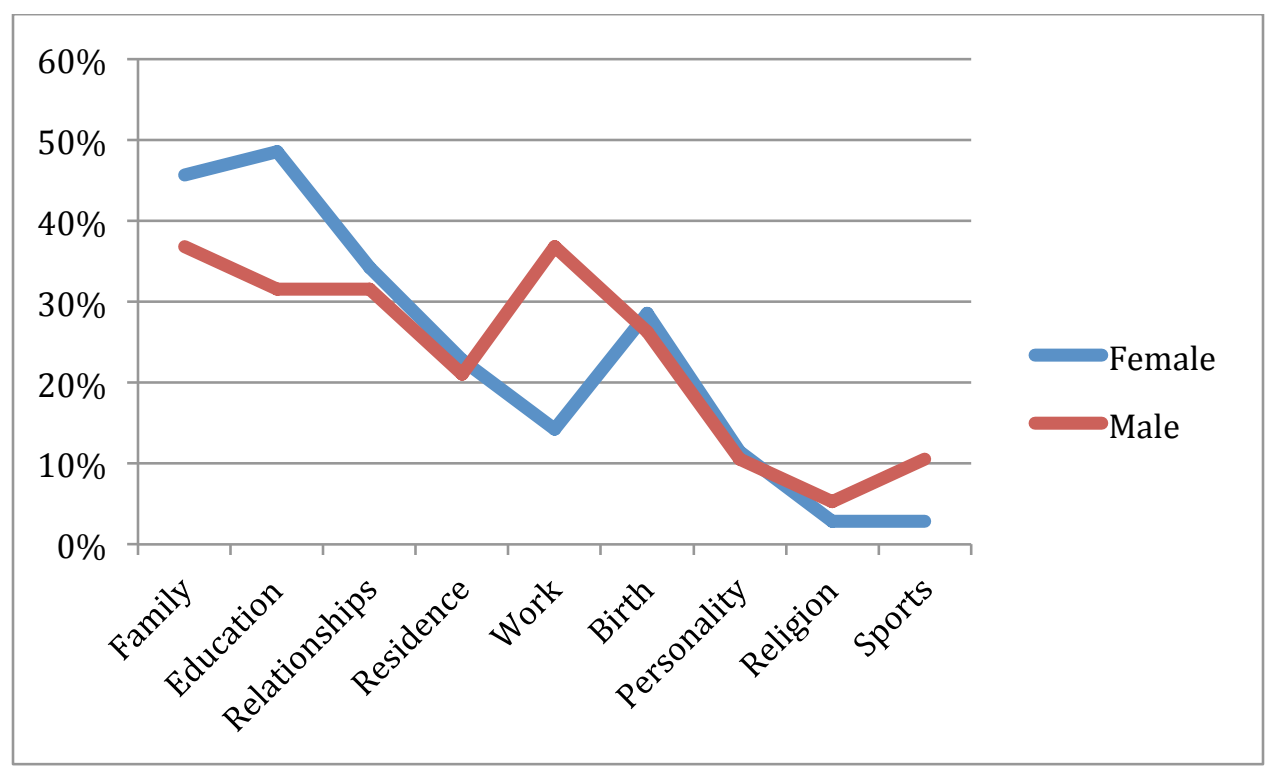

Table 6: Distribution of Vital Conjunctures by Gender

As can be seen in the above graph, females had a higher frequency of recounting vital conjunctures related to family, education, and birth than males, while males were more likely to share vital conjunctures concerning work. This follows Tahitian gender roles, although I had expected the male numbers for work to be even higher. The consistency in vital conjunctures about relationships and residence is also striking. I had considered that the move to the big city would affect young women worse than young men, but it is about the same for both.

On the other hand, $52 \%$ of females made decisions concerning family and $55 \%$ made decisions concerning education, while only 27 percent mentioned work (and two of those were in relation to education). In both cases, the majority of youth mentioned decisions surrounding quitting or continuing their education, but few mentioned the decision to attend one or another program, although my pilot studies suggested that this was an important emic turning point in many of their lives. 
Decisions concerning work seemed to be more influential in the lives of males than females, as only 20 percent of women interviewed mentioned decisions about work, while 40 percent of men did. This could be tied to gender norms both in traditional society and French and international media influence. While education is relatively equal between the two as far as importance within their life story, work seems to have more of an influence on the life narrative of males. However, in total, only 30 percent of youth interviewed even mentioned work having an influence on their lives, while half mentioned either family or education.

Males worry about being able to find a job, and many of those I had been friends with during pilot studies had left for the army to earn a livable wage as well as increase their employability in the long term. The job prospects for these young men are few and far between on Rurutu. The local government tries to give as many short-term contracts in research, secretarial, and public works as they are able to, however these jobs depend on large subsidies from the government and often change year to year.

For many young men, the vital conjunctures having to do with work and employment coincide with not being able to find work, or being denied a future prospect that they had worked for. Two separate young men spoke of wanting to be pilots and being denied. Both have had to find a new dream. For both Reva and Hatitio this became a turning point in their education. Reva is now completing a BTS in France (another important decision he mentioned) in order to pursue his career in architecture and engineering. Hatitio had not yet decided on a path for his BTS.

On the other hand, when the young women spoke about vital conjunctures or decisions concerning work, it tended to be more focused on a new job and deciding whether to take it. Ita, 30 , spoke of her decision to leave her daughter at home to take a new job as a security officer at 
the post office. She spoke of how it hurt to leave her baby, but the money was necessary for them. Laina's decision concerning her work was slightly different. She lives on Tahiti, but is from Rurutu. Her dream is to be a teacher, and when interviewed she had just passed her licensure exam and was student teaching at a local elementary school. For her, this was less difficult of a decision, because she had only her boyfriend, who is also gainfully employed on Tahiti, and lives with his family. She speaks of a future where she can teach, but understands with a heavy heart that the jobs she obtains may never allow her to live on her home island.

Along with education, work can provide a path of striving toward dignity. This path exists for both youth who have attained a BAC and those who have not. For those who have attained a BAC, gaining employment is an assumed next step, but does not hold the same amount of potential esteem or respect. For youth who did not attain their diploma, finding work is another path toward dignity, even if it is a short-term contract. Jeffrey (2010) also researched this issue among young men in India, who were over-qualified and under-employed. The question for those young men, much like the young men in my population, was whether the social status of being highly educated was enough, even if it did not lead to gainful employment. 


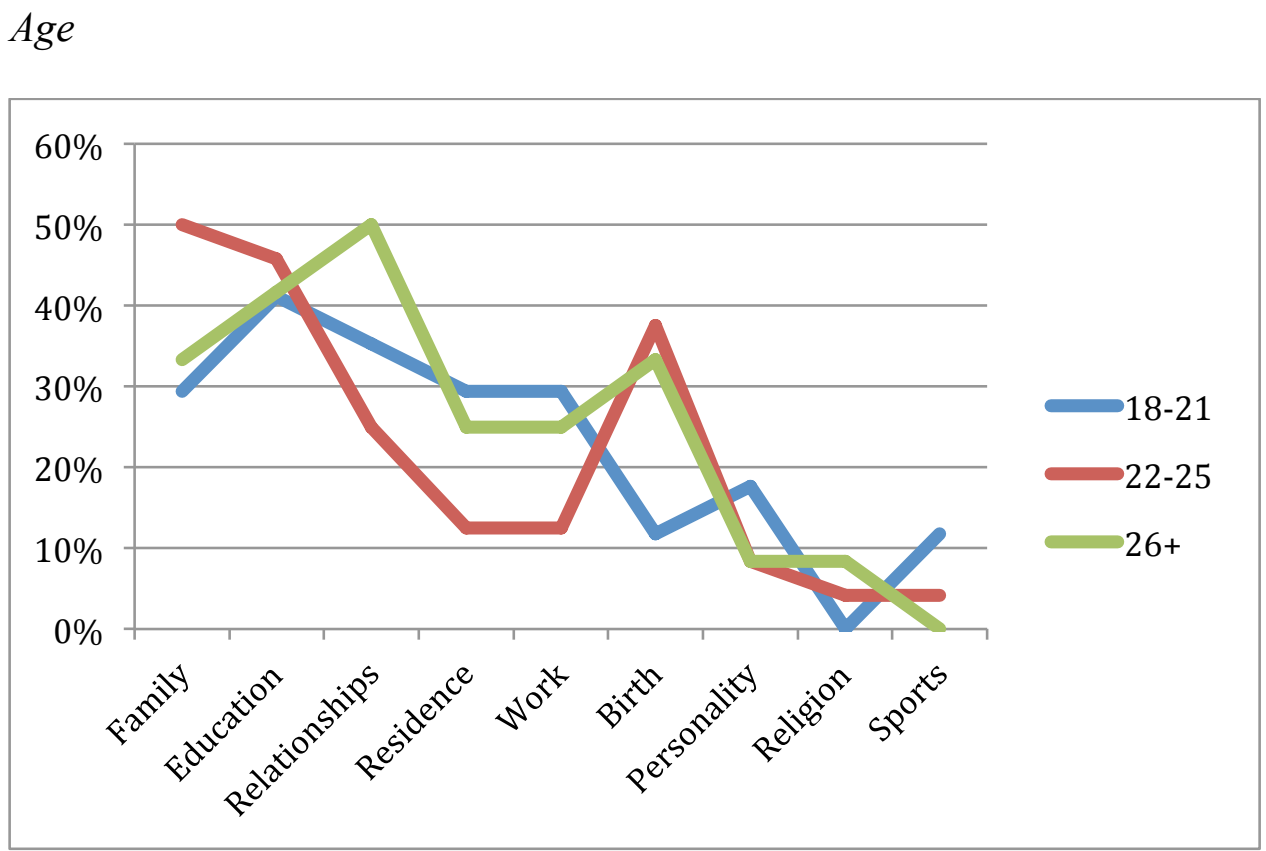

Table 7: Distribution of Vital Conjuncture by Age

I had originally hypothesized that for those in their early 20 s the important decisions regarding education would still be fresh in their minds, and thus they would have more vital conjunctures concerning education while those in their late 20s, having moved on from the victories and setbacks of education, would tell narratives that include other themes more exclusively. However when the decisions are graphed, there is a relatively equal spread of educational vital conjunctures narrated by each age group. The differences, as can be seen in the graph above, center around vital conjunctures concerning family, relationships, and reproduction.

For the 18-21 year olds, their experiences of the main three vital conjunctures - family, education, and relationships - are on par with the average, but they have spikes for work and personality changes. This makes sense, as it is a time of great transition to the main island of Tahiti, where there are many new influences for those looking to change their perspective. 
For the 22-25 year olds, they are still remembering how their experiences with education affected them, while also being of the average age for childbirth. Thus their vital conjunction narratives tend to spike for those two codes, as well as family because they are the age where traditionally one would start to prepare to leave the family home. Youth of this age want social maturity and independence, but economic setbacks do not allow it. For this reason, I was surprised at the low number of young people in this demographic referring to their experiences with work as vital conjunctures.

Lastly, the $26+$ group has spikes around vital conjunctures of relationships and birth. This matches what I had originally theorized, as this is the age when couples begin to think seriously about having children and staying together, if not about marriage. This is also a time at which many of the heartbreaks of the mid-twenties have happened and have thus left their mark. Residence decisions also fall within an interesting aged pattern: Those in their early years have a high number of decisions concerning residence, as do those in their later 20s. This could be because the younger individuals are making decisions or going through changes associated with moving for school, while those in their late 20s are making decisions regarding moving out of their family or in-laws houses and into their own. 


\section{Town Identity}

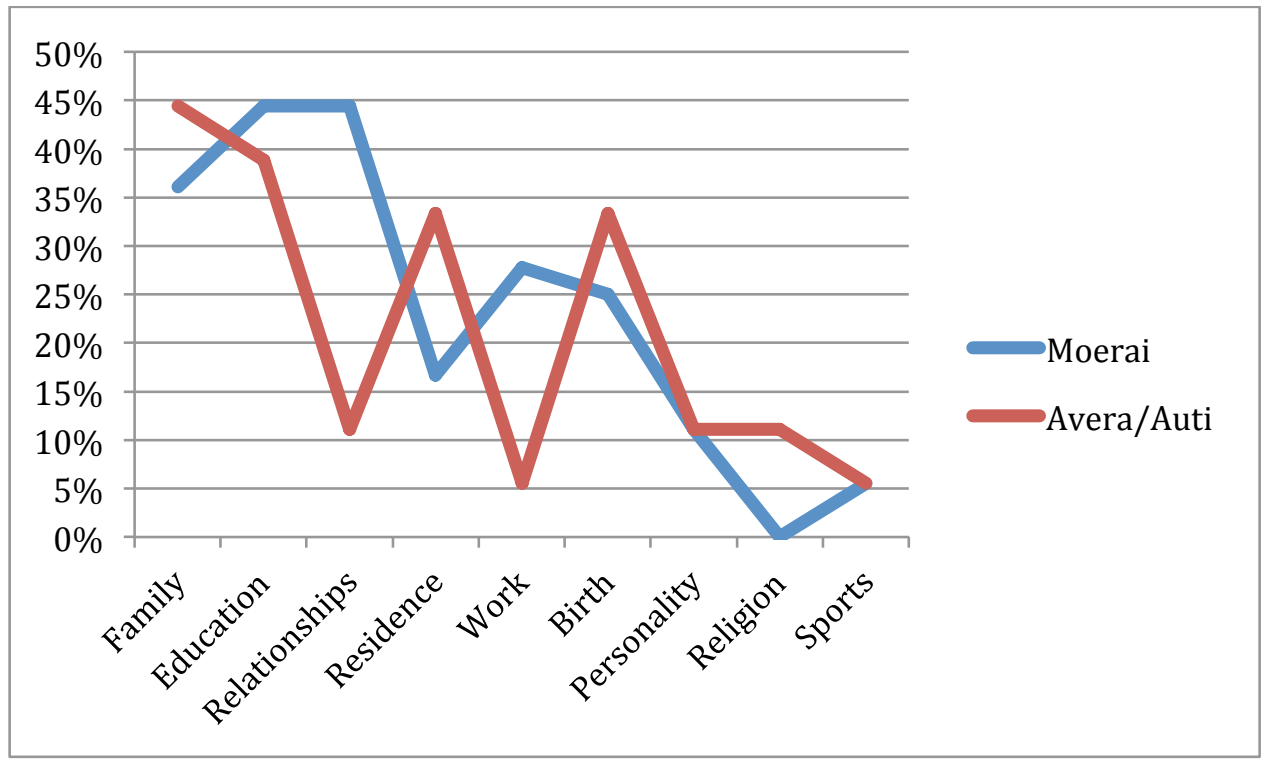

Table 8: Distribution of Vital Conjuncture by Town

There were also differences in decision-making between the three main towns of Rurutu. This should be prefaced by explaining that, as mentioned before, the majority of interviews came from Moerai (30 out of 54) while roughly one fourth came from Avera (14) and very few from Auti (8), as they were less outgoing and willing to participate. Therefore, the percentages are much more representative for Moerai than for the other two towns. However, there were a few interesting developments. For instance, youth from Avera narrated decisions and transformations concerning their families than the other towns $(57 \%$ of youth from Avera stated at least one decision regarding family, while only $25 \%$ for Auti and $35 \%$ for Moerai). On the other hand, romantic relationships held the highest percentage of decisions for youth from Moerai (37\%, as compared to 7\% from Avera and 13\% from Auti). Education was a highly mentioned decision theme among youth from Moerai and Avera (46\% and 43\%), but was much lower in Auti (25\%). This follows the assumption about youth from Auti that I heard many 
times during research. For youth from Auti, family and continuing traditions such as planting and artisanal crafts is most important, and finishing school comes in a distant third. As mentioned in Chapter 4, Auti is considered the most tupunami of the three towns, and thus the parents and families from there put much less emphasis on education, if not countering it outright. Two of the parents I interviewed from Auti described education as a nice experience, but not necessary for their way of life.

Additionally, the number of youth who named residence change as a vital conjuncture is also higher for youth from Avera and Auti. Changes in residence, especially during the time of transition to Tahiti for secondary school, might be more traumatizing an experience, or at least a jarring lifestyle change, for those youth from Auti and Avera, because they are less likely to make frequent trips to Tahiti than those from Moerai according to my interview and participant observation data. I would also argue the more stressful nature of the transition is due to the relatively more traditional nature of Avera and Auti versus Moerai, but this would require further research. The drastic differences between the towns could certainly be due to sample bias, but the differences are something to pay attention to. More research is needed, but the different upbringings could impact these diverse experiences as well. 


\section{Level of Education}

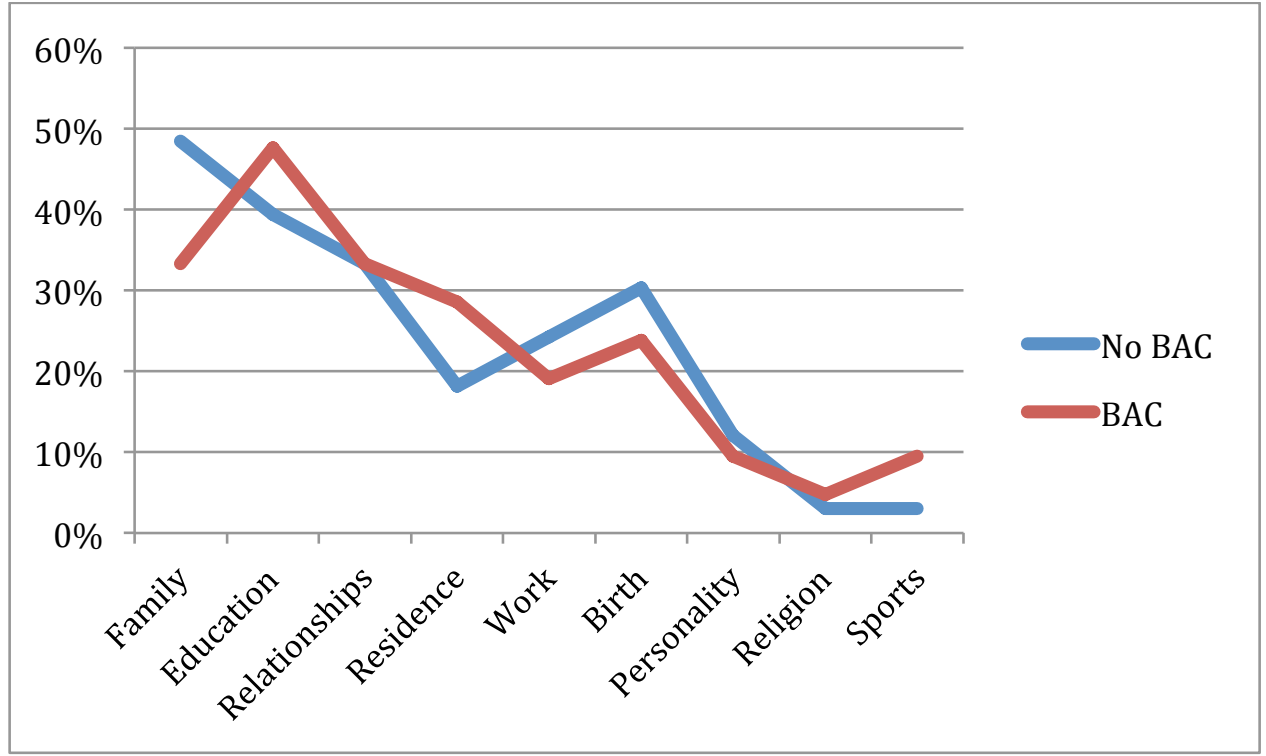

Table 9: Distribution of Vital Conjuncture by Level of Education

This graph shows how little difference there is in the codes of vital conjunctures between those young people with higher levels of education and those with lower levels of education certification. An interesting pattern might be how those youth with higher levels of certification have higher occurrence of vital conjunctures regarding education while those with lower levels of education have higher levels of vital conjunctures dealing with family and birth. Considering my case studies, these discrepancies could reflect young people who experienced illnesses or deaths in their immediate family that forced them to terminate school early, or those who got pregnant during secondary school and thus had to change plans.

The graph also does show that those with a higher level of education have experienced a higher percentage of vital conjunctures concerning residence (33\% of those with higher education mentioned residence, compared to only $17 \%$ of those with less education). This could 
mean that the change in residence between Rurutu and Tahiti has made an impact on those young people who have chosen to continue their education on the main island.

Perhaps most interesting is the lack of difference between those with diplomas and those without. I originally assumed that having a diploma opened different pathways and thus would change the kinds of decisions youth took - increasing decisions concerning work or residence change, and decreasing decisions concerning family - but to the contrary the youth with degrees did not make decisions that were drastically different from their less qualified counterparts. This could be due to the relative lack of opportunities on Rurutu. The modern lifestyles they were promised with increased education have not panned out for those youth who end up living on Rurutu. For that matter, even those with diplomas who live on Tahiti are not necessarily experiencing vastly different lifestyles. For example Pitu, who has a CAP in masonry, lives on Tahiti, and is in the military, passes his days waiting to be able to spend time back on Rurutu during his brief time off.

While these decisions, on their own, make an interesting pattern for different ages, genders, town, and levels of education, there is still one last perspective from which to analyze these narratives. In the next section, I analyze the vital conjunctures that overlapped between two different codes. For instance, I will discuss decisions that were made between education and family, family and residence, or family and reproduction. These overlapping vital conjunctures show the instances in which diverse institutions and cultural practices come up against each other. 


\section{Conjunctural Interactions}

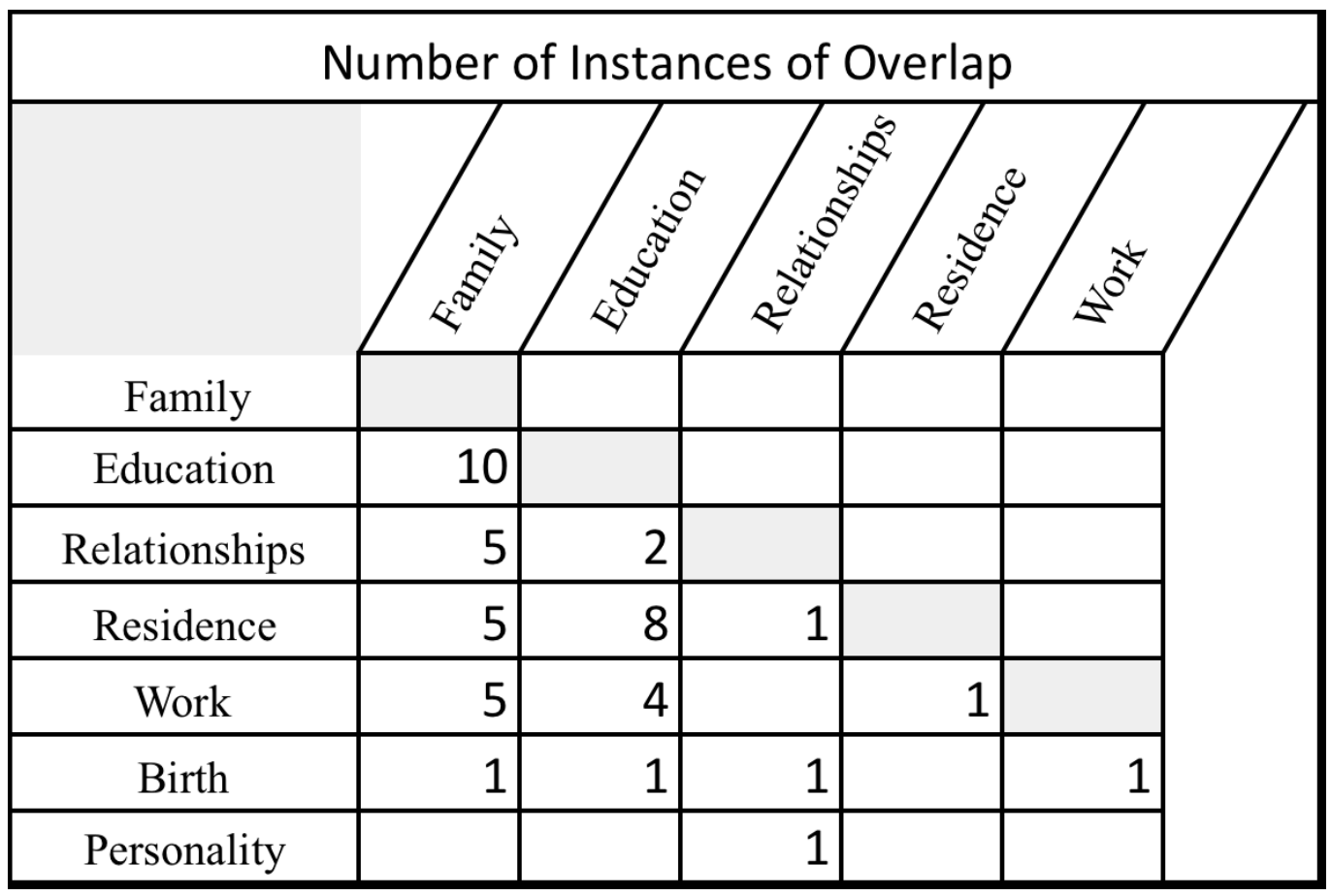

Table 10: Overlap of Coded Vital Conjunctures

Within my examination of frequencies and distributions of coded vital conjunctures, there were times when a certain decision spanned two themes, or combined them. In terms of useful percentages for analysis, I made an executive decision on how to classify each in order to best catalog frequencies of decisions per age group, geographic area, level of education, and gender. However, it is important to discuss this phenomenon as well.

There were, out of the 115 vital conjunctures I recorded, 43 that fell somewhere between two themes. Family was by far the most likely to combine or overlap with another theme. Family actually overlapped with education, relationships, residence, work, and reproduction. Family and education overlapped the most with 10 instances, which follows the experiences of youth quitting school to care for sick family members or quitting school because their host family situation was unbearable. There is also the case of Poe, whose father's dying wish was 
for her to finish her teaching degree is also an example of this overlap. This wish pushed her through much of her higher education, but eventually she realized that her calling lay elsewhere, and she was forced to come to terms with the dissonance between her wants and her father's. She explained that it was an excruciating time in her life, because she loved her father so much, but his dreams for her were making her incredibly unhappy. Her case study will be fully explained in the next chapter, which details education-related vital conjunctures.

Flora, a 26-year-old mother of one also narrated a vital conjuncture that meshed two themes. In this experience, her relationship also came under scrutiny in her family. After dating a boy against her parents' wishes and becoming pregnant, she found she was forced to make a decision between staying with her boyfriend and being welcomed back into her parents' house. Originally, she chose to go with her copain and to have her baby, much to the dismay of her parents. However, after some time, she returned to her parents' house to raise her son..

Vital conjunctures that involve both family and residence often are filled with strife and internal battles as well. These experiences are split between those who experienced troubles on Tahiti when they left home to attend school, and those who went through adjustments upon moving in with their significant other or in-laws. Natalya tells a beautiful story of change and growth in learning how to run her own household outside of her mother's house. She recounted this story in the midst of telling me about the time she almost went into the army:

But one day, my husband came. We knew each other already, but we discussed, and he asked if I'd like to come stay with him. I didn't really want to accept, and my mother was afraid to let me go. So I only talked about it at first, I wanted to see how he treated me and the like. And I said to myself, why not? So I came and stayed with him. And we really had our ups and downs when I came to live with him. It was just us, and then we had two kids, and we really needed something. I really needed something. We could not support our life in his family's house. We had a dream - of having our own place. Our own little cabin. And now we have it. It keeps me busy, with cooking and cleaning without electricity or a stove. I have to call on my mother a lot for guidance - the baby is sick, I don't know how to 
make puatorro ${ }^{10}$ So now our dreams keep moving forward. Now we want a real house. Bigger than this one, so we can provide for our kids. For their future. But my husband is like, "we'll probably die before we get there!" We demand a lot from him, me and our kids

Although nothing changed demographically, Natalya narrates this vital conjuncture as very important to her life. It fundamentally changed who she was. Here, Natalya speaks about the goals of a lot of youth from Rurutu in having her own nuclear family and house. It does not bother her that her house is tiny and does not have electricity or a stove. She just cooks over an open flame. She is also still connected to her birth family. She plays volleyball with her sister, cousins, nieces and nephews, and goes to her mother for advice. Her husband helps to plant her father's taro as well.

\section{Conclusion}

These vital conjunctures show a narrative of Rurutu identity that has endured even with changing cultural patterns in the midst of rapid globalization. The narrative of family first, over education, relationships, or residence maintains the cultural schema of The Tahitian Way (family, land, and church). While the youth in my sample narrated their vital conjunctures of the clash between family and other priorities as choices, my field observations show that the older generation knows that if they ask, the youth will always come home. I did not find any instances where young people chose priorities that were in direct opposition to the needs or wants of their family, especially in the case of serious illness of a loved one. Even Flora, who did choose her relationship over her family, ended up coming back after she had her child. Chapter 7 speaks more fully to the reasons behind this decision, reasons that fundamentally have to do with maintaining one's Rurutuness by holding on to familial connections.

10 Favorite Rurutu dish - a corned beef soup. 
Work decisions among males and females seem to mesh with the script of Tahitian gender roles as well. Employment is part of the adult male persona, but is less important for women to be seen as attaining status and, by association, dignity. However, education seems to be much more important to women, and is becoming increasingly more important to younger males (18-21). Young women seem to see education as a form of respectability, tending to choose more literary specialties that would lead to positions in teaching, even though this profession has little space for new recruits. On the other hand, young men understand that the typical male trades associated with subsistence economy, such as farming and fishing, are becoming increasingly unsustainable. Therefore, many of them choose to specialize in technological or scientific subjects. Young men have also shown a penchant for joining the army.

This chapter points to the frequencies of and demographic variations in different vital conjunctures in order to understand how various influences on identity and aspirations are navigated by youth. Giddens (1984) argues that one's choices are always political, that they show an individual's motivations and perspective. If we examine these vital conjunctures in terms of showing what is, at any given point, important to youth, then we have illuminated their motivations and aspirations. We can utilize these narratives to see what is most important to the creation of their identity and social navigation as well as the diversity of decisions and transformations that can point to these motivations.

In the next two chapters, I will further examine the different types of vital conjunctures that were provided here in quantitative terms. I will dig deeper into the diverse reactions and narratives youth have when presented with a vital conjuncture. Chapter 5 offers an examination of vital conjunctures that are linked to education, including deciding on specializations as well 
as the experiences youth go through during the transition to Tahiti. Chapter 6 analyzes diverse vital conjunctures that especially show how youth navigate changing priorities. Lastly, Chapter 7 shows how youth narrate their vital conjunctures in order to cultivate connections that enable a foundational identity from which to navigate changing social constructs and provide a social security net in the case that their aspirations don't work out. 


\section{Chapter 5 Je Suis Fiu, Tu Es Classe: Education as Vital Conjuncture}

In my last chapter, I analyzed quantitative aspects of various vital conjunctures, including the frequency of vital conjunctures within my research population, how they can be coded, and how some themes within vital conjunctures interact in concert or in opposition. The quantitative analysis shows how different influencing scripts and institutions coalesce and contradict over the course of a Rurutuan's teens and twenties. In terms of the narratives of vital conjunctures, the time of great change and transformation often begins with changes within the institution of education. Education is seen as an important stage globally, as it can open doors to future opportunities. However, in terms of rural youth in French Polynesia, continuing education means travelling 150 miles away from their home, and incurring the emotional and monetary costs involved. The education system is also one of the last vestiges of the French colonial system, which youth also struggle with not only because it does not provide realistic specialties for their circumstances, but also because they sense the lack of interest from French teachers.

In this chapter, I therefore analyze the second most frequent theme of vital conjunctures found in research: education. I examine experiences that were detailed during the vital conjuncture narratives as well as one etic theme concerning education. Education-related vital conjunctures seem to be the foundation upon which the paths that youths take sit. Educational transitions start with the time at which youth from Rurutu must make decisions concerning the latter portion of their secondary education, which occurs at roughly the ages of 14-16. It 
continues on Tahiti, where youth go through numerous difficulties with family, school, friends, and living situations. The transition between life as a college student on Rurutu and a lycée student on Tahiti can be quite difficult, and it starts with choosing one's educational specialty. This time in their lives is important for three reasons. First, the French education system tends to group students by their grades in certain subjects, instead of what they actually want to do. Second, the branche in which young people find themselves can limit or expand their perceived possible futures. Lastly, this decision often highlights the generational gaps between adults/parents and youth. Much of the older generation on Rurutu did not get a secondary education. Many never went to school on Tahiti, or made the choice to follow a certain branche after obtaining their DNB. Therefore, for this generation of students, these decisions, which are some of the first times they have had to deal with contradictory motivations and wishes in their social navigation, were often made with no idea what to expect. After the vital conjuncture that is choosing one's branche, there are plenty of other vital conjunctures experienced by Rurutu youth. These often include positive and negative experiences and transformations while living on Tahiti.

The analysis of school transitions as vital conjuncture must be approached from both emic and etic perspectives. Many youth mentioned the experiences they had during school in their vital conjuncture narratives, but few spoke of the experience of actually choosing their specialty. Instead, I specifically asked for more details about it during interviews because I wanted understand the process better. From my experiences on Rurutu, education, economics, and changing identities are deeply interconnected. Thus, I wanted to examine the experiences of this important decision that has the potential to change the path of a person's life. There were three questions I set out to answer. How much agency did young people experience? How did 
that experience correlate to high school attrition, graduation, and tertiary education numbers among my participants? What are the motivations young people prioritize during these decisions, and how do these priorities relate to their own navigation of modern social and personal identities? The vital conjunctures and experiences relating to school will be organized into three sections: secondary specialization decision-making during 3eme year, positive and negative experiences at school on Tahiti, and getting an education while avoiding becoming "too modern".

The first series of questions I asked each youth in my study were related to education. I asked the easy question of their level of education followed by what branche they chose. These first questions were met with straightforward answers - CAP, BEP, BAC, BACPRO, License, and then Literature, Science, STSS (Heath and Medical Science), Aesthetician, Couture. Following that information, I asked what I had assumed would also be a straightforward question: How had they come to choose that concentration? At this point, I was met, repeatedly alongside an amused but weary laugh, with "Alors la!” This phrase, which I have trouble translating into English, was often used in narratives to portray a hilarious dismay at an outcome. It was somewhere between a "bloody hell" and "well lemme tell ya," and conveyed that there was a story behind the choices they had made.

Therefore, even though few highlighted the specific branche decision in their vital conjuncture narrative, I chose to include it as a vital conjuncture here because my direct questions about it garnered so many various reactions. This vital conjuncture is important because so many external and internal factors play into this transition. Availability of paths depends heavily on one's academic record - if a student does not have good grades, s/he is unable to go into certain specialties. On the other hand, if their grades are too high, then they are 
pushed away from more useful vocational degrees, even if that is the path they prefer. This is quite similar to the experience of high school seniors here in the United States. The difference is in the age at which it happens, and the perceived power of those in education positions. Furthermore, for rural French Polynesian students, the transition is mandatory. There are no secondary schools on the outer islands. In addition to the interaction of educational institutions and personal strengths and preferences, there is also the pressure of family and finding a place to stay once a student arrives on Tahiti.

Although there were some participants for whom this transition meant very little, and for whom there was no story, the majority had a story to tell. Some stories were filled with anger, some with happiness, and some with a bleary resignation, but it was clear that this determination shaped a lot of their future: future decisions and the future selves they would inevitably grow into. From the narratives I collected regarding what path of education to pursue, three main influences emerged—school system, parents and family, and peers. These influences can either enhance or contradict an individual's wishes for his or her education.

Originally, I was going to analyze these narratives about education decisions with other decision narratives as just one potential piece of an evolving puzzle of vital conjunctures and growing up. However, a second experience made me change direction. Gaining an entree to the secondary schools on Tahiti proved much easier than I had first expected. The school administration had no issues with me being on campus, and two different schools allowed me access to their student registers. This allowed me to better understand how the numbers of enrolled students from Rurutu had changed over the previous 12 years. Two schools also permitted me to interview the professors. The caveat: the school was not allowed to endorse or 
advertise my research interests. I had to go out and find the professors myself. The principal showed me to the teacher's lounge, opened the door, and whispered, "Good luck."

When I first approached a group of professors to ask them to participate in my research, I introduced myself as an American who was interested in the particular plights of outer island youth coming to school on Tahiti. None seemed interested in helping, but steered me to one teacher who they claimed was from the outer islands and would know best. I thanked them for the information but persisted, indicating that I wanted a perspective from those teachers who were most unlike the interlocutors. They were still baffled. One teacher said, "But we don't know them very well. We don't know their experiences. Most of what I know is they are disruptive to my classrooms." This interchange was not shocking, as many young people, during informal discussions, talked about how they did not feel their teachers took much interest in them.

The second half of this chapter is framed in terms of two emic terms that seemed ubiquitous during my field work: fiu and classe, because they represent the two extremes of the experiences youth have during their secondary education. To be $f i u$ is to no longer see the point of doing something, or to be completely exhausted by a situation. For instance, during arguments someone might say "this is fiu..." to mean that they are done with the argument, or cede their point. In terms of youths' interviews about their education, fiu referred to the feeling one might get of mental or emotional exhaustion because a situation is not working out as expected. For most of the young people I interviewed, the reason given for quitting school early was that they were fiu. Classe, on the other hand, is just as uncomfortable of an experience. This term is not one that young people would use to talk about themselves, but about others who have strayed too far into the modern identity, and thus have lost their Rurutuness. This can be 
represented in material ways, such as clothing, hairstyle, or lifestyle choices, or immaterially, such as if a young person stops calling home or disrespects his or her parents' or family's wishes. These two terms are best understood in the context of decisions concerning education pathways because these decisions and transitions to Tahiti affect how youth navigate not becoming fiu while also not being seen as too classe.

The theory of conjunctural action put forward by Johnson-Hanks et al. (2012) argues that it is important to examine the various aspects of a decision, or conjunctural action on its own. Through the lens of dignity, we are able to analyze the motivations behind each decision. With dignity as something to be strived for, we can best understand what is at stake with this decision. The lack of housing, jobs, and upward mobility are taking a toll on youth - they are no longer sure of the appropriate track toward adulthood. Many of them are not sure whether to continue in the old ways of farming and fishing, which no longer seem as exciting or important on the global scale, or to leave to find more "western" work. They must then live with these decisions, as the changes and new experiences become part of each youth's negotiated identity.

This process begins with the choosing of a branche in lycée. As I mentioned in Chapter 3, there are various ways a youth can pursue their secondary education. There are professional degrees in such subjects as jewelry-making, beauty, mechanics, electrical, painting, cooking, tourism, and other vocations that last anywhere from two to six years, depending on the type of certification. There are also tracks in the sciences, humanities, and engineering with a BAC degree program. While the former degrees may be useful, they hold less regard as far as one's ambitions or skills. The latter degrees are impressive, and open more pathways, but they will more often than not lead youth away from their island, as there are few opportunities for young people with BAC degrees to find wage work on Rurutu. Simultaneously, changes in the CPA 
program now prohibit youth with BAC degrees from participating in short contract apprenticeship programs. The problems with lycee, as I have seen, is five-fold: having little autonomy over one's area of study, shifting living situations, feeling bête, or like an outsider, worry over straying too far from one's community linkages, and striving for the dignity that comes from continuing school.

\section{Experiences of Agency in Educational Decision-Making}

Educational outcomes as compared to agency in decision-making

\begin{tabular}{|l|c|c|c|c|}
\cline { 2 - 4 } & No Agency & Some Agency & Agency & Total \\
Quit School & 7 & 5 & 2 & $\mathbf{1 4}$ \\
Obtained Lower & 4 & 8 & 4 & $\mathbf{1 6}$ \\
Degree & 3 & 10 & 8 & $\mathbf{2 1}$ \\
Passed BAC & 1 & 7 & 5 & $\mathbf{1 3}$ \\
BAC + Tertiary & $\mathbf{1 5}$ & $\mathbf{3 0}$ & $\mathbf{1 9}$ & $\mathbf{6 4}$ \\
\hline
\end{tabular}

Table 11: Educational Outcomes and Agency in Decision-Making

As is seen in Figure 3, the highest rates of quitting school are among those youth who narrated the school decision vital conjuncture as "out of their hands," where they did not feel agency, but instead were subject to the whims of outside influence. These youth would be categorized as those most likely to find school fiu, or find themselves $f i u^{11}$ while attending. Although I had originally assumed that the different age groups would have different numbers within these categories (for instance, that the younger demographic would have a better idea of what they want to study, since many of them have older siblings who went through the system),

\footnotetext{
${ }^{11}$ Fiu can be used both to describe oneself and a situation. In this context, it would be a way of describing school as boring or pointless.
} 
there was no difference in how many youth experienced no agency between those who are older and those who are still in class at lycee. There were, however, drastic differences in graduation rate between the older youth I was able to interview and the younger. This was corroborated by the information I was able to ascertain from two of the larger lycees on Tahiti. That is to say, the graduation rates of people within my research went from roughly $20 \%$ among those over 26 years old, to $45 \%$ among those who are between the ages of 18-21 in the year 2015. This is on a par with the change in graduation rates seen by the outer islands, which rose from $18 \%$ to $45 \%$ between the years of 2004-2014

The decision to follow a branche is not just about life courses, growing up, or figuring out who one is. It is an amalgamation of diverse influences from institutions such as parents, siblings, peers, teachers, educational institutions, and economic availability. The same patterns of behavior can be found in universities in the United States, and in educational systems around the globe. Although Schlegel and Barry (1991) argue that the power of the family was diminished in the advent of strong educational institution, these two vignettes show that some parents still hold sway over their child's dreams.

Haina, who is a 21-year-old woman who has a son and lives with her parents and copain took the BAC exam three times and failed all three times. She blames this inability to pass on the fact that she is terrible at science even though she is in a health sciences specialty when everyone knows she "was born for languages." The cause of this mismatch is her father, who pushed her toward a science field, claiming "Science is the future" even though Haina is a whiz at languages and hates science. On the other hand, Vania's mother pushed her toward a school that did not have her intended field of study simply because it was the only school to which she felt comfortable sending her daughter. To some extent, I would argue that the youth trust these 
individuals (i.e. their parents) to have their best interests at heart, or they are ambivalent or apathetic about their chosen studies, even though choosing the wrong branche, especially if it is not a subject he or she is good at, could be catastrophic as far as gaining a BAC diploma goes. Sometimes there are few decisions to truly be made, but examining this specific decision from various perspectives and experiences might yield important feedback about how to help youth negotiate these decisions and changes in the face of contradictory desires

There are a few details that this table does not show. For instance, the label "Some Agency" is broad and tends to mean the youth had assistance in choosing their branche. This could mean anywhere from asking the opinion of a favorite teacher to having a teacher outright tell a young person what s/he would be good at, but then the youth agreeing that the teacher is probably right and feeling as though the decision was made on his or her own. Also, the one person who experienced "No Agency" but still continued on past her BAC test actually quit during her original time in high school and had, at the time of my field work, recently gone back to school at the age of 28. The local university added continuing education programs for people who had quit secondary school but wanted certification.

As my research confirmed, there are several types of experience in choosing, or being placed in, a lycée branche. These experiences range from complete agency over the decision to little agency wherein the youth sees it as a transformation he or she has little power or desire to change. Some young people feel they have a lot of autonomy over their decision. Teachers or family members may have given them advice, but the students felt as though the choice was theirs. These students usually got into their first choice program, or at least the same branche at a different school. Although this level of autonomy does not necessarily correlate to a higher rate of graduation and $\mathrm{BAC}$ attainment, it is an important experience to note. The second level 
of autonomy belongs to those youth who would have preferred a certain branche, but were kept out due to grades, or lack of available programs at the schools for which they had living arrangements. These youth either ended up in a slightly different program, or were forced to change their educational path completely. However, most of them still feel positively about how their program match worked out. The third group are those who experienced little to no power or autonomy in their choices of lycee program.

The following case studies show these differing levels of autonomy, as well some of the distinctions depending on diverse ages and levels of education. Laina is a 25 year old who grew up in Moerai and was at the time of my research living on Tahiti with her boyfriend and his family and finishing up her student teaching to become a college-level French language teacher. Her life had really been devoted to her education, which she wanted to use to continue to teach the children of French Polynesia - especially the outer island youth. She finished her BAC in Languages at Taaone, and then went to the local university to study Tahitian. Finding the program not to her liking, she restarted in French. When I met her she was just beginning her second year of her Masters in Polynesian Studies with a focus on education and teaching. She was also starting her student teaching at a local primary school. Her experience in choosing her educational path was aided by her ability to follow the path she wanted.

I chose BAC L because I loved languages - especially French... No one really helped me choose to go into languages, it was always what I assumed I would do. My friends all went into fields like ES or SS, math and science based studies, but I loved French as much as I loved Tahitian, so I decided languages would be my future.

For Laina, who was as good at school as she was excited about learning, these choices came easily. She had the grades to go into any specialty she preferred, and the confidence to continue even though the competition for jobs as a language teacher is fierce in French Polynesia. She 
knew she might eventually have to move to a far off outer island that was not her home, but it seemed worth it to her. She was excited for her future and her education, and confident in her ability to obtain it. According to Laina, her mother, also college educated and well-travelled, had instilled these values in her at an early age. Although she loved Rurutu and the culture and traditions there, she knew that her home would stay while she grew up and went on to other places.

Fara is a 23-year-old mother of one who lives with her boyfriend as well as her mother and grandmother in a tiny house on the high side of Moerai and earns a wage weaving flower hairpieces for a small artisanat co-op. Her experience was one where her own goals and desires were thwarted by the rules laid out by the school system. Fara confirmed that she had earned her BAC in Accounting, but was currently part of an artisanat co-op with her aunt while she awaited work in her specialty on Rurutu. When I asked how she made the decision to go into Accounting in high school, Fara told the story of a sort of counselor coming down from Tahiti to discuss their grades, and to analyze their best and worst academic qualities. Fara remembers wanting to go into Mechanics and Physics (MPI), a more technical general program. However, she didn't have good enough grades in her 3eme Physical Science classes.

There is a person who picks you for things, like a psychologist, to talk about the different branches, and tell them which ones they could take. "I wanted to go into MPI, but they said no. And when I asked why, they said it was important to be good in Physics, and I didn't have good enough grades.

She did, however, have good grades in Math. Thus, the counselor advised her to go into accounting and enterprise. She was still unsure about her ability and excitement to study accounting. During the original discussion of branches and education, Fara only mentioned the MPI versus accounting issue with choosing a branche. Later, however, during her explanation 
of her decision (what I would label her vital conjuncture) another issue came up. It turns out accounting was not her second choice but a distant third. Originally, she wanted to get her secondary education in aesthetics and beauty. She thought that being able to do hair could be a useful skill to have.

Ok, if you'd like... the first one... was that instead of economics, for my studies, I wanted to learn to be an aesthetician. I wanted to start school there. But they refused my request for money. And since it was my second choice, they just put me in accounting. But now, aesthetician... see, I was at Taaone ${ }^{12}$, but for aesthetician you have to go to Mahina. And I was living in Mahina. And that school is in Mahina. But they didn't choose me. They preferred to send me back to Taaone to do my accounting.

When it came time to apply for programs, since she was steered away from the MPIO branche, she put down aesthetician school at Mahina as her first choice. However, Mahina did not accept her application or her bourse (government need-based school payments), so she was essentially stuck attending Taaone and majoring in accounting. Having to follow that branche, she still managed to earn her BAC, but the process of studying for it became so tedious that she decided not to continue on to university. Now, she has her BAC but cannot find any work in her specialty on the island. While she sometimes loved it (learning economics) and sometimes hated it (anything having to do with math) she looks at the outcome not with regret or disdain, but with hope. Those classes, she tells me, brought her to the party where she met her tané. He, in turn, gave her her son, who is her life. The other two decisions she made revolve around them and her family.

Fara is not the only person who went through this indecision and inevitable relocation for school. Many participants cited either the psychologue who came from Tahiti or their homeroom teacher as influences on their decisions to apply to certain programs. However, the

12 Taaone, Mahina, Aorai, and Taravao are four popular secondary schools on the main island of Tahiti. 
system of choosing three programs and potentially being denied from certain schools or programs due to the program's popularity, the student's poor grades, or a lack of space in the boarding dormitories, often changed their paths.

Poe, a 26-year-old female who grew up in Auti and currently lives there while she works on a cultural research project at the Moerai mayors office, had this sort experience while choosing a branche:

All my profs. Actually, I had one teacher during 3eme and I asked her, "Madame, do you think I should go to beauty school? Become a hair dresser?" And she said "WHAT?!? You have a 15 in French, 18 in history, 18 in math! You have the best grades! And you're gonna be a hairdresser? You're crazy!"

It was, indeed, this sort of inspiration that made her continue into the sciences, and stay there until she earned her BAC even though, as she puts it, she hates math. However, once she knew a little better where her strengths were, she chose to continue to university as a geography student.

Manu is a 28-year-old young man who lives on the lower side of Moerai and makes money for his family through tending his father's taro fields. He also wanted a different course for his lycée, but was turned away because he was not able to find housing at the school he preferred. Although agriculture is a way of life on Rurutu and throughout French Polynesia, finding a lycée program in agriculture is actually quite difficult. They are very popular and, as far as I understand, there are only two of them. There is one on Moorea (the small island off the coast of Papeete), and one on the eastern side of Tahiti in Taravao. It speaks to the ongoing colonial influence of France that even though agriculture is a useful professional trade, the French school system does not see it as a proper specialization for secondary school. It is assumed that youth from Tahiti learn to farm from their families, and that learning new techniques is not something to do in high school. 
No... my first choice wasn't a program they had a Taaone. I wanted to study agriculture. That's at Puro on Moorea. I didn't get my placement there. So I got my second choice. And I'll be honest, it was my mom who gave me the idea for my second choice. She wanted me to continue my studies. So that was the branch that she gave me. So I did what I could!

Although Manu grew up with his grandparents on Rurutu while his parents lived on Tahiti, it was his mother who helped him to change his plans in the case of the school system's inability to cater to his preferred specialty. She pushed him into a CAP program in magasinier, which is learning how to run a store. He said he was happy to find a specialty that suited him, even though it was not his preference. However, he was forced to quit after attaining his CAP but before he could go on to a BAC-level program because his grandfather, the man who had raised him, fell ill and needed care.

Manu's mother's insistence was accepted by him and turned out for the best, but family interference in the branch decision is not always positive. The rigidity of the school system is not the only institution that makes young people feel as though they do not have agency in their decisions. Family can also get in the way. For many youth on Rurutu, their parents do not have a formal education. Of the 64 I interviewed, 10 had parents with a higher level of education than 3 eme, which is roughly the equivalent of a $9^{\text {th }}$ grade education. Therefore, parents tended to allow their children's futures to be decided between themselves and the schools. However, for some youth - especially those whose parents have received a formal education - parental input was an aggravating reality. For Vania, whose mother is a nurse and who was finally finishing a degree after years of being out of school, this issue eventually made her quit (the first time around).

My mother's only goal for me was to go to the Catholic high school she herself had attended years earlier. I wanted to study to be a nurse, so I tried to apply to the 
nursing program at St. Marie's. However, that program no longer existed by the time I went. So it was either find a different program at that school, or find a nursing program at a different school. My mother chose to send me to the Catholic school, where I studiedaccounting and entrepreneurship. I hated it. It was fiu. Hated it. But there wasn't anything else to do, so I quit.

However, Vania eventually was able to find another path toward becoming a nurse. At the age of 27, she moved in with her older brother on Tahiti and signed up to earn her BAC equivalent at the university. Once that was done, she was planning to continue on to get her nursing license. Although she had taken years to get there, she knew that to have any chance at her desired future as a nurse, she would have to make adjustments. It may be pertinent, as well, to mention that between the years she had quit school and those when she had decided to return she had changed partners. The former was a man her age who had quit school at a very early age, while the newer was younger and still attending university. As far as outside influences go, this may have played a part in her changing priorities over the years. Therefore, even the decisions that are made as youth sometimes lack permanence, and thus are less likely to be a formal indication of which way an individual's life course will head. As Johnson-Hanks argues, the interaction between these decisions and the definition as "youth" or "adult" is fluid.

Haina, as mentioned before, also had a difficult time with family expectations during this vital conjuncture. Her father, an Italian man who had married her mother, moved to Rurutu, and opened the sole gas station on the island in 1991. He was an authoritarian parent who instilled many of the European values that he had grown up with. Particularly, in 2009, he chose a STEM path for her. She signed up for an STSS (science technique sanitaire et social - basically LPN) specialty in secondary school, and hated almost every moment of it.

I didn't really choose it! Me? I wanted to do a Humanities branch. I am gifted in languages, I love history, geography, philosophy... I was really good at it. But you know my father! "The future is not in the humanities! It's in Science!" So I listened, and I completed my BEP CSS at Mahina, and then the next step is STSS. So I did that 
branch at Taaone. But even my teachers told me that I'm crazy for following that branch. My report card has two sides: There's the literary and language side, and the science and math courses on the other. I mean, English BAC? 17 oral 17 written, French? 18 oral 14 written. I love literary studies. But alas, they forced me to follow a scientific branch. So that part? Terrible.

The experience of these vital conjunctures and the eventual consequences are all part of the process of growing up. As argued by Maira and Soep (2005), as well as by Langevang (2008), identities are made up of decisions and experiences throughout one's life as well as their changing positionality. The decision about a path of education is one of the first vital conjunctures that come up in a young person's life course on Rurutu. It is the first real time when they must stand up, examine themselves and the institution of education, and make decisions for themselves, but it is not the entirety of the story of education. In the next sections, I will discuss an emic style of talking about these transitions within school: in terms of feeling fiu and feeling classe.

\section{Feeling Bête, Feeling Fiu}

Little else engenders the "postcolonial disorder" (Good et al. 2008) like education in French Polynesia. The French government is wholly responsible for curriculum and supplying teachers to French Polynesia, which means youth, for the most part, learn from the French perspective. Although Tahitian language and culture is one class in the local curriculum, other classes are not in any way "localized." Economics is learned in terms of the Euro, and does not include the study of the local economic or political context. Political Science books in French Polynesia are similarly Eurocentric. If students want to learn about the intricacies of local practices, they must specialize in Tahitian cultural programs. Otherwise, their educations are centered almost entirely on a western mentality and context.

Although few actually like the school system, it is understood that earning a degree 
gives one better prospects, and that one must do what is necessary to earn a certain level of dignity. Nikita, a 22-year-old when I interviewed her, and who had been in the MFR program on Rurutu because she had not earned high enough grades to continue on to 3eme year in secondary school, understood that it was not the same as regular school. She remembers, "I didn't do well at school. It's been a long time. I think I was 14 when I quit. It all just felt hopeless. I could barely read, and I was at MFR. The boys in the class all mocked us and told us we were worthless." If a student wants to learn traditional crafts such as farming, fishing, cooking, and artisanat crafts, it is best to get a French education certificate and learn them at home.

However, it is not only those who do not succeed at school who are made to feel lesser. Young people from Rurutu who attend lycée have experienced similar stories at the hands of teachers and administration. Natacha, a 26-year-old mother of 3 also remarked: "I quit when I was 20. I still hadn't managed to get my BAC. At school at Papeete it's different. I hated life there. Most of us did. It was fiu. You get the impression that they don't like you there - it's not the same as when you are chez toi (home)." This notion came up often in discussions with youth from Rurutu. The professors I spoke to also echoed it. They saw differences between those students who came from the main island and those from outer islands. Two teachers referred to outer island students as bête, which means savage or beastly.

Students often complained that their teachers think they are too loud, too argumentative, and too unrefined. It saddened many of my interlocutors, because they mentioned not trying to be loud or argumentative. "It's just the way we speak! We are a loud island of people! Everyone knows this!" exclaimed Roti, in trying to explain why she hated school so much. Haina, for example, recounting her experience with teachers on Tahiti, remarked: “They really don't care 
for us. Most of them are only here for two or four year contracts. They come to swim, learn to surf, and do a good job before returning to the Metropole." Niau, 24, also mentioned, "they seem to think we are all bête-sauvage, you know? Because we speak louder than the demis ${ }^{13}$ and youth who grew up on Tahiti." These conversations piqued my interest to learn more about the interactions between youths and a school system that does not always know them or even really have people who care about their futures.

These experiences were a key vital conjuncture in many Rurutu youths' lives. Of the 23 youth who mentioned education as one of their vital conjunctures, 13 of them detailed the experiences of becoming fiu. Examining the phenomenon of fiu in terms of dignity would make sense of the high attrition rate. If we consider it as a mathematical equation, there is a tipping point at which the loss of dignity in quitting school outweighs feeling fiu and losing one's everyday dignity with the continued status as outsider at school. Although I am not arguing that young people quantify dignity in this calculating fashion, I do think there is a subjective tipping point at which a youth may deem education fiu.

French teachers who do not understand them are not the only problems Rurutu youth have to battle. The students, at the age of 15 or 16 , set off for secondary school on the main island of Tahiti. The majority of lycées on Tahiti are in and around the main city of Papeete, but some are spread all the way across the island. In addition to the culture shock of moving from an island of 2800 inhabitants to one of 180,000 inhabitants, young people are also forced to live either in dormitories with up to 40 other students in one room, or stay with extended family who often expect them to work around the house like paid labor. The lucky ones have family who are able to pick up and move to Tahiti with them, but most do not have this kind of experience.

${ }^{13}$ As mentioned briefly in Chapter 4, demi (French for semi) is the term used for people who have a mix of Tahitian and European heritage. 
If they are living with their family or a host family, they often have commutes to school of upwards of an hour (as there are no short cuts through the island, and everyone must travel along the circumference). While living with extended family, one is subject to their whims. Nat, an 18-year-old living in Moerai with his mother, sister, and cousin, recounted how his host family took every penny his family sent to him for personal expenses and did not allow him to purchase anything. The uncle and cousins he stayed with always referred to it as "family money" even though his family also paid them for his room and board. He also spent a lot of time cooking and cleaning in the house for the three other brothers who lived there. When it came time to apply to university, Nat was accepted, but was not given a dorm assignment. Knowing that meant another year living with the same extended family, he pretended his registration got lost in the mail, and returned to Rurutu.

Not only are these transitions important in understanding the experiences of youth, but for understanding what it takes to strive for modern dignity in French Polynesia. Often, youth are exposed to many different potential futures, but the reality is that the path to education is often full of obstacles and adversity. The youth of Rurutu struggle between experiencing a lack of dignity (being seen as bête or living with hostile host families) in order to strive for a narrative of dignity given by French colonists and accepted locally.

\section{Classe}

It is worth mentioning that not all youth from Rurutu hate school. There are also many who finish with baccalaureate degrees, as well as tertiary certificates and diplomas. However, for those who take to education, who pursue it and try to fit in, there is another fear. I mentioned before that identity for the youth I studied on Rurutu is rooted in towns that have fierce rivalries, but while on Tahiti this rivalry is all but forgotten in favor of banding together under a Rurutu 
identity while they are far from home. Youth living abroad worry about the health of their Rurutu identities, and thus use their relationships with others from the island to hold on to their ties to home. They fear the onset of a classe identity, in which they have replaced their wellworn traditions and thought processes with new, western, global perspectives. In the case of Tereata, he experienced the $f i u$ of school when they tried to force him to be classe. Tereata was a 20-year-old chef who lived with his parents and sister on Rurutu during my fieldwork. He explained:

I went to lycée to learn how to cook, but they kept trying to teach me how to cook the French way. They only cared about food cooked the French way. I hated it, and I hated Papeete. Everything revolved around the clock, and there was too much pollution. It's so different from the native village where we're close to nature, there there's nothing but concrete. They tried to get me to be like them, but I just couldn't. So I got the skills I needed, and I left!

Tereata was, at the time of my research, a moderately successful chef in his small restaurant on Rurutu, combining his French skills and Rurutu flavors in his dishes. "I went there to learn what I needed. Everything else? Fiu." One cannot be classe and Rurutu; they are mutually exclusive. Young people with aspiration for work must contend with the worry of becoming classe by leaving Rurutu for extended time. They want to leave Rurutu to gain other experiences, but they do not want to give up their connections.

Sustained absences from the home island can bring about certain fears of losing one's Rurutuness, or the ties to island identity, family, and reciprocity of home. As mentioned earlier, the schools on Tahiti use French curricula, and many of the professors are French. The way of life taught at lycée differs from that which is taught in the home. Thus, students may fear the process of growing up and learning new things. Tinihau, a 24-year-old mother of 2 who lived in Moerai with her boyfriend with whom she was planning a wedding, experienced this guilt 
through the French style dress and comportment her hotèlier school mandated: "Then, I became obsessed with shopping. All the clothes, and they wouldn't let us wear flip flops so I finally had a reason to buy those cute shoes... And then I realized that is not who I am. I felt like I had to get out." In this case, it is not just the teachers, but the students who made her feel as though she was changing her basic personality to fit in, and thus losing her Rurutuness. This change through exposure to the new lifestyle in Papeete or even just on the main island of Tahiti is a theme that ran through much of my research with Rurutu youth. For them, the curriculum and teachers are not always the driving factor for them to lose their Rurutu identity; it is the other students and life in general in the urban center of the country.

Mairau, the mother of one of my participants, spoke candidly about the contemporary youth on Rurutu when she said, "the youth now are not the same character as when I was a teen; some of them are really terrible. But they are more serious about their studies, which is good. There are lots of students who go to university, and the teachers helped. They did good work." Although the generational differences lead to misunderstandings between young people and those of their parents' generation, older folks still understand that youth have come a long way in their appreciation for education, which is something that most people on the island consider a good path. For Rurutuans, it seems that being educated carries with it a level of dignity and victory that is otherwise unattainable. Using one's education is a different story, and much more difficult considering the ongoing underemployment throughout most of French Polynesia. Those who manage to make it through their BAC tests are in a much better position for finding wage work, even if they move back to Rurutu, but more than that they are commended for their academic successes. Getting there, however, can be a harrowing journey. 


\section{Conclusion}

The use of experiences during education helps explicate how young people interact with one of the most powerful institutions in their lives. Due to the ongoing French colonial influence in French Polynesia, and especially on the school system, the transitions associated with education were important to examine through vital conjuncture narratives. Education is becoming a method of finding one's way in the world. Haina called it an opening: "A BAC is just an opening in order to find what you truly want to do.” But the education system has pushed students into certain tracks, or branches in schools that do not always match up with opportunities in the local job market. For instance, there are roughly 300 students in the "local language and culture" track at the university, but, according to Laina, there were only around 20 openings for language teachers at the time of my research, which is the job they are all hoping to get once they finish.

The vital conjuncture narratives demonstrate that the youth of Rurutu negotiate the modern identity that education may offer through a concept of dignity that is strongly associated with maintaining their sense of being Rurutuan. Thus, youth from Rurutu walk a fine line in continuing education. On the one hand, it is important to be educated, and show that one has the capability to continue. Success, as defined by the French government and development mentality, is largely dependent on education. It is the number one priority of many developmental and globalizing programs. Thus, dignity, as defined in school, is pursuing a degree that leads to wage work. However, dignity as taught at home is defined by one's continued connection to the life and heritage of Rurutu. Youth come home for holidays to take part in traditional celebrations and learn local dances, folklore, and production, and then many leave again to take part in school and learn about global consumption, labor, and modern skills. 
The value placed on education, and the ease with which one finishes lycée had changed even in the matter of 7 years. As the members of students' social networks become more educated, and more focused on education, so the younger individuals of those networks choose education. As Facebook, a form of mediascape (Appadurai 1991), has become more ubiquitous, it has played an important role in making education no longer an imaginary future toward which youth are striving, but a future they can see, that their friends have attained. On the other hand, the ties to family, land, and heritage are still there, making these decisions even more difficult. Thus, the branches students end up in can both say a lot about their own perspectives and their potential for future selves. They can show a youth's motivations and social identities, as well as his/her level of autonomy within the family, network of friends, and social institutions.

The next chapter will examine vital conjunctures outside of the experience of agency, fiu, and classe. In the case studies presented there, the dignities being strived for are not straightforward. The young people in these cases are navigating available social fields and identities both by choosing one path over the other and by narrating their decision in terms of prioritized motivations. 


\section{CHAPTER 6 \\ AMBIGUOUS DIGNITY: NEGOTIATING PRESENT AND PREFERRED FUTURES}

In the previous chapter, I focused on various vital conjunctures in the context of education. Youths' experiences of coming up against colonial powers through education, and how they deal with the contradictory definitions of dignity shows the interrelation between traditional and modern influences. This chapter will continue to try to understand the motivations and experiences behind the diverse vital-conjunctures youth narrated during interviews. I will explore two general trends in identity negotiation: the experience of utilizing liminal status to avoid losing one's dignity in choosing the wrong identifier, and the experience of making a decision to define one's identity in a dignified fashion. Both of these strategies are used even within the same person's vital conjuncture narrative, thus both are reasonable ways in which to examine and understand a youth's perception of his or her own transformations throughout their lives and negotiation of conflicting definitions of dignity.

Identity negotiation is defined as the interaction between an individual's agency and outside influences (Maira and Soep 2005). The decisions I coded for and analyzed in Chapter 4 range from experiencing a lot of agency and power over the decision to very little to no power over a decision. The individual experiences of these vital conjunctures, with varying levels of bounded autonomy, may give us a better understanding of how youth prioritize certain identities and find motivation to head in one direction over the other. I argue that the process of growing up is becoming non-linear, and the goals of independence unattainable such that the importance of adulthood as a destination is almost negated. In looking at striving for dignity instead, we can 
problematize decisions as they concern the constructed as well as momentary identities of young people.

Of equal analytical importance, and associated with ideas about agency, is the concept of becoming, which philosophers define as a process or state of change and "coming about." Anthropologists João Biehl and Peter Locke $(2010,335)$ describe becoming as a form of microanalysis, which "brings into view the immanent fields that people, in all their ambiguity, invent and live by." They suggest that this can be deployed to "allow for larger structural institutional processes to become visible." I use the concept of becoming as a framework for understanding how young people react to constant change and precarity in their lives. As social fields continue to shift even as youth age and mature, the end goal may also become more or less easy to find. Rather, I argue that they are striving to become themselves, whatever version works out. There is no longer a definable "adult" status, or a shaking off of "youth" or taure'are' $a$. Instead, there is the ongoing path, with ever-changing courses and contexts. Thus, I have termed this phenomenon that of "becoming" - youth do not attain a status, as these can change depending on context. But they do become their own individual definition of an adult. These definitions may even vary depending on the experiences and values of each individual youth. Each youth, as s/he narrates a life, paints a picture of the choices made that have led to a current identity.

The youth within my study are not just becoming adults, but becoming themselves; they become who they want to be within and outside of the roles that have been constructed for them. The youth whose case studies follow in this chapter represent two of the three towns on Rurutu, as well as various household contexts, economic situations, levels of education, gender, and age. The decisions represented are also diverse - while the first section deals with 
pregnancy as it relates to different aspects of social and personal life, the second deals with vital conjunctures surrounding family, relationships, residence, work, religion, and sports. One example is provided by the experiences of Poe, whose father wanted her to become a teacher. She tried because it was his dying wish and she was such a "rotten child" that she thought she owed it to him, but she could not complete the program because in the end she believed her heart simply was not in it. At the time of this interview, Poe had just finished turning in her paperwork to leave the ESPE program, and was thinking about what to do next. While it may not have been in her best interest in life to say 'no I don't want to do that, my heart isn't in it,' Poe is not the only young person who changed her mind when considering other values or confronted with other opportunities. Hotu, another participant in my study, is in some aspects the same. Throughout her young life she prioritized her education, but as soon as she was pregnant and faced with a choice between raising her child or continuing her education, she stopped choosing. While social navigation helps to understand how constantly shifting social roles alter the available options and pathways to follow, as well as the experiences of growing up, there is also a sense of becoming something. Although the number of paths available is limited, especially on Rurutu, youth seem to narrate their vital conjunctures as though they are making choices for themselves, and sometimes these decisions are difficult. Hotu wanted to be a mother; it was "her calling". Laina found her calling in being a teacher. It's really what she is good at, even though it is a challenging and competitive field. After failing her BAC STSS exam three times but passing the language portion, Haina realized that she could go back to school and still be educated: even four years later and with a child. "I hate science, I've always hated science, I want to go get my BAC in languages, because it's what I like and I have an affinity for it, it's what I'm good at. I should have done it in the first place. But I will do it 
now." She then acknowledged that she might go to university and study something else, but the point is that she realized, through the experience of failure, what she's good at, and has learned that her parents don't know as much as she thinks they do. Therefore, the decisions youth make and the motivations they prioritize may have less to do with what jobs are open and more to do with their own self-defined skills and aspirations.

Thus, in looking at these transitions and decisions through a lens of dignity, we can add that changing political and economic institutions shift the definitions of an attained status or dignified future. How does one prioritize consumption and individualism while simultaneously making the welfare of their family a motivation? How can youth gain favor and respect through the work they do for their families while going out and pursuing a career? Often times, they cannot live in both worlds. However, those who choose wage work narrate it in ways that prioritize family. Those who choose family narrate those choices as having been in favor of family over some offered chance at a career.

Throughout this chapter, I will examine how youth deal with "ambiguous" or shifting definitions of dignity both by consciously trying not to make decisions, as well as using decisions to navigate their lives and negotiate identities. In the first section I review the idea of trying not to make decisions, which has been labeled by anthropologists of youth as "opting out” (Mendoza-Denton 2005), but which I will label “conscious liminality.” MendozaDenton's opting out has a distinctly political bent to it, such as the Occupy Wall St. movement. However, the experiences of many young Rurutuan men and women, particularly in the realm of reproduction, show that they intentionally choose not to find out whether they are pregnant, or once they know, they put off making a decision until something comes up that chooses for them. 
Thus, I define conscious liminality as choosing to not choose. Literature on adolescence and youth posits that youth use their liminal status to their benefit (Fokwang 2008; Jourdan 2004), and I agree that this is something that also happens with youth on Rurutu. In my research I have seen this conscious liminality, but it is especially poignant in the context of oncoming parenthood, where we can see how young people find themselves caught between contradicting priorities and identities, and many choose not to make a decision until they absolutely have to, if at all.

In the second section of this chapter I will discuss the term "social navigation" as it related to case studies from my research. As Vigh (2009) defines it, social navigation is the idea that one must chart a course on an ever-changing and unstable social field. This idea encapsulates the ways young people use their decisions to transition into new social identities or to prioritize certain aspects of their identity. The stories included in this section describe vital conjunctures relating to work, education, residence, and relationships.

\section{Conscious Liminality and Delayed Choices}

During my time on Rurutu, conscious liminality played out in many different scenes. The most poignant of these scenes was in relation to parenthood. My female friends and interlocutors were excited by the prospect of being mothers, but never seemed to want to be pregnant, although they did accept it and celebrate upon hearing the news. Male friends and research participants looked at fatherhood in much the same way as they looked at planting taro. As Manu, a 28-year-old father of one said, "This fatherhood thing is easy. He cries; I pick him up!” But even young men worry about their children, and whether they will be able to do enough for them. Sennott and Yeatman, in their research among young women in Malawi, argue, "childbearing ambivalence is dynamic and situational, resulting from the multiple 
sociocultural frames surrounding childbearing" $(2018,888)$. They tie ambivalence over pregnancy and childbearing to such transitions as economics, education, and relationships. This argument supports the idea that conscious liminality during pregnancy, and even after the birth of children, could be seen as a type of social navigation through times of vital conjunctures.

The young women among whom I spent time seemed to be caught between the "scripts" of growing up, finding a partner, and having children and the possibilities that modernity and colonial connections to France promised. They felt there was more than motherhood, but that it was still a strong calling. Therefore, many were frozen when struck by the crossroads - unable to choose one and give up the other. So instead, they just waited. Knowing there is more out there than making it work with less-than-ideal partners or living situations made them question the automatic acceptance of their pregnancy.

I did find two instances of abortion among girls still in their teens - but women over 20 did not seem likely to proceed with an abortion. This is most likely due to their strong ties to the church and their religious beliefs, as well as an extensive family-oriented adoption practice. However, the women and couples from Rurutu were still ambivalent about their relationships, their place in the world, and their potential education. They seemed just as ready to be pregnant as they were to be not pregnant, but not at that moment. They needed a little bit more time: 30 seconds to continue to not have to worry about being pregnant, or just one more day, week, month before having to accept their new world. Or, in the case of abortion, maybe they simply were not ready yet.

I had many different conversations about pregnancy, motherhood, reproduction, and contraceptives while living on Rurutu. Since condom use is not the norm, many young women worried over the potential for pregnancy, or whether they should go to the clinic and ask for 
birth control, but risk being the next victim of the town gossip. Once teens get to Tahiti, it becomes a bit easier to find birth control, out from under the watchful eyes on their home island. Still, women get pregnant: many times unplanned, and most often out of wedlock. Of the numerous conversations I had during my 16 months of fieldwork, six stand out, because they centered on the idea of "can we just take a minute, I don't want to be pregnant yet," or "is there a way to not make a decision about being parents?" The case studies presented here include two from women who were about to find out whether they were pregnant, one who recounted her termination, one who has a 1-year-old son, and two couples who mentioned the birth of their children during their vital conjuncture narratives.

\section{Vania and Tino}

The first conversation I had was with Vania in the summer of 2015. She was 28 at the time, and had just finished the French Polynesian version of a GED course, in order to continue her studies and fulfill her dream of becoming a nurse like her mother. She came home just in time for the July Heiva festival, a time of dancing, celebrating, and more than a little bit of drinking. It was at a small get together with Vania, her boyfriend Tino, and their friends (in which they had decided to introduce me to the local moonshine) that she brought up her potential pregnancy. I immediately responded with "congratulations! Have you gone to the clinic to get a test yet?" After shushing me, and reminding me no one knew yet, she replied, "I could go to the doctor's tomorrow, but I promised I would show you a good time while I'm home, so I figure we'll fé la fête this weekend and then I'll get my results next week!"

When I asked if it was okay to drink if she was pregnant, her reply was interesting. She said, “The local wine is supposed to 'help' women with this particular ailment (pointing at her stomach). If it works, and the doctor proclaims next week that I am not pregnant, then we get to 
celebrate the Heiva together. If he tells me I am pregnant, then there is no harm." I then asked her if she was excited, if she knew what she wanted to do, realizing my congratulations may have been premature, and she said, "Of course I want a baby. I just don't know if now is the time. You've met Tino; you know how we fight. Would God really give us a baby right now? Ugh, and being huge and pregnant during my classes! What a curse!"

For the rest of the conversation, we talked about potential plans. She never mentioned abortion, or even adoption. If she was pregnant she wanted to keep her child. Vania knew she would be a good mother, because she spent so many years as a nounou to her sister, Maruia's child, Ina. Although she worried about the timing of giving birth during finals period, she had no worries about having a support system so she could continue her education and eventually become a nurse. Her hesitation was, however, tied to her relationship. Her boyfriend, who was four years younger and had recently quit university to devote more time to sports and bodybuilding and had plans to join the army and leave for other islands for undisclosed amounts of time, was slightly less mature than she would have hoped. "If I have a baby with him, we become a family. I don't want to be a family if we are not ready. I don't want to become Ro and Pierre.” This fear was true in many cases. Weddings on Rurutu are a complex and expensive affair, so most people under 35 are not married. More than that, relationships tend not to be overly committed. That is, until there is a child in the mix. Childbirth seems to take the place of marriage on Rurutu, and is thus seen as "making a family" instead of just "having a child." And this didn't always work out for the parents. Maruia and Pierre were a pretty good example. Their story, which follows, shows how conscious liminality is not only something youth utilize when pregnant, but at any point in the spectrum from considering being pregnant to years after the birth of the child. 


\section{Maruia and Pierre}

Maruia, 25, already had one child, Ina, when she was 15 . Ina is a lovely 10 -year-old girl who likes to run and play soccer, and is the light of Maruia 's life. However, 10 years ago, when Ro first suspected she was pregnant, she cried for three days. She tried to stay in her liminal period as long as possible, months even. She tried to force a miscarriage by drinking copious amounts of local moonshine. She had only been with her boyfriend, Pierre for two months at that point, and she was supposed to be heading off to Tahiti to continue her secondary education in couturier, or fashion design. She felt a lot of shame and embarrassment for having allowed this to happen. She waited months before finally telling to her mother and taking a pregnancy test, which came back positive, but when her mother suggested abortion the thought "devastated her". Her mother then forced Pierre to get on a plane to Tahiti to comfort Ro and figure out their next plan. As she tells it, "I told him, I am having this baby. If you don't want him, you can leave now." He stayed, and they are still together, but it is a well-worn gossip in the family that he stayed because her (rather intimidating) mother forced him to take responsibility. This experience has changed Ro - she quit school to be a mother, and wants more children now that she feels more grown up.

In the summer of 2015, while I was living with her, she thought she was pregnant once again, but hadn't taken the pregnancy test at the clinic yet. She was excited to be a mother again, especially since Vania was now officially pregnant and her brothers had recently become parents. But she still wasn't sure about Pierre. They had been together for 10 years, but he was still very much an adolescent, drinking with his friends, gambling, and lacking employment. When she told me she thought she might be pregnant, I was skeptical. She and Pierre had not been sleeping in the same room, but that rarely means anything. Just as I had with Vania, I said congratulations, and then asked whether she could still take part in the beers we had purchased. 
Her response was 'Oh, I'm not pregnant until I'm pregnant. I'll stop when the doctor tells me I need to." For Maruia, it ended up being a "Not Pregnant" moment, and it seemed to crush her just a little. While Vania was not sure she wanted to be pregnant, Maruia, it appears, was putting off knowing so that would not have to admit to not being pregnant. Interestingly, both vignettes from Maruia 'slife show her own ambivalence about being pregnancy, and that a perceived loss of dignity can happen whether it turns out one is pregnant or not pregnant, depending on the context. In both cases, Maruia was unsure, and needed time to come to grips, and both times the results were not what she wanted.

Although Maruia did not terminate her first pregnancy, there are others who did. In this case, the liminality of not knowing stretches indefinitely. Maima felt the need to stay "not pregnant" for a while longer, because her education was important and her relationship rocky.

\section{Maima}

Maima was 18 years old at the time of my fieldwork, and enrolled in tertiary education on Tahiti, even though I interviewed her on Rurutu. I have known Maima since the summer of 2011; her family lived near me and I occasionally played on their volleyball team. Her parents worked as a bus driver and a well-known local artisanat. Although I interviewed Maima, and discuss her other vital conjunctures in the next section of this chapter, this discussion about pregnancy came up during a more casual conversation when we were discussing her most recent year of school, and just starting university. While asking how she faired in her first Pre-Law class, she responded, "I missed a lot of school at the beginning of the semester, what with the terrible morning sickness and the week it took to get an abortion." She too, originally thought she was pregnant, but wanted to wait to find out. She would have waited longer, if it hadn't been for the terrible morning sickness. However, she described that when she finally took the 
test, and it came back positive, she didn't even question it. She found the first friend she could who was over 18 (as she was a minor at that time), and went to the doctor's office. The abortion process in French Polynesia follows that of France. It is a complex process that must be completed by week 12 of the pregnancy, but is covered by the nationalized heath care system. One must first go see a doctor to determine pregnancy, and then the doctor refers the woman to a psychologist to make sure she is making the decision with sound mind and body, and is also "emotionally prepared" for what she has chosen. Then, a woman must wait three days before appearing for the procedure together with an adult if she is under 18. Maima explained the entire process in objective detail.

When I asked why she chose an abortion rather than to give the baby to a family, she answered quite quickly.

I didn't even tell Raitu (her boyfriend) that I was pregnant. I know better. He would want the baby, and then I would be stuck with him. I love him and all, but I was 17 and he was barely 19, and I don't know what my life will be like next year. If he knew we made a baby that would be it, and I can't count on him enough to risk that. He would never allow me to give the baby up to be adopted, or even cared for by a family member. He's crazy!"

Maima's ideas about her baby being adopted also show ways in which youth can delay parenthood. However, her fear of her boyfriend wanting the child shows an interesting paradox. Most women in the United States worry about being left alone to care for the baby, while young women from Rurutu worry that a baby will tie them permanently into a relationship--as if it is the man and not the baby that they are worried about. As Jennifer Johnson-Hanks (2008) argues, women in Ghana experience doubts about whether they will be good mothers. I think this is another issue for these youth. Not only are there contradicting dignities that come up against each other when pregnant while in school, there is also the fear of a loss of dignity in not 
being a good, responsible parent. Furthermore, women also fear the shame from having a child with an irresponsible partner. And they fear making the wrong decision, and losing dignity.

It is not even just apprehension about an inability to drink, party, or go out with friends anymore; there is a certain preparedness that these young women are now considering. One must square away their relationships: with their significant other, with their family. They have to make plans: "Will I live on Rurutu or will I live on Tahiti? Who is going to support the baby, do I have enough money? Will this be a step forward or a step back in my life plan?" There are a lot of these thoughts that go through their heads upon finding out that they're pregnant. But they do not have to make those decisions until they find out that they are $100 \%$, without a doubt pregnant. So there is this liminal, or fluid period when they can still deny that they have to take any sort of responsibility for a baby, that their life isn't about to change, that they are not taking on yet another lifetime of responsibility for another human. For the youth I met on Rurutu, this period of liminality, this period of knowing but not really wanting to be sure, could last weeks or even months. In the case of Maruia, it lasted until the only choice was to keep the baby, while for Maima the liminal period ended up being a more permanent state. They are ready for a child, but for the majority of them, this state of not yet knowing, of both wanting a child, not wanting a child, and thus not wanting to know, is one more part of the experience of pregnancy, and life. Having a baby is one of the most permanent vital conjunctures. Unlike relationships, work, or education, the decision to have a baby and keep it cannot really be undone. The magnitude of this one transformation could coincide with why it is the most likely time of conscious liminality.

In their article on selective reproductive technologies, Gammeltoft and Wahlberg (2014) define ambivalence as "Hope, joy, and anticipation merged with dread, fear, and anxiety" in 
reference to older mothers' fears about the futures of their fetuses. In research on motherhood, there is also reference to ambivalence: the rational feelings of raising a human mixing with the irrational feelings of being absolutely, irrevocably in love with a tiny creature. But the irrational love they know will be there gives many Rurutuan parents pause. In many cases, they are struck by a moment of asking, "Can I do this? Can we do this? Is this the right decision?"

The next three stories about pregnancy and parenthood were narrated to me after-thefact. Temere and Niau's baby was one year old when I interviewed them, Loma and Michel's was 8 months, and Hotu's little boy was almost two years old. However, it is still possible to see how the liminality of pregnancy is seen as ending once they become parents, or can continue for years as decisions about other aspects of life are deferred.

\section{Temere and Niau}

Temere and Niau were both 22 years old and living in Avera when I interviewed them. Temere grew up in Moerai with her mother and grandparents, and Niau in Avera with his parents, brother, uncle, and cousin. They met and began dating seriously while they were both still in lycée, and Temere told me, during her vital conjuncture narrative, that she found out she was pregnant at the end of their 1ere year, when she was 18. By French education standards, that would have left them with part of a year to finish and the BAC exam to study for after she had given birth. Both of them, in separate interviews, mentioned the birth of their baby as a turning point in their life paths.

Niau's story of becoming a father is one of change, but surety: of growing up, and following the more traditional Rurutu life course.

And there was, also, when we had our baby. That really made me grow up, you know? Way more responsibilities, and your vision of things change, you can no longer do exactly what you want to do. It's a way of life that changes. 
Temere also listed the birth of their baby as a turning point in her life, although for her it was the pregnancy more than adjusting to parenthood:

When I found out I was pregnant... it was... a decision... actually it wasn't really, because I didn't even know! I didn't know. I didn't know until we had to look at the stick. And I just thought, "What do we do?" But voila, we didn't have to make a decision, because my beau pere ${ }^{14}$ took care of things. I said, ok you guard the baby and then when we finish [school] we can take over. And if they hadn't agreed to that, I have no idea what I would have done.

Although Niau narrates it as just another part of his growing up, Temere claims that at the time they had no idea what to do, and that it was a bit of a miracle that his family was willing to take care of the baby while they finished school. The ambivalence that they felt, at wanting to finish school but also wanting to start a family, and the inability to make a decisions shows how difficult times of vital conjuncture can be. It was important to Temere's family that she finished school, and as a mother she knew, because of traditional and Christian gender roles, that she would be the one who would have to give up her education if they could not figure something out. Niau, on the other hand, would have been sure to finish school, albeit without Temere there on Tahiti with him.

It is relatively normal for family to take care of a baby if the parents are not able to. The instances of $f a^{\prime} a^{\prime}$ 'amu as well as long-term nounou relationships ${ }^{15}$ were numerous among my interlocutors. Of the 74 youths I interviewed, 3 had grown up with adopted parents who were extended family of their birth parents, 5 had grown up with grandparents, and 4 had had nounou

${ }^{14}$ Beau pere, meaning "father-in-law" is a term for one's significant other's father. Although they are not married, they often will use the term beau to refer to a boyfriend's family.

${ }^{15} \mathrm{Fa}$ 'a'amu is the local tradition of familial adoption, which is often not formally reported and thus is not well tracked or calculated. Nounou is a nanny of sorts, usually a family member who either stays with or brings the child to live with them or stay for long periods of time. 
family members. Niau's parents made this offer. In this instance, family and educational values are working in the same direction for these two young people. Temere's characterization of this vital conjuncture as "not making a decision" is also an interesting point to note - sometimes, vital conjunctures do not end in an either-or decision, nor a decision that points to one set of cultural influences over another.

The next case study, of a slightly older couple, shows that a lack of decision-making can be experienced in positive ways as well. For Loma and Michel, whose past experiences had already set them up as Rurutuans and caretakers, there was no real decision to be make in terms of pregnancy. Their story is one of fluidity, where there was not really a decision to be made to showcase the diversity in vital conjunctures and liminality.

\section{Loma and Michel}

Loma and Michel were both 24 at the time of my interview, were living in Avera with Loma' family, and had a 6-month-old baby. I had been a friend of Michel's since my first summer in Tahiti in 2011, as he is a good friend of my host brothers. Back then, he had a lot of issues with his birth family on Rurutu, and had chosen not to continue his studies in Tahiti. He stayed on Rurutu to continue his family's farming. He met Loma at a Heiva celebration just after she had decided to return to Rurutu to care for her family. They started their own family. Michel now lives with Loma and her family in Avera, and tends to their taro fields as well as those of his own family. They make enough money to support themselves and her extended family through the sale of his crops.

For some young people, the transition into parenthood is scary, or abrupt. Loma and Michel, on the other hand, experienced a much smoother transformation into becoming parents. Loma was already caring for her young nieces, as their parents were on Tahiti and they were left with 
her ailing grandmother. While everyone else in the family had wage work, it fell to Loma to care for the young ones. Although Loma described her vital conjunctures as revolving around her family, she did not mention her experience in having a child as one of them, even though the majority of participants did. When I asked her about this, she laughed. She responded, "I was basically already a mother with my nieces. Now that they are more grown and can help, why not bring another person into the family?" While this case study does not show conscious liminality in the same way as the others in this chapter do, there is more in common than I first thought. There is still no definite decision to have a child. However, when they got pregnant there was also no discussion of what would happen. There was no decision, and no sensation of change or growing up to be made, because both had already experienced it. In their case, the prior vital conjunctures of quitting school to care for family members and farms allowed for the embrace of a local kind of dignity in having a family. Their previous experiences rid them of the contradicting influences many youth have. Even youth who realize education may not change outcomes are still bombarded with other potential futures through media. However, having already made the choice to take the Rurutu path may have made this transition easier for Loma and Michel. Hotu's story is also one of "not making a decision," as she is a mother who keeps telling everyone she will register for her next year of classes "next semester."

\section{Hotu}

I met Hotu during my first summer on Rurutu. She was a member of the Catholic church that my host family and I attended. At the time I met her, in 2011, she was attending lycée in Tahiti and was home on Rurutu for the summer. Only her father was on Rurutu, as they were lucky enough to have bought a house on Tahiti where her mother was living and working while the children went to school. Their family, with two working parents, is certainly better off 
financially than some of the other families on Rurutu, which may be one reason all three of the siblings were able to obtain their BAC certificates. Her older brother is currently employed on Tahiti while his copine finishes her ESPE contract, and her younger brother is enrolled at the university. This family does not seem to worry about becoming too classe.

During our conversations in 2011, while Hotu was in the early years of her secondary education in finance and enterprise, she spoke animatedly about the prospect of continuing on to get her Brevet Technicien Superieu (BTS), which is much like a Bachelor of Science in Engineering in the US. When I returned in 2012, I only saw her once, as she was taking the summer to intern on Tahiti in her chosen field before beginning her BTS program in urban engineering. She was a very diligent student, and her parents were extremely proud of her.

Upon my return in 2015, I was living in a hostel outside of the city. I was on my way to the beach one day when I ran into Hotu and her sister-in-law, who is also from Rurutu. It was surprising to learn that Hotu, who was at that point 22, now had a son, who was one year old, and was postponing her tertiary education after her BAC. She was living in her family's house on Tahiti with her mother, little brother, older brother, sister-in-law, and her copain. He had found work as a carpenter, so between the wage earning family members, she was able to stay home with her son and care for him solely. When I asked again about her education, she explained where she had run aground. The BTS program required the third year students to go abroad to France to study at the Ecoles Superior. Because of her child, there was no way she was willing to leave French Polynesia. She assured me she was headed back and had turned in her paperwork to transfer to the university the next year (a plan that never did come to fruition). At first, she blamed the outcome on misfiled paperwork on the part of the university, but did not seem worried about taking "just one more year" with her baby. 
This drastic change in priorities made more sense when I was finally able to interview her and ask about the moments in her life that most defined who she was. Her response was immediate: the birth of her son.

When I was pregnant with my baby, because at first my boyfriend and I didn't want to keep the baby, because he hadn't found a job yet, and we were still in school. But in the end we decided to keep the baby. After that, when he was born, my life totally changed.

Beyond just having the baby, Hotu has realized that her perspective on life has changed.

Much like many of the other women I interviewed, the birth of her first child was a turning point. As Johnson-Hanks points out, these demographic changes become a sort of rite of passage in the lack of a linear lifecourse. For Hotu, it may not have been a rite of passage, but she did notice how much she had changed since his birth. However, Hotu also mentioned how much the baby changed her own perspectives on life as well.

And if not, since I had the baby, it's very much changed. You know, it's, you get it. When you have your own baby, you understand why your mom did all those things for you. All the sacrifices you must make. Not like when, when you don't know that you're gonna be a mom, you get to go where ever, like that... after, when you have your baby, it's then when you really understand all the responsibilities there are.

Her own juxtaposition between experiences of not being a mom and being a mom, coupled with her continued argument that she is headed back to school "soon" show that she has taken up residence in her liminality. "Taking another year" while discussing the responsibilities of motherhood is her extended liminality. As she is caught between the value of being a mother and the pride of finishing the education she started, she is content to "not make a decision" about her future. As it stands, because of her unique position between finishing a BTS and beginning her License, she is able to extend this conscious liminality as long as it suits her. Since she has not yet settled between the competing aspirations (nor does she have to, given her 
situation), she is keeping her options open by not choosing one identity over the other.

All the cases discussed in this section show that young women in French Polynesia, much like elsewhere, have trouble connecting present values with future options when they are dealing with pregnancy. Even in a place like Rurutu, where family adoption is well-known, young women and men still have trouble coming up with next steps. When this happens, they may take advantage of their liminal social position to put off deciding. But, if Viatu's case offers an example of the constant postponement of a decision, there are other examples of vital conjunctures in which a decision is made and an identity firmly chosen.

\section{Social Navigation}

As mentioned in the case of Loma and Michel discussed above, the ability to make a decision one way or the other can assist youth in navigating future decisions. If one is able to prioritize a certain way of life, without feeling as though one was forced or had choices taken away, it can ease the experience of later conflict. Although I would have liked to gain perspective on whether this is true for those youth who chose Tahiti or France, that will have to be a topic of future research. Consequently, since most of my research participants were living on Rurutu, their decisions and social navigations tend to lean toward prioritizing their Rurutuness and their connections to their home island. The priorities and identity fears of those who live in France could be very different. For instance, Raimana, a 19-year-old young man from Moerai, had to make a decision about continuing his work toward his BTS at the Ecole Superieure in France. However, his narration of this decision still prioritized Rurutu. He argued that at some point, Rurutu would have to deal with overcrowding on the tiny island, so having a BTS in architecture would help the islands. Thus, narrations of decision motivations as well as the actions associated with them are both important to understand social navigation. It is 
important for these youth to have the social network that comes with support from home, and Rurutuness is the best way to feed that network connection.

Social navigation, an important dimension of vital conjunctures, is the act of choosing a path that provides dignity and aspirations within a social context that is constantly changing. The case studies discussed in this section include many of the same young people discussed earlier, but follow different vital conjunctures that may have occurred before or after those of conscious liminality. The first case study also includes experiences of reproduction and parenthood, but with a much different outcome. The other case studies include many different vital conjunctures, but they all can be seen as youth choosing a path and negotiating their own identity amid uncertain futures. These decisions differ from those of school because of the mandate around education. France requires students to remain in school until the age of 16. Although there are some young people who disregard this rule, turn 16 before the transition to Tahiti, or attend the local MFR program, for the most part this means youth are required to spend at least one school year on Tahiti. The vital conjunctures in this section of the chapter instead show how youth search for dignity in everyday victories, whether that is finding inroads to the global economy from Rurutu, choosing to disregard modern life and celebrate traditional ways of life, or anywhere in between.

\section{Viri}

Viri's way of being in the world was always interesting. An introvert, which was uncommon on Rurutu, Viri had a quiet sort of strength. Although I met him in the summer of 2012, while he was walking down the street holding his prized rooster, we conversed very rarely until he was willing to sit for an interview halfway through my fieldwork in 2015 . He 
finally opened up after witnessing me make a fool out of myself trying to ori ori ${ }^{16}$ at a wedding reception. Viri had quit school as early as 2010 , even though he was only 23 when I met him. I learned during the interview that he had two children with a woman on Tahiti who had been a neighbor of his during his time there as a student.

In the case of Viri, the birth of his first child made him realize that making money for the next generation was important. Although he had come home, along with his brother, to help his aging father with the taro planting and coconut harvesting, he had also started planting more profitable herbs among the rest of his crops. When I asked him about his vital conjunctures, he immediately replied:

It was the birth of my first child. I was still young, but I could only think of him. It was for him that I worked hard at school, and that we now have expanded our fields to make money instead of just to eat.

Although Viri's children live on Tahiti with their mother, who chose not to move to Rurutu when he returned home to help his family, he sees them every summer while they are on Rurutu during vacation, and he admits that everything he does is for them. Although he chose to return home, he is doing it on his own terms, and for more than just subsistence and a bit of profit for buying new equipment or fixing up the house. He has plans to take the money he makes and build a place where youth on Rurutu can go to hang out and be safe.

Viri navigates his constantly changing social fields by utilizing crops he knows will make money he can then give to his children. Although he was willing to come home to Rurutu when it was necessary due to his family loyalty, he has found ways to not only support his children, but to enter into the global economy. Even if by the black market, Viri has found ways to contribute. This need to support others is an important theme that emerged in the interviews

${ }^{16}$ A particular Tahitian dance, usually of two people, similar in movement to a Hula. 
with men. It is one that also characterizes Raitu's vital conjunctures. In this next section, we can see that Raitu made his decisions with his brother in mind. His aspiration is to make enough money to support his brother in his goals of attaining higher education. Raitu wants to be able to send him to any school he chooses. Growing up poor, Raitu is still dealing with being ashamed of his household and thus spending his childhood hiding in his room.

\section{Raitu}

I met Raitu through two of my male interlocutors. He played soccer with Manu, and had spent most of his childhood on Rurutu with his grandparents, even though his parents and little brother lived on Tahiti. When we met, he was 19 and had just finished his BAC. He had been accepted to university, and was planning to go. During our interview, when I asked whether Raitu had a girlfriend, he laughed and told me that he did. With a wink (assuming he knew we were friends), he said, "She's horrible! You know her, she's your stubborn neighbor." It turned out that Raitu was the boyfriend of Maima, who I had interviewed earlier. He credits her with allowing him to come out of his shell by being supportive. Raitu's impoverished upbringing with a strict mother and an absent father was one of the factors that impacted his formative decision-making. After discussing the honte ${ }^{17}$ that he felt living with his mother and his family on Tahiti, and how he was not a very proud or upstanding boy, the fact that the first vital conjunctures he mentioned upon being asked was moving away from home did not come as a shock.

I decided to move away from my parents. Like I told you, that life wasn't very stable. And since we don't get along very well, I came [to Rurutu] to live with my grandparents. Now, I always tell myself that when I grow up I'll have a good steady job to support my family, unlike my father. That's really my objective in life right now.

${ }^{17}$ Honte is the French word for shame, or loss of dignity. 
Here, Raitu is holding himself and his decisions in contrast with those of his parents. He is identifying himself as connected to Rurutu, instead of connected to them. This is a point of pride, of dignity, for him. Not only did he have to make the decision to leave his brother behind after his studies and return to Rurutu to live with his grandfather, he also had to change a lot about himself to be able to live elsewhere than under his mother's roof. This passage is poignant because we can see that Raitu found himself through living with his grandparents on Rurutu, even though his future goals revolve around supporting his family in ways that are often unsustainable on Rurutu.

Because before I was really sauvage ${ }^{18}$ - I never said hi, or how are you, and when people came to visit my family, I always hid in my room. I was always so ashamed. I told myself, it's important that I try to be more open and extroverted toward others, and not hide myself so much... how do we say in Rurutu? Etene? It's mal-elévé ${ }^{19}$. So there was that also - to be more open.

He claimed it was Maima's support that made him accept these positive transformations: "Before I met Maima, I kept my head down. I was always worried. Then she came and things changed. I am happy now and I see a future." Maima, his girlfriend of one year when the interview took place, was the epitome of the open and extroverted Rurutu girl. She was smart, motivated, and happy. Although the decision he made for himself allowed him to get out of his home situation and become more successful, he is clear that he is not doing it only for himself. In his third vital conjuncture he discussed the choice to remain in school while making a small stipend playing soccer for a local team. The stipend, he says, allows him to provide a little bit to support his brother while he attends school.

All I really want right now is to be able to provide for my family and my little brother. When he gets to the age he has to go to secondary school, I want to be

${ }^{18}$ Sauvage is a French term that translates to English as savage, but they use it to refer to people, specifically young people, who are very shy, talk little, but are active or strong. ${ }^{19}$ Mal-elévé means to be brought up badly, or not taught proper manners. 
able to send him money and everything else he might need. That way he has no stress. He can stay with my mother and be happy and successful. Hopefully I will be on this team and make money for a while. All I want is for him to find a good job. That's how I am. It's always about my family. I put my family ahead of myself. So if my brother can be successful and take care of our mother, then I can maybe think a little bit about me.

In terms of the connections between youth, globalization, and vital conjunctures, these choices are not much different from those of young Ghanaian men whose uncertain futures lead them to attempt a life of professional soccer even if the odds of succeeding are low (Esson 2013). Raitu is torn between wanting to make money for his family and find dignity for himself through is skills as a soccer player. As the analysis in Chapter 4 demonstrated, work as a vital conjuncture was not among the most frequently mentioned during interviews; however, the ongoing uncertainty with work has led young people to try to frame their hardships and narrate these vital conjunctures as separate from their own social identities - that these decisions were made, but are not a representation of their true priorities.

\section{Fara}

Fara, whose experiences with education were mentioned in the last chapter, also spoke of two other decisions that have changed her way of being and her life course: choosing whether to continue her education or come home, and her continuing search for work. Although Fara is having a hard time finding employment in her specialty with her diploma, she is still happy in her life. She narrates her transformations with a positive outlook. She does not feel shame over living on Rurutu with her level of education. She seeks dignity where she can - in raising her son and bringing in money when she can through her artisanat work. 
As mentioned before, she did experience issues with her secondary schooling branche. She was unable to pursue her first choice, which she viewed as having greater potential to lead to a good job. However, she does not look back at those roadblocks in a negative way:

So I went, and I don't regret it. It would have been nice to see a little over there. But if not, without having that, accounting was good. Aaorai is where I met my tané, too. So I cannot complain!

This narrative may have been different if I had interviewed her years before, but narratives can change as identities and social contexts shift or solidify. Fara is currently in a stable relationship and happy about her life course. Thus, she is able to look back on these decisions with happiness. In regards to her discussion of continuing education or coming home, she made it pretty clear that it was due to her lack of excitement over her not-so-chosen field.

Alors, la? Me? I wanted to continue my studies. But when I took my BAC tests, it was way too difficult for me. All I did was study, study, study. Even if I took a break, I still was stressed, you know? In my head. And I thought, if this is what it's like to continue my studies, if after this I'm gonna go back to school, my brain would explode.

As mentioned previously, Fara wanted to go to school to be an aesthetician, but ended up in an economics and accounting program instead. If she were to continue on to university, it would have been a lot of the same sorts of specialties. However, what really solidified the decision was her son. This, she said, was her choice of family over continuing her education. She didn't want to leave her son behind while she pursued a course of study as her mother had. She wanted to be home.

Because they say, when you have a child, you take responsibility for your child. It's important not to lean too much on your parents, or... Like, my mother, when she had me she left me with my grandparents to continue her education. And I am so proud of her... that she got an education, you know? And she told me. She said I could do what I needed to do; that she would care for him. But I just wanted to be home with my son. On the other hand, I'm now a mother, and now I don't even like to go out! He's totally just, my heart! It's funny... my baby made me a different person. 
This is also an example of the interplay between family and education that came up in my quantitative analysis of the overarching themes of vital conjunctures of youth from Rurutu. Family and education tend to coincide frequently during these formative years. Sometimes they work in the same direction while other times they are contradictory. One can also see here that Fara, knowing that becoming a mother could be just as dignified and respected as continuing on to university and getting a License, allowed her new identity as mother take over and push out the future that she actually did not want to fulfill in the first place.

Fara's last vital conjuncture revolves around her inability to find work. When interviewed, she was part of a small co-op that made artisan crafts such as bags, rugs, and decorative flowers. While this sort of work is respected and popular for women on Rurutu, Fara wants to find wage labor. It's harder than it sounds, though.

The employment system here is so political. Me? I really want to work. And the people who look for employees, you have to apply for jobs with them. And the people who fill those roles work for the mayor. So if you know them, you're all set, and if you don't know them, then you're screwed.

What she means here is that job openings are not handled as they might be in the United States. For most open positions on Rurutu, one gets a contract through the mayor's office. If a youth has connections there, or with the employer, s/he is more likely to find a job. Therefore, the line between politics and economics is blurred. This issue is further complicated by the lack of open enrollment in CPA apprenticeships. While they used to be open to anyone under the age of 30 who was currently unemployed, the government has since changed the rules to stipulate that only people under the age of 30 without a BAC diploma can apply (Interview, 2015). Fara took serious issue with this, as she has her diploma, but no real job prospects. 
They told me that the CPA, which used to be CAE, they told me that now, they do research, they research information on you, and your education, and if you have your BAC they won't take you. In the beginning, CAE was only for those who wanted to work in stores or the mayor's office, but now they have them for the associations too. Like when you do tressage and stuff. At the beginning they took us (youth with BAC degrees) for those things, but not now. I tried to sign up for it! They won't let me. So now what do I do, you know? I really only know how to make these little flowers, but I could make real money if I could really weave.

This inability to acquire steady employment is a problem for many young people with BAC degrees. Although the government has programs for those without degrees, these young people with degrees are having a difficult time being employed on the island where there is little high-level work and most jobs are menial. Again, this may be connected to the ongoing colonial disentanglement, because the French-supported government only has the ability to support those without certification, a position that many French citizens believe is the norm in places like Rurutu, even though that is rapidly changing. Fara's struggles show how the incongruity between the educational opportunities offered in French Polynesia and the jobs available affect youth. However, she is figuring it out by joining a coop and learning to weave. Her path shows the different ways in which youth can strive for dignity - with education, employment, and family connections. She does not worry about becoming an adult; she is worried about not contributing to her family.

Niau

Niau, who was first mentioned as having experienced the conscious liminality involved in making decisions about parenthood, can also be seen here navigating changing social contexts while constructing an identity for himself from the diverse narratives available. Although Niau is more educated than most - he has a BTS, which is a BAC +2 years of science and technological training and internships - he has decided to stay and make his life on Rurutu 
instead of leaving for elsewhere. He constructs this Rurutu identity in contrast to his many friends and relatives who have left the island to find work or pursue potential pathways elsewhere:

Yea, it was important for me, and also for my family, because... since there's more and more youth who leave - army, France, Tahiti, elsewhere- I told myself, if we all leave there won't be any of us left, and who will take up the responsibility of continuing our traditions? There won't be anybody left. It's for that that I really decided to stay here. Now, I put time and effort into the dances we put on for the festivals, and our customs. I hope to one day become an orator for our tour de l'ile $e^{20}$.

Here, Niau is making a more extrinsic choice. He is outright choosing to stay behind and continue the ways of life of Rurutu. His motivation here is taking responsibility for continuing valued traditions. Hall (1988) and Bhabha term this motivation the "authority of tradition," which displaces the present in ahistorical ways. Although Niau is clearly motivated by his desire to respect traditions and carry on life on Rurutu, the decision is also made easier by his gainful employment as a boarding school attendant at the local college for the children from the neighboring island. He was able to find work and break the holding pattern that many BAC youth like Fara experience. Although finding a job or not being able to find a job influenced Niau and Fara's vital conjunctures, Loma's was actually about leaving education and leaving her job.

\section{Loma}

For some, vital conjunctures come down to choosing one cultural institution over another. For instance, Loma (whose experience with pregnancy I discussed in the last chapter)

\footnotetext{
${ }^{20}$ While tour de l'ile, translated literally, means a trip around the island (something youth are known to do for fun), here he is talking about the specific celebration of the New Year in which most of the island parades around the periphery, stopping at every town to hear the orators recount local myths and legends and witness the lifting of the heavy stones by representative strong men.
} 
experienced her first important decision when her grandmother fell ill and asked her to come home to help the family. Her vital conjuncture was the decision between continuing school to completion and the urge to come when called by her family. Within the interviews and participant observation, I noticed that the requests of older family members were taken very seriously - if someone requested a grandchild come home, it happened.

Although Loma wanted to stay in school and get a degree, to do that to the detriment of her family would make her feel bad, and open her up to shame and a loss of dignity. Staying in the extended family's good graces is also important to both male and female youths' future prospects on Rurutu, as their land inheritance must be granted by extended family.

So I quit school because of my grandmother... It was really a decision between school or my grandmother, since she was really sick. So I had to decide whether to come back here or stay on Tahiti and finish my studies. So I decided to come back here. Since she is the guardian of my three nieces, she couldn't do it herself. So that was a decision.

Her second decision showed the same loyalty to family in the face of individual growth. This decision was between taking a position in the military or staying with her significant other and starting a family. She chose to stay with Michel to start a family, but she laughed about being able to hold her sacrifices over his head.

Well, I was supposed to go into the army, but that's just... whatever... I was supposed to leave, they said I had to move to Tahiti to register, so I went, but then I came right back! And I was so happy to have done that! Because I can now tell Michel that I had the choice between the army and him, and I chose him! But really it wasn't just because of him...

As she tells it, Loma had actually signed up for the military before she and Michel met.

She had signed up because her grandmother was doing better and she was not needed on a regular basis to care for the family. She was floundering when it came to her next move, because she had already quit school. After three CPA apprenticeships in childcare and weaving, she registered to join the military, as those contracts go longer and provide good job training. 
When she was finally called in to attend, she had started seriously dating Michel. So she chose a life with him on Rurutu over her plans to join the army. As her social field changed, she adapted her aspirations and actions.

\section{Poe}

Poe was living on Tahiti when I interviewed her. It was the end of summer break and she was supposed to be heading back to university for her third and final year in the Ecole Supérieure du Professorat et de l'Education (ESPE), which is a very competitive program for prospective teachers in French Polynesia. During our interview, she was still grappling with herself over whether she was going to finish the program or quit, because her experience had showed that teaching was not a profession she was interested in, nor was it something she found herself particularly good at. She had done her internship the year before and was overwhelmed with the amount of work it was to make lessons and then teach them to rowdy primary school children. We had mostly discussed this experience before we got to her vital conjunctures narrative, so when I asked about her most important vital conjunctures, I was shocked when she responded, "The death of my father." When pressed as to why, she replied:

I was really a $t e ̂ t u^{21}$ child, but my father loved me so much... So when he died, it really marked me. I wanted to... since he asked me to follow in my his foot steps... That really changed me. So I spent 10 years following in that path to be a teacher. But then my second important decision will be whether to quit the program. Because I have worked so hard for so long, 10 years I've worked toward becoming a teacher, to just quit. But I heard a voice, telling me that it was okay to do what I wanted to do, and not continue down a path just because I promised my dad that I would. Now I am free to find out what it is I want to do. I have no idea what that is.

Clearly, the expectations of family, friends, and teachers weigh heavily on the minds of youth as they are making important decisions. Poe worked for ten years to fulfill a wish from a

${ }^{21}$ Têtu, in French, means stubborn or headstrong. This term tends to be used when children are whining, being bratty, or misbehaving. 
time barely recognizable in hindsight. As the labor pool for teachers grows, opportunities to pursue teaching become more competitive. Therefore, the dreams her father instilled in her are more constrained. She thus navigates away from this goal toward another source of dignity, which for her is finding what she wants to do. For Poe, being free of her father's expectations was both liberating and terrifying. When I interviewed her, she was still in her masters program, and trying to figure out how to make her education useful outside of teaching.

\section{Hotu}

Although Hotu is comfortable in her liminality when it comes to motherhood and education, there is one particular decision that does loom over her: living with her family. Although economically she understands that she and her boyfriend cannot afford to move away from her family, they are also, as she puts it, in dire need of their own space.

It's really... the fact that we stayed chez nous... sometimes there are discussions with, between my mom and us, because not often, how to say, she's always saying "don't do this, don't do that," and it's fiu... so... uh... we really want to move, to have our own place, you know? Like that, you can do the things that you want to do. To leave, to keep your respect, to not let your family shame you. But just as well, there is very little means to get there.

This experience of wanting to move out but having no means was one that came up a lot in my research. It is a common theme among youth in developing areas - the inability or disinclination to stop leaning on family (McGrath 2001; Smith-Morris 2007) is a major experience of youth in modern times. Here, it is doubly difficult because it is part of the Rurutu identity to be connected to family. Especially since land is family-owned, even to move out does not mean to separate from family, unless one is able to buy a plot of land elsewhere. The secondary issue that Hotu and her boyfriend have is the lack of familial land on Tahiti. Even the house her family was living in belonged to relatives who were currently living on Rurutu. As Hotu and her boyfriend were hoping to stay on Tahiti, where he would be better able to find 
work in his field and she would have the university if she decided to go back to university, they would need a large sum of money to afford it. But this vital conjuncture that she was living through during my time in the field, was ongoing. Bringing this up as a choice while knowing that it was quite improbable as far as potential future path shows how important this was to her. There are motivations behind this choice as well. Beyond wanting to be out from underneath her parents, Hotu has grown to be aware of the need for young people to declare their independence from their parents, even if moving out is not a possibility. She is, in this instance, positioning herself as a dignified mother and significant other who is "too grown" to be listening to her mother's advice about raising a child or living with her partner. In this instance, Hotu is striving for dignity even if it is not through direct action.

\section{Conclusion}

This chapter has illustrated that while there is commonality among youth from Rurutu in terms of the options that are available, as well as their social support networks, there is also a good deal of diversity in the situations in which vital conjunctures may arise, as well as differing ways in which young people deal with the decisions they must make and the

transformations that ensue. There are certainly gendered as well as age similarities; for instance, the female role as mother is still a strong identity from which to negotiate, and may make decisions concerning the distinction between school and motherhood easier than others such as finding work or supporting one's family. Young men also have roles that they fill, and that of supporter is still part of the navigable social identity. These roles influence the aspirations of the youth in each case study, but they are also shown to be in flux. Each of these youth is experiencing "becoming" - he or she is navigating toward an idea that is itself constantly shifting as social positioning changes. For instance, in the case of Vania or Maima, the 
ambivalence toward being a mother shows that the strength of this role in relation to one's education or other aspirations and definition of dignity shows the shifting social context in which they live. Their search for liminality or search for identity can both be seen as autonomous and symbols of agency, because they are utilizing breaks in the shifting social field to their own advantage.

Although many of these experiences are vital conjunctures that could occur anywhere, the context of Rurutu changes them. Furthermore, these instances of becoming reveal certain structural institutional processes that exist in the connections between Rurutu, Tahiti, and France. First, because of the ongoing generational social hierarchy - one chooses family over education because it is expected, even if they narrate the vital conjuncture as a choice instead of a requirement. Second, there is the ongoing safety net of family and Rurutu. In the case of failure, a young person can always claim that they were choosing family and regain their dignity in the situation. Third, the postcolonial economic and political spheres in French Polynesia are marking ways in which youth produce modernity on Rurutu. Whether the choice is between education and family, how to support those around them, or how to assert independence while still living at home, youth from Rurutu claim pieces of divergent identities in order to navigate their constantly moving social fields. For the youth who grew up on Rurutu, there are a lot of diverse experiences with vital conjunctures. Some also spoke of vital conjunctures that had yet to come up or be acted upon. For instance, Hotu spoke of her boyfriend's and her eventual decision to leave her family's house and make their own. This is a goal of many young couples in French Polynesia, and one of the 'rites of passage' that are becoming more and more difficult to attain. Thus, if I were to return in the future, I might find Hotu and her partner still living with her parents and still planning their eventual move. 
Throughout these vital conjunctures, as mentioned, there are levels of autonomy. This "bounded agency" shows in the decisions made by Poe, within and outside of her father's wishes, as well as Niau's choice to make his life on Rurutu instead of leaving like so many others their age. He has the ability to make those choices because of the availability of work on Rurutu. Niau's job at the college enables him to support himself and his family. Thus, he can to continue to participate in the dances and other traditions of his home island.

The interplay of outside and inside influences is also an important theme in this chapter. These vital conjunctures uphold the arguments that Good et al. (2007) make about subjectivity as the ways in which a person's inner state reflects their lived experiences, as well as the model of social navigation, of moving within an already moving world (Amit 2017; Vigh 2009). People negotiate who they are between the influences of external as well as the internal motivations instilled in them. The big stories of education, family, and social change intersperse with the little stories of love for one's brother, boyfriend, or child. Changing levels of loyalty to the memory of one's father interplay with the likelihood to actually find a job in a chosen field.

For the most part in anthropology, vital conjunctures and narratives of youth becoming adults are placed in contexts of extreme volatility, violence, and political upheaval. Here, we can see the decisions youth make when there is not as much on the line, and to argue that even when it is not life or death, these decisions still mean something and are important to study. In the absence of volatile precarity, we can still examine how colonial and postcolonial modernity, and the friction (Tsing 2011) between global encounters with French inspired imagination and local loyalties, replaces the linear progression of maturation with a sense of becoming (Biehl \& Locke 2016). 
In the next chapter, I will wrap up my case studies with a glimpse of the ways in which young people from Rurutu manage to claim their Rurutu identities and their modern, global identities in vastly different contexts and situations through their everyday interactions, both on Rurutu and on Tahiti, as well as through imagination and technology. 


\section{CHAPTER 7 \\ JE SUIS RURUTU: CONNECTION AS DIGNITY}

"Rurutuness", as mentioned in Chapter 4, is centered on Family, Land, and Church. What this really means, is that identity for youth from Rurutu is based on connections. Connections to people, whether through family, church, sports teams, or work, to land, and even to media and education, have great impact on how young people see and represent themselves. These connections maintain a more stable foundation for young people even in an increasingly global, consumer, and capitalist context. The ability of Rurutuan youth to continue these connections may actually be thanks to the ongoing French colonialism - they have the government-backed economic safety nets that uphold these connections. In addition, the connections that characterize Rurutu identity have survived a modernity that is becoming increasingly individualized. Cultivating connections is an important way for youth to strive for dignity in a way that upholds even in shifting contexts and future vital conjunctures.

Dignity, as something to be strived for, is an important part of the lifeway of youth on Rurutu, and is directly associated with the connections they cultivate. On one hand, to strive for dignity according to the French education system and modern consumer lifestyle, one must work toward being educated and finding wage labor. The most popular future careers in this perspective are teachers, architects and engineers, or the military. On the other hand, dignity according to the traditional landscape of Rurutu culture revolves around connections to family and homeland. Good (2012), in her dissertation on morality among Tongans, also argues for mediation through connections. The youth in her research use ancestry to claim their identities 
Lowe's (2003) Samoan youth in Australia experience stress and illness because they cannot afford to express their connections through the continued sending of money and material goods to family back home. Putting family first, no matter what, is seen as extremely dignified. Thus, youth will often decide to quit school in order to care for family members or even to start their own families. Connections to the homeland are also important, so young people are learning how to navigate these connections while experiencing unstable and unknown futures.

\section{Connections to Land}

The connection to land is of utmost important to Rurutuness. As Kahn $(2011,63)$ argues, land is the foundation of Tahitian consciousness and a symbol of life." On Rurutu, place is culturally inscribed with history and tradition (Basso 1996). I learned during participant observation that one's familial and individual identity is rooted in place, as well as genealogy. The caves of Rurutu, especially, hold sacred power in the eyes of even the youngest of Rurutuans, as all are exposed to the stories told during the tour de l'ile celebration each year. Even when Rurutuan youth are not on their island, they use Facebook and other social media to post pictures from Rurutu, and to declare how much they miss it. Although the traditional act of burying a baby's umbilical cord in the ground outside the home has been lost in the face of western medical influence, there is still a strong connection to the homeland. On Tahiti, one of the main complaints from youth is the negative feeling associated with not being chez toi, or on one's home island.

Niau's's decisions to stay on Rurutu even after obtaining an advanced degree, which were mentioned in the last chapter, can also be seen in reference to his connections to land. Telatu, another young man from Avera, had a similar experience. Especially for young men, the connection to land is an important one. As they are usually the ones to take over farming for the 
family in the event that they do not finish school or decide to come home, this connection to land provides them a common sense of dignity. As I heard during fieldwork, one is not Rurutu without land to harvest.

\section{Telatu}

Telatu is a 24 year old male who I met while walking through Avera with my friend Vania. She knew him because they had gone to school together, and he was willing to be interviewed. We hung around for a little while, mostly talking about what he and Vania had been doing since they had last seen each other a couple of years ago. He was very outgoing, and we joked about his lack of participation in the Heiva festival. He responded, "I don't need to dance about planting taro and growing coconuts. I actually plant taro and grow coconuts. I am already Rurutu enough." This offhanded comment shows how important connections to place and land are to young Rurutuans, whether they show it through their daily responsibilities or through rituals such as dance and folklore.

For Telatu, there were a few experiences that really grounded him in his reality. Growing up with his grandparents instead of his parents instilled in him a love of Rurutu and an intimacy with the place. Even though he finished his BAC PRO, he returned to Rurutu almost immediately and has never been back to Tahiti. At the time of our interview, it had been five years since he had stepped foot on the main island. The catalyst, he says, was the death of his grandparents. For many young people on Rurutu, their grandparents represent more than just more people who love them. Grandparents are also a link to tradition and land. Their loss made him realize that he must grow up and make a life for himself, and carry on the dreams and responsibilities of the man who raised him.

The day my grandparents left me. It was at that precise moment that I realized it was time to grow up, you know? I have to be mindful of the things I do. I have to 
reflect, and correct the things that I've done wrong. I have to have confidence in myself. At the age of 20, I had a strong feeling that I had to stay here on Rurutu. I made decisions, all the way up to the present, to make sure I can function how I want. And I succeeded. I didn't go elsewhere for whatever. I reflected and realized this is where I wanted to be. And it was thanks to them, they left good things in my head. I want to grow up and do what my grandfather did, you know?

His decisions and the experiences he found most poignant to his current identity show that even those who go to Tahiti and succeed in receiving their BAC do not necessarily abandon their Rurutu identity. Both Telatu and Niau's, who grew up in Avera, have chosen life on the island over life elsewhere, and are proud to do so. Although the males seem to show their connection to the land in a more overt way, by choosing life on Rurutu or narrating their decisions to show they have chosen that way, the females of the island also show their connections.

\section{Haina}

Haina, whose educational vital conjunctures were revealed in Chapter 5, spoke of her plans revolving around her home island:

I never did receive my BAC, but I found a great online course that I can take to prepare myself and take it again as an independent student... I could take the course at the university on Tahiti, like Vania, but then I could not stay chez moi. Life is so different, Laura, when you're not chez toi I am Rurutu. The food, the dances, the culture - I love that everyone is family here. This is where I belong. This is where I will raise my daughter.

Haina's interview was one of the longest due mostly to her explanation of how the dances she performs connect her to her heritage. This connection to the shared history of Rurutu was very important to her sense of identity.

Many youth who quit school or came back to Rurutu after finishing their studies made the same sort of remarks. One of the most common complaints about going to secondary school on 
Tahiti is that they do not feel comfortable being so far away from home. While this could certainly be normal homesickness that youth feel, I would argue that it is something more. The connection to the island is part of the identity that they construct and that is constructed for them by family and peers. Although youth can also portray identities that are influenced by French or international media, they still most often turn to what they know from their homes. Being able to claim Rurutu while navigating other social positions is extremely important.

\section{Heiva Festival}

This connection to land can also be seen during the Heiva festival held on the island (and throughout French Polynesia) every July around Bastille Day. Although the timing correlates to French celebrations, and does include a parade and honoring of the French and Tahitian flags, for the youth on Rurutu this celebration is a way to stake their identity through their ties to and knowledge of local culture, history, and space. The Heiva festival is a 2-weeklong celebration of Tahitian and Rurutu tradition and heritage. Everything is done tupuna, such that the competitions are in traditional talents such as cooking ma'a Rurutu ${ }^{22}$, weaving items in the local style, dancing to represent aspects of the local culture, or traditional tests of strength. Youth often look to this time of year as the epitome of living their Rurutuness. Specifically, one's Rurutuness is demonstrated through the annual dance troupe competition.

The dance troupes rotate members every year, and of the three times I witnessed the dances, I never saw the same group of people dance together for a town. Depending on when people come home from school, or if they have an internship during the summer, the lineup of dancers changes. Each year the three towns choose different themes to represent through their

\footnotetext{
${ }^{22}$ Ma'a is the local word for food, so ma'a Rurutu refers to local dishes prepared in traditional fashion, with such tools as a machete, bamboo spikes, stone mortars and pestles, and earthen ovens.
} 
dancing. In 2011, Moerai's theme was pandanus (weaving), in 2012 it was la peche (fishing), and in 2015 it was a historical Big Man. Avera's theme in 2015 was also based on mythology, while Auti's dance represented the breadfruit tree. Each costume was made with only natural fibers found on the island, dried and processed to create different colors, textures, and appearance to best represent each theme. The dancers must have an extensive knowledge of the meanings of each dance move and how it represents their theme, as well as an extensive knowledge of local flora to be able to collect the materials for their costumes. Dancing also necessitates strong family connections in order to find someone to put each costume together. There is, in addition to the dance competition, a competition for costumes, welcoming parties, and the chorale. Each town takes the creation and production of its costume and dance very seriously. No photos or drawings of the costumes are allowed. Each costume maker must work by remembering the design as she weaves, sews, and processes each piece. There are prototypes hung in a locked room inside the town meeting hall, where most of them toil away until the wee hours of the morning. There is pride in this work, as each person in charge of a costume was chosen by a dancer to produce it. Most of them are mothers, grandmothers, or aunts, but there are the occasional uncles, and some dancers are forced to design and fabricate their own costumes.

For these competitions, the youth who are home will join their town's dance troupe (although one can actually dance for any group, the town ties are usually firmly rooted). The dancers and others involved take the competition to represent their town very seriously. For instance, one year the team from Avera refused to attend the closing ceremonies and presentation of prizes because they had done so poorly in their dance. Originally I assumed they did not show up because they were angry that they had lost, but my dancer friends assured me it 
was because they were ashamed of their poor performance and less than satisfactory

representation of Rurutu. These dances express Rurutu's identity, history, and traditions, and are a main component of "Rurutuness". I did not meet a single youth from the island that missed dancing for at least one festival during his/her lifetime. "We dance because it's tradition. It's important to us," said Robbie, a 20-year-old dancer from Moerai. The costumes take over a month to fashion, and the dance practices run for three hours every night for the month of June. Anyone over 16 is welcome to dance. However, participation is not always as upbeat as it sounds. There is a lot of hard work, as well as infighting and cliques to deal with. The winning town's dancers, chorus, and orchestra win a pot of money to be distributed or used however they prefer. It is interesting that there is a small wage to be earned through the celebration of one's cultural heritage, but once distributed, the winnings are merely an honor.

Whether one's connection to the island is portrayed through residence or dance, it is clearly an important piece of the identity, and one that can be used to negotiate in the case of setbacks on paths that prioritize more global or French ideas of modernity.

\section{Connecting to People}

In addition to the connection to land, connecting to other people is also an important factor in youth Rurutuans identity negotiations. Whether it is through religion, family, sports, or work, Rurutu youth speak constantly of their connections.

Furthermore, these connections are the best way for those who are unable or unwilling to stay on Rurutu to keep their Rurutuness. Much like the Samoans in Australia (Lowe 2003), those who are not on Rurutu send money and gifts back often. They also utilize the available technologies to keep up with everything happening on the island. Skype has become a verb due to the ubiquity of its use when youth need to continue to feel connected to the home island. 
Young people also make sure to keep connections with others from Rurutu while on Tahiti, or other Tahitians when abroad.

Tying the connection to land with the connection to people is the fascination with sports on Rurutu. In particular, futsal (soccer played indoors), volleyball, and va'a (canoe rowing) are the three main team sports played on the island, and throughout French Polynesia. During the season, there are weekly games between the teams on the island. The team with the best record goes on to play in the regional tournament of the Australs, and then eventually in the tournament on Tahiti. Although there are a lot of healthy (and some unhealthy) rivalries between the teams, everyone comes together to support their winners that are sent to Tahiti to represent Rurutu. "We are Rurutu!" can be heard at volleyball tournaments on the main island. In addition to connecting youth to their town and island identities through competition, sports also allow young people to connect to groups on the island. It has been shown that mediating levels of belonging and negotiating "self-other divides are integral to the process of identity construction" (Roth-Gordon and Woronov 2009). Youth make lasting familial and reciprocal connections by taking a serious interest in sports. Men and women each have a separate league for futsal and volleyball, with regular practices and matches. The leagues are open to all ages as long as the players are good enough. My neighbors on the island run the Are'arii team of Moerai. The parents play along with any of their five daughters who are around and willing or old enough to play. They round out the teams with cousins and other local young people. The men's teams are always easier to complete, as they have fewer household obligations at night. The women on the volleyball team are usually younger girls still at the college, young women who have quit school or are home on vacation, or older mothers who 
play volleyball as a way to get out of the house. Though this seems like a ragtag bunch of players, they take their volleyball very seriously, and practice almost every weeknight.

\section{Maima and Raitu}

As mentioned in the previous chapter, Maima and Raitu were a couple in their late teens when I interviewed each of them during my 2015 fieldwork. Maima experienced vital conjunctures during her pregnancy and subsequent abortion, while Raitu experienced vital conjunctures in leaving his family to find a new path for himself. Lastly, they both mentioned vital conjunctures pertaining to the connections within the sporting community. For Maima, choosing school over ping-pong, even though she was internationally ranked, was a difficult decision to make.

Ping-pong became too much. I was constantly travelling, whether it was to New Zealand for invitationals, or China, Japan, Los Angeles... It all became more of a job than a sport. So I quit the year I started lycée. I miss it, but it allowed me more time to devote to my studies.

Here, Maima shows that her education is more important to her identity than her success in sports. Even though ping-pong allowed Maima to travel the globe, including trips to New Zealand, China, and the USA, her connections to home and her education were more important. She claimed that because she is the eldest of five girls in her family (her twin, as she prides herself in saying, was born two minutes later), she feels it is her duty to show her younger sisters the importance of having an education. But quitting ping-pong does not mean she quit sports. Maima is still an avid volleyball player on her local Rurutu team, which gives her even more connections to her family and island. For Raitu, finding success with his soccer team as well as finding connections with other males his age and older made him feel more outgoing and able to come out of the shell of his childhood. These connections to both home and sports support their definitions of dignity in activities as well as conversation. 
Sports are not the only connections outside those of family that provide routes to claim dignity for young Rurutuans. Niau's transformations were based around how changing his religion altered his outlook.

Niau

In an interview Niau indicated that he used to do whatever he wanted, but becoming a member of the church made him realize how important he is in other people's lives. Having been born to non-practicing Catholic parents, Niau did not spend his Sundays the way many young Rurutuans do: church from 9-12 and then home to eat a feast of ma'a Rurutu. ${ }^{23}$ When I asked young people about one aspect of life on Rurutu that sums up their experiences there, most would point to these experiences of $m a^{\prime}$ ' Rurutu. Many youth also claim their connection to church through taking part in such activities as the Saturday cleaning groups who prepare the church for Sunday mass, and the Fête de Mé parade, where they open their houses to passersby.

When I was baptized into the Protestant religion... that really changed me. I was a little rowdy. I went out and caused trouble with the other youth from the neighborhood. But that, that really put me back on the right path. I felt as though I had purpose.

Not only does connection to people make youth feel like they matter, but situational identities are also important to social navigation. Niau shows his ongoing connections to Rurutu through his new religious identity, as well as his declaration as Rurutuan through his choice to reside on the island.

Connections are not used only to proclaim one's Rurutuness. They also have quotidian uses. The next two sections show the ways in which youth utilize connections to battle boredom, and how consumption can be seen as social connection.

23 Ma'a is the Rurutu word for food, so ma'a Rurutu are the local delicacies that are prepared and served in traditional style after church on Sundays. 


\section{On se promène: Connecting to fight boredom}

Many days during my 8 months living on Rurutu, I experienced boredom. I woke up bored, ate breakfast bored, cleaned the house bored, or swam in the ocean bored. There is a certain level of daily boredom that those without steady employment must contend with. It is a theme that came up not in interviews, but in life. When Pierro got bored, he bought a bottle of liquor, grabbed his friends, and hit the Kikiri ${ }^{24}$ boards pretty quick. Vaetini favored playing volleyball out on the dirt road. Fara and Heinari both joined an artisanat co-op to battle their boredom.

On se promène is a word I learned my very first summer on Rurutu. The word, translated literally, means "we promenade" or "we walk around", but it is often used for any sort of casual gathering of young people on Rurutu, whether there is walking around or not. This sort of casual, communal entertainment is important to those young people who call the island home, because there is a certain amount of ennui or boredom inherent in the slower pace of the small island. For instance, Reva, a 19 year old I interviewed, was just beginning to transition back to the small island way of life from her time on Tahiti:

"I finished my BAC, and I am ready to go to work. I am so full of ideas, but it's hard to find a job here on Rurutu. In Papeete it's easier, but they are only 2month contracts. So I'm here on Rurutu on standby. I'm adapting back to life here on Rurutu. If you don't adapt you get bored. So I spend a lot of time on the Internet, talking to my friends on the big island, and walking around with friends here. I do chores and housework to stay busy as well."

The idea of "ennui" is very prominent among the youth on Rurutu, but especially those who have spent time elsewhere. The idea that one must re-acclimate to the slower pace of the outer islands is an important way to adapt.

${ }^{24}$ Kikiri is a gambling dice game popular on the island because anyone can act as the "bank" during games, so long as they have enough money to cover winnings. The bets are usually made in $20-100$ franc $(\$ 0.20-\$ 1)$ increments. 
Furthermore, se promener, like sports or other activities, provides a way to solidify relations and reciprocity, form identity, and in some cases, delay feeling like an adult. When interviewed during my first visit to Rurutu, Roti and Michel explained about boredom: "We get bored a lot, so we visit with each other. On se promène. We walk around, hang out, and drink when we're bored. No! We're certainly not alcoholics!” The next summer, I witnessed a lot of boredom on their part. I was living in a house with their best friend, and we had the best yard for petanque, so there was a lot of drinking and carrying on that I witnessed. There was a "bande" of eight late teens/early twenties young men, and they often drank, joked around, and played games on the small road in front of our house. I occasionally joined in the festivities, but it was very much a "boys club." In my last fieldwork in 2015, both of these young men were in serious relationships, and Michel had his baby with Loma. Michel still works in the fields like he did in 2011, but Roti joined the military and travelled the world. When I saw him, he was on leave on Rurutu with his copine, but they both lived on base on Tahiti, and mentioned that it was nice to come to Rurutu to "slow down" for a while before going back to the faster-paced life on Tahiti.

For youth on Rurutu, there are few places to go to hang out. There are no nightclubs or bars in which to gather and dance and drink, but they make the most out of their situation by having their parties on the quai or the beach. At night, one can hear the sounds of different groups of young people at these locations, places that are out of sight of adults. Curfews are not usually enforced on the island, and during weekends, or especially during the Heiva festival in July, when it is normal for adults and young people to stay out until the sunrise, drinking, dancing and partying. On nights that are not festivals, youths are often seen congregating on the beaches and near the general store to party, play music, and sing. They use many holidays to go 
out together and party, including Christmas Eve and Christmas, where they are expected to go out after opening presents among family members at midnight. Often there are numerous musical instruments, even if they consist of rattling spoons in an empty beer bottle, and most youth will sing songs or play along during the night. It has, I have noticed, also become popular for one person to bring speakers, so they can listen to music on someone's cell phone. The music found on their phones ranges from local music (even as "local" as having been recorded first-hand) to Spanish and Latin musical beats, slow ballads from Whitney Houston and Celine Dion and billboard favorites of Taylor Swift, Rihanna, and Kygo. There is even a reciprocal relationship with music on the island. Young people have developed a sharing system between cell phones using Bluetooth. In this fashion, I witnessed my favorite Taylor Swift song go from my cell phone, to a friends, and before the week was out, I heard it at a party on the other side of the island.

\section{Connecting through Consumption}

The other phrase used to talk about when young people get together is le trip ${ }^{25}$. Whether during Heiva, or any other time people have a reason to celebrate, they would ask (or declare), “On se trip?" With the exception of those who abstain due to religious reasons, there were not many young people, between the ages of 18 and 30, who did not drink. The amount they claimed to drink regularly varied from very little to drinking almost every day, but everyone I spoke to had at least tried alcohol (getting numbers on marijuana use was much more difficult, as it is illegal, and asking about it as an outsider elicited a near total shutdown of all talk of parties). Most young women mentioned that they drank very little, mostly on holidays.

${ }^{25}$ Le trip comes from the English word trip, which colloquially means to take drugs. Your Rurutuans use the term to refer to partying, or drinking heavily. The term is rarely used to describe any hanging out during the day. 
However, participant observation showed that "holiday" could mean anything from Christmas and New Year's Eve to having enough money to afford a few six-packs of beer to drink among friends. For the most part drinking among young women was saved for special occasions, but some young women and most young men drink much more frequently. This behavior was often frowned upon by family members and occasionally considered a sign of unhappiness and immaturity. Young men of Moerai often gathered at an abandoned restaurant to gamble and drink whatever alcohol they had bought. It is important to note here that guys and girls rarely drink together once they are older than teenagers. Taitia, a 23-year-old who lives with her copain and his family, remarked: " Oh no, I almost never drink with my tané. I drink with my friends, and he drinks with his friends. There are issues if we all drink together." The teens tend to party together, but once they age past lycée, they separate unless they are courting each other.

In my experiences with drinking among youth on Rurutu, there is a sense of reciprocity, in that if one person brings alcohol this week, someone else will have to bring it next time. They are merciless in their teasing and gossip about those who do not "pull their weight", but it is understood that those without jobs are not obligated to bring anything, but as soon as they are employed again they will start to give back once more. In order to keep things fair, all alcohol that is brought to a gathering is drunk then. There were many times I found myself embarrassed by my inability to help finish a case. "We don't return full bottles, Laura" was a I joke heard often. Other times it was "Once we buy it, we have to finish it." So it was important to balance how much to buy, as one would not want to run out early, but also would not want any leftover. If they did run out, they often disbanded (although we spent more than one night calling and driving around to see if anyone else was available to sell us more beer). Otherwise they will drink into the late morning if that is what it takes to finish off the case of beer. Many parents 
seriously frown upon the overconsumption that occurs almost every weekend during vacations. Studies throughout the Pacific (McDade 2007, La Vie Quotidienne 2012) have researched the issues with alcohol and drugs on the islands. The short and long term effects of these practices, especially when done in excess, include increased violence, alcoholism, and risks of depression and suicide. Although alcohol and drugs have the potential to become a problem, youth still see them as a way to bond, and show friendship.

In addition to the potential issues studied in the Pacific, overconsumption of alcohol is also one of the most frequent reasons for relationship angst, and is often cited as a reason to delay marriage, as well as childbirth. As Maruia, a 25-year-old mother who lives with her mother, daughter, and boyfriend claims, "my partner works and brings home food, but he also wastes money on alcohol; we fight about it a lot, but it passes quickly." I have witnessed these fights; they are not pretty. Both Maruia and her boyfriend can get quite violent. My first year on the island, they fought because he came to the Miss Rurutu competition drunk and was hanging around outside the temporary woven walls yelling to her during the show. She was horrified, and thus we left early. The shame, she said, was due to his inability to "grow up". There were many tearful endings to nights of drinking, as the young men and women argued over jealousy and immaturity when one or the other gets drunk. Therefore, although drinking can maintain friendships and connections between friends and groups, it can also be an antisocial behavior that is detrimental to romantic as well as familial relationships.

Another aspect of le trip that bears analysis is a certain obsession with consumption of media. As I mentioned earlier, in talking about se promener, young people on the island are increasingly attuned to international, and particularly American, media. While years ago, their mediascapes extended almost exclusively to Mexican and Brazilian telenovellas, American 
movies, music, and television shows have also infiltrated the social circles of Rurutu youths. From "Glee" to "Teen Wolf" to "Fast and Furious", they download numerous American shows and films, which have the potential to change their ideals. One of my first experiences when I arrived back on Rurutu in 2015 was an island-wide "movie night." The local MFR school had brought together a projector and one of their computers, and was hosting a movie theater at the gymnasium in Moerai. Since the island does not have a movie theater, it seemed like a big deal. There were chairs placed all around the screen, and the MFR students were selling popcorn, cakes, and other snacks to the patrons. The movie was a double feature, with "Fast \& Furious 6" and "The Avengers: Infinity War", both dubbed into French. Hollywood blockbusters had replaced the Bollywood films I had come to know from my earlier trips, and Teen Wolf, Glee, and CSI had replaced the telenovella obsessions. The difference here is that both the Bollywood and telenovellas were centered on family relationships, family support, and the like. The American shows seemed to revolve around very different relationships, specifically with friends, romantic partners, or coworkers instead of family.

The last example of connection through consumption for youth from Rurutu is the increase in popularity of social media. Zhau, Grasmuck, and Martin (2014) argue that Facebook users claim identity implicitly, not explicitly, meaning that they tend to show their selves through showing group and consumer identities over personally narrated ones. If identity is the part of self "by which we are known to others" (Altheide 2000), then these public shows of self are statements about identity. I found the online identity portrayal particularly fascinating. While on Tahiti, Rurutu youth will post numerous pictures of their home island, or even just the name, and state how much they miss their island home. Many have photos on their timelines of the outline of the island with the words "Je Suis Rurutu" emblazoned across. They post about 
dancers and sports players from the island, as well as their own friends. Facebook has become a way to portray one's identity without even having to step foot back on Rurutu. Connecting to friends near and far while on Tahiti or Rurutu is also especially important to the youth I interviewed. This is helpful to them, because they can go out and achieve goals or live modern lives without giving up the important connection to home. To keep ones Rurutu Identity is to feel as though one belongs even when one is far away.

Consumption has been linked to globalization, modernity, and development since the beginning. Youth utilizing consumption as identity markers have been shown throughout the world (Besnier 2012; Celentano 2002; Durham 2000; Jourdan 2006; Liechty 2006). However, I find that the ways in which Rurutu youth consume alcohol, luxury goods, and media shows that they still accept and thrive on some of the more traditional lifeways of their home. These patterns of consumption show how their hybrid identities (Bhabha 1994) affect everyday values and decisions. They are constantly balancing global influences and local connections in new ways. Consumption as connection instead of as individuation is an important distinction. For Rurutu youth, consumer connection to peers seems almost as important as family connections. This can be seen as a local reflection of global changes. Young people are finding modern ways to uphold long-held traditions, thus making their own definitions of modern identity. Unlike areas such as Kathmandu (Leichty 1995) or Samoa (McDade 2001; McDade \& Worthman 2004), Rurutu youth use consumption patterns to experience modern identities while using the connections facilitated by consumption to prioritize their traditional identities.

\section{Conclusion:}

In this chapter, I discussed how connections work to strengthen cultural bonds to homeland and to one's Rurutuness. Both everyday lifestyles and vital conjunctures show the 
importance of connection to the identities of young people from Rurutu. As I mentioned in the introduction to this dissertation, on of my first striking moments on Rurutu was during a Heiva festival. I found myself eating soft-serve ice cream and playing foosball in an arcade with two friends in full, all natural dance costumes after they performed an interpretive dance about harvesting and utilizing taro. This experience symbolized the complex ways in which young people connect to modernity, global influences, and their own traditional way of life and heritage. Furthermore, these connections to home provide stability in an economically and socially precarious global world. Youth are able, if nothing else; to narrate their identities in terms of connections to land and people back home. These connections thus assist in their navigation of changing social fields.

In the case of Niau, Telatu, and Haina, their connection to the land and its representations upholds their ideals of belonging. For Maima and Raitu, their sports teams allow them to connect to others and open up. In the case of boredom and consumption, these connections allow youth to lean on one another. 


\section{CHAPTER 8 CONCLUSIONS}

Through my research, I was hoping to better understand the themes and patterns that arise out of the vital conjunctures of youth. In her article on the anthropology of youth, Buckholtz $(2002,544)$ argues, "The most productive view of youth cultures and youth identities, then, must admit both the ideological reality of categories and the flexibility of identities... [drawing] from theories of practice, activity, and performance to demonstrate how youth negotiate cultural identities in a variety of contexts." The research discussed in this dissertation further expands upon Buckholtz's call for examining the flexibility of identity in different contexts by allowing youth to narrate their own experiences with practice and performance under varying degrees of social pressure. In examining both conscious liminality and social navigation, this research shows that youth react in diverse ways in relation to both a local and a global habitus. The research has identified diverse cultural scripts to which youth must respond as they navigate their lives: among these are colonial French education, traditional dances and connections to land, and the various ways in which people live while growing up on Rurutu. Although these scripts are antipodes, youths' identities are flexible and able to take on or reject multiple seemingly contradictory or coalescent institutions. They find themselves constantly transforming and repositioning.

Additionally, as Mendoza-Denton and Boam $(2015,394)$ mention in their review article about the conflicts with which youth are confronted, "More studies need to look at the connections between family and state and their roles in the formation of youth." In examining 
how these and other institutions come together during times of transformation and decision making, this research shows that youth in Rurutu utilize connections to family as a foundation upon which to build precarious futures that interact in different ways with state level influences and state defined aspirations.

The history of colonialism and French influence has had an important impact on life in French Polynesia, Tahiti, and most importantly, Rurutu. Specifically, in terms of the impact that shifting political and economic contexts have on the certainty, or lack thereof, of future paths for youth. This history is also important in the context of youths' educations. My research revealed that there are not enough vocational schools to accommodate the number of youth who are looking for certification in a trade, especially if that trade is agriculture. Education is presented as the key to a respectable, dignified future, but it often leads nowhere. Youth are forced to choose a random subject in order to get the certification of having a BAC, only to come home and learn a different trade from their parents. Or conversely, youth can wait for a job to open up or leave Rurutu in search of employment on Tahiti or abroad. While none of these outcomes sound ideal, youth navigate their potential futures by utilizing family and community connections (Fokwang 2008) while they wait for something to open up (Langevang 2008). Although education in and of itself can be seen as contributing to dignity, it is shown here to be an empty engagement with the "modern" world, or even the global market. Youth are allowed to learn about globalization, but the path they must take to become part of the global world is often undesirable. I argue that these precarious future aspirations, as well as the constantly shifting social fields they must navigate have actually destabilized the formation of youth and fragmented the formerly assumed linear transition into adulthood. 


\section{Vital conjuncture narratives: a nonlinear life course}

Narrative analysis of experience is a useful practice in anthropology. Vital conjuncture narratives, as influenced by the illness narratives made popular by medical and psychological anthropology (Saris 1995), allow the interlocutor to narrate and experience a level of continuity of their most important transformations and decisions, as well as permit the analyst to examine the role of institutions within the constructions of the narrative. These vital conjuncture narratives also allow for a more emic view of the non-linear life course, rather than an examination of an important stage in the life as defined by the anthropologist. As JohnsonHanks (2002) defines it, a vital conjuncture is a moment in the life course where aspiration and experience come together to forge a person's uncertain future. In the case of the youth from Rurutu, young adulthood is filled with uncertainty, but the ongoing connections to home provide stability and continuity; youth attempt to reach for certain goals while remaining rooted in their homeland. Thus, vital conjuncture narratives give the onus of defining what is of importance back to the interlocutors. My research has shown the various ways in which young people use both the decisions they make as well as the narration of these transformations to gain agency. Furthermore, decisions and transformations are only half of the vital conjuncture. The memory and narration of them are just as important for social navigation and identity negotiation. In the case that aspirations cannot be met, or a certain definition of dignity is unavailable, youth learn to narrate these vital conjunctures in terms of paths that still carry dignity, which include connections to family and land.

Anthropologists have been using the term vital conjuncture to identify non-linearity in the transition from youth to adulthood, as well as to examine transitions and transformations such as timing of childbirth and continuing education (Johnson-Hanks, 2005), school to work 
transitions in Ghana (Langevang 2008), and underemployed female migrants (Liversage 2009). In this research, I deployed the idea of the vital conjuncture to understand how youth move through their adolescence and their social fields. There is so much going on during this time: school decisions, residence changes, relationships beginning and ending, childbirth, death of loved ones, and the search for employment. Shifting influences and the diverse paths that youth can take or be sent down leave very few role models for youth to follow, and there is little in the literature that deals with how youth negotiate these experiences, or what the diverse shapes of their lives say about social navigation and identity negotiation in times of great change and encroaching modernity.

This research adds to the current body of literature on vital conjunctures by demonstrating that self-defined vital conjunctures can still be important even when they do not fit the description of "vital events". Although some of the vital conjunctures youth narrated in the case studies presented in this dissertation revolved around vital events (deaths, births, changes in residence), many were also mundane experiences that young people defined as tranformative. Anthropology, as a study of culture and practice, must not overlook the everyday interactions between those who are being socialized and the social institutions they come up against. Every experience has the potential to be transformative. Furthermore, within one person's life can exist vital conjunctures that make them shy away from decisions and embrace their liminality as well as others where they make a decision in order to solidify their identity.

Lastly, vital conjuncture narratives that allow for youth to pick their own transformative experiences can also be subjected to a form of quantitative analysis that reveals how external and internal forces change the kinds of experiences as well as the flow from one to another. The quantitative analysis deployed in this research demonstrates, for example, that the experiences 
of vital conjunctures can be affected by age and gender.

Although the experiences of vital conjunctures cross gender boundaries, there are certain ways that Rurutu gender norms affected outcomes. For instance, conscious liminality, in terms of pregnancy, is a phenomenon that is mostly experienced by women. This is based around both the fact that they have to carry and bear the child, and that most responsibility for their offspring falls on them. Women are socialized to take care of children from a young age, and this comes through in their (in)decisions about motherhood (Sennott \& Yeatman, 2018). However, there are some types of ambivalence that are important for both parents, mainly the idea that in the absence of marriage due to economic precarity, having a baby is a signal that the relationship is now serious, and cannot be easily disbanded.

Another vital conjuncture that appears to be gendered is the portrayal of Rurutu identity. While young men for the most part utilize their connections to the land through their role as farmer in the family, women must find other ways to stake their claim to the land. Most often, this is in the form of dance and food. The dance troupes are always weighted heavily toward women - to the point that bystanders can usually tell which town will win by who has the most young men in their dance line, because otherwise the lines are unbalanced. However, many young men respond to these requests with such exasperated claims as, "why would I pretend to plant taro in a dance when I have real taro to plant?"

\section{Rurutu Identity as Beacon}

While this research began as an economic study of how youth react to globalization and its many obstacles and opportunities, it developed into a more specific focus on how youth define and strive for their own definitions of dignity in a constantly changing social field. The narratives told a story not of precarity, but of connections, victories, and navigated identities. 
These issues are still influenced by shifting economic and political situations, but the youth in this study have found ways to resist their economic precarity by turning instead to cultural connections.

As mentioned in Chapter 3, The Tahitian Way was identified as Levy (1973) as a new local identity that is a mixture of both traditional perspectives and colonial influences. This identity, although originally conceptualized in 1973, is still an important part of the local identity. It is based in the triad of "land, church, family," but some of these definitions are clearly colonial institutions, others are traditionally local, and still others are newer, hybrid additions. For those on Rurutu, this means that religion, meaning Protestantism, Catholicism, or Mormonism, is so much a part of daily life that only two young people identified religion as a theme of one of their most important transformative experiences. On the other hand, land and family are so engrained that they emerged in the majority of narratives about transformative experiences.

Outwardly, politically motivated senses of identity are characteristic of other postcolonial areas in Oceania; for example, the popularity of Hawaiian tattooing among native Hawaiians to identify themselves in opposition to the white colonizers (Linnekin 1983). Tahitian youth who live in the urban areas on the main island also use activities (for example, canoe racing or surfing) and patterns of material consumption (for example tattoos) to represent their Ma'ohi identity (Celentano 2002). By contrast, "Rurutuness" is much less quantifiable and more fluid; it is based on songs, dances, knowledge, and the connections to people and lands that have been passed on across generations and hence survived over time.

However, these identifiers are also changing; as more emphasis is placed on education and upward mobility through wage labor, young people must find a way to show their identity 
without the traditional ties. This change is manifesting in the ways in which young people use their environment, come together, work within their families, absorb media, and speak about and react to the education system. It is even apparent in their use of Facebook and their selfportrayals on various other forms of social media.

This research has shown how important social connections are to the beacon of Rurutu identity. Connections are often used as a safety net when youth are uncertain of their paths. In the case that attempting to be "modern" or succeed in places such as Tahiti or France, it is a comfort to young people that they have a dignified identity to fall back on. Thus, they cultivate connections to their home island and the family there.

\section{Dignity as Lodestone: Searching out dignity in everyday victories}

As I mentioned in the introduction, "dignity" as a word was not one that my interlocutors mentioned a lot during my fieldwork. It was, however, a concept that I found fitting to describe the ways in which youth strive to live well through everyday decisions and transformations. For the most part, the vital conjunctures that take place in the lives of the youth in this research are "everyday" vital conjunctures. Although there is uncertainty in one's social status due to quitting school or acting irresponsible, the types of vital conjunctures youth narrated are those that could be found in anyone's life globally. However, the definitions of dignity that exist in French Polynesia generally and Rurutu specifically make these specific decisions important. The way Rurutuan youth negotiate times of uncertainty by grasping on to one identity or another, or foregoing choice altogether shows a different side to everyday victories. How young women deal with unwanted pregnancy is important, but so is examining how young people juggle work and family, deal with harmful or helpful relationships, or transform into their present selves. 
In anthropology, the study of dignity tends toward research on populations whose experiences are traumatic. Nora Jacobson (2012) examines how dignity can be violated, but also promoted or even ordinary among vulnerable individuals, focusing on how changing political discourse economic precarity, and social inequality can increase violations of dignity. Other anthropologists studying death and palliative care have also spoken about "dying with dignity," in that the ability to have autonomy in the end is important to people (Chochinov 2002; Madan 1992). However, the research discussed in this dissertation shows that dignity can be strived for, and found, in what I have termed "everyday victories." Another day that my young participants do not have a crisis of identity or anxiety over their futures, another day that they have made a decision that will lead them in a good direction is a good day.

Due to these transformations and ambivalences, the experiences of young people during these times vary drastically. Most have few real memories of choosing their classes for lycée without being prompted, because it just did not seem important, but will talk endlessly about their problems throughout the rest of secondary school. Of the 64 interviews I performed, four youth had changed their track before seconde and eight had dropped out completely. However, they were more likely to discuss problems within their family on Tahiti or Rurutu, issues with relationships, pregnancies and abortions, or the trials of finding employment. Throughout this dissertation, one can see that these various issues and local culturally relevant obstacles will pop up, necessitating each young person to negotiate priorities to uphold their own sense of worth and dignity. Some chose in ways that broke them apart from their families, while others chose or were forced to give up long-standing goals. But what I noticed, in most of the narratives, was that these youth utilize the vital conjunctures as milestones to organize an otherwise chaotic 
period of change, even including times of strife, depression, trouble or success. The people they have become are in and of themselves locally defined snapshots of modernity.

What these experiences show is agency through the reconfiguration of one's transformation scripts. Earlier I argued that precarity could be physical or social. This research shows that dignity can be seen as the obverse of social precarity. In the face of modern social precarity, or a loss of dignity through the inability to reach the colonial definition of modern adulthood, youth are able to intervene by narrating their decisions or transformations toward other forms of dignity, specifically those that are tied to "Rurutuness." The young people from Rurutu show how people negotiate modernity, especially when defined by a powerful colonizing force and required in some ways through arbitrary educational standards; that is, situations where modernity is tantalizing but unachievable. When there are few opportunities, youth rewrite the script to indicate that they have chosen a life on Rurutu, or chosen their Rurutuness, thus reestablishing agency and allowing themselves to claim dignity.

\section{Future Research}

The more pressing next steps for this research would be to examine the vital conjuncture narratives and experiences with "Rurutuness" for those who are living elsewhere. The location and timing of this dissertation research limited the scope of youth available to sample. Asking the same questions to more Rurutu youth on Tahiti, on other islands, in France, or abroad would complete the picture of these experiences of social navigation. As mentioned in Chapter 3, the connections between those who live on Rurutu and those who live ailleurs are multitudinous, and consist of complex economic and social components. Examining these connections from the other side, and not only in terms of those receiving luxury consumer goods and sending local foodstuffs, would be an important next step in understanding how modernity and 
(post)colonial relations affect social navigation throughout the time of change and transformation that young adults experience. I would like to expand my examination of the use of technology and social media as social navigation. In this dissertation, contact and social technology is an aside in the analyses. Given more time I could present a much more detailed and nuanced look at the diverse ways in which Rurutuans of all ages and geographical contexts utilize media

As previously mentioned, one of the main worries of youth from Rurutu is losing their claims to their local identity. One way they have found to continue these ties even when migrating elsewhere for work, school, or relationships is through the use of the internet. Wi-Fi and 4G cellular data has slowly but surely made its way into the lives and lifestyles of Tahitian and Rurutu households. When I first arrived on Rurutu in 2011, there were always young people standing by the wall of the hospital, as that was the only place to find Wi-Fi for free. Wi-Fi has been available on the island since 2007, but was very expensive and impractical for the first 5-7 years. Upon returning in 2015, a large portion of households (roughly 15\% of households in Moerai) had purchased and installed Wi-Fi. Those who did not have it in their houses could be found at an aunt's, cousin's, or friend's house using theirs. Three different participants claimed that they continued relationships with friends because of their access to internet. Today, youth on the island can consume outside ideas through the media; they can also see it on their friends' Facebook pages or Instagram accounts. This idea of exploring the world is made that much more real when it's someone's friend who has seen the Eiffel Tower, and not just the boy in the French textbook. Youth can also learn firsthand about life elsewhere, instead of just seeing the glamorous side of things that are shown on television. Although this was an important piece of 
identity negotiation, I merely scratched the surface of the effects of these newer technologies on the experiences of identity among youth. In the future, this is an area of great potential for research.

In addition to young people's use of Facebook and social media, the older generations are also increasingly utilizing social media websites, including Facebook, Instagram and, most importantly, Skype. Skyper has even become its own -er verb in their French Polynesian vernacular. Families and friends that were once separated by oceans and time zones can now stay in touch through video chatting, text messages, Facebook messages, and posts on one another's walls. The world is becoming increasingly small as technology progresses. Does this make life harder or easier? I would argue that in terms of negotiating the terrains of both traditional identity and modern consumer life, the internet has certainly made it easier.

Lastly, for those who have stayed on Rurutu, Facebook, Skype and the internet have now made it easier to continue friendships with those who live far away. Often, youth will befriend other youngsters from far off islands during school on the main island. For them, going home often means leaving these individuals behind. Now, however, they can find ways to keep in touch and continue to speak to each other even after graduation. Connections seem to be of utmost importance to the youth from Rurutu, and further research into their use of Facebook, Instagram, and Snapchat to express their identities would be timely and useful work. 


\section{APPENDIX}

\begin{tabular}{|c|c|c|c|c|c|c|c|c|c|c|c|c|c|c|c|c|}
\hline \multirow[t]{2}{*}{ 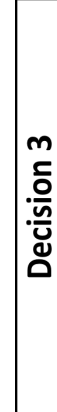 } & 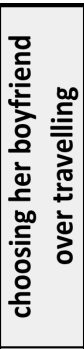 & 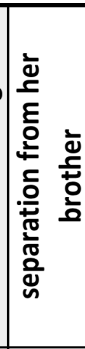 & 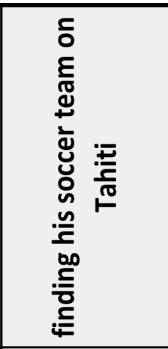 & & & 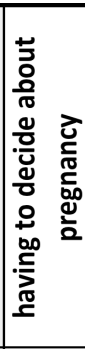 & 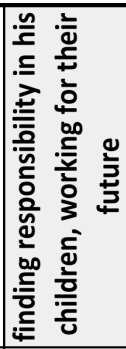 & 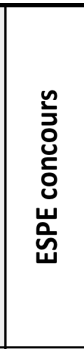 & & 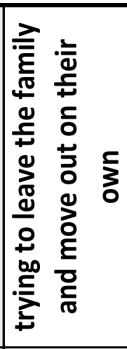 & 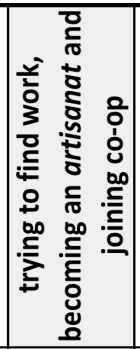 & 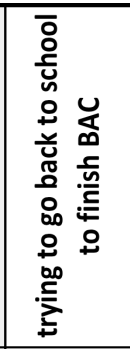 & 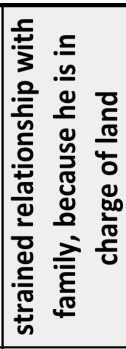 & 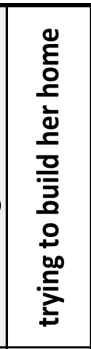 & 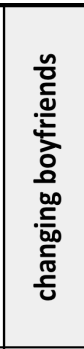 & \\
\hline & $\bar{\Phi}$ & $\underset{\varpi}{E}$ & 음 & & & $\begin{array}{l}\frac{7}{0} \\
\frac{\pi}{\pi} \\
\end{array}$ & 咅 & J & & ణ్ & 产 & ¿ & 8 & $\underline{\underline{\Xi}}$ & $\overline{\mathbf{\Phi}}$ & \\
\hline \multirow[t]{2}{*}{$\approx$} & 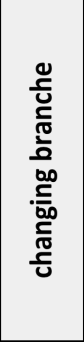 & 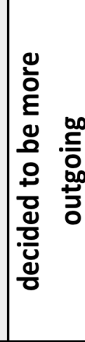 & 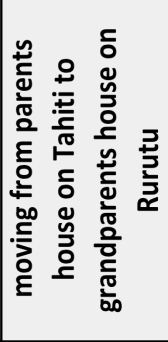 & 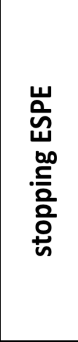 & 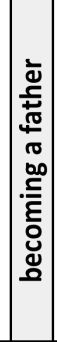 & 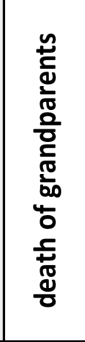 & 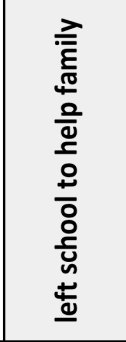 & 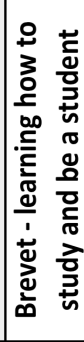 & 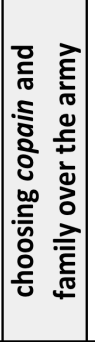 & 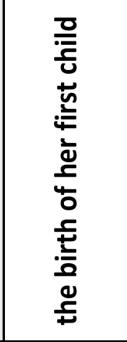 & 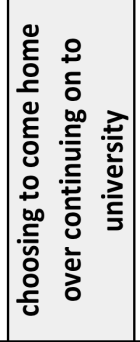 & 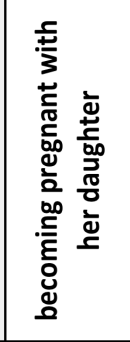 & 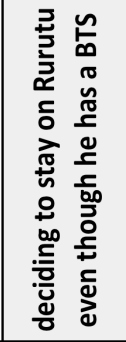 & 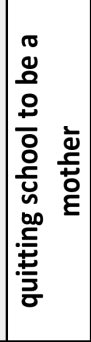 & 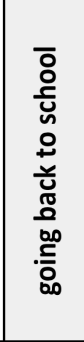 & 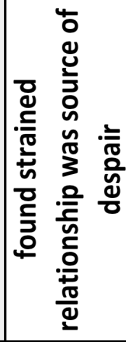 \\
\hline & ¿ & 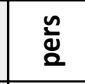 & $\underset{\leftarrow}{E ్ ~}$ & ठ & \begin{tabular}{|l|}
$\frac{2}{0}$ \\
0 \\
\end{tabular} & 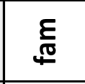 & $\underset{\Phi}{E}$ & ¿ & 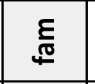 & 尊 & 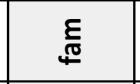 & 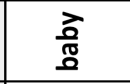 & 凹 & ¿ & ¿ & 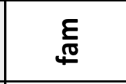 \\
\hline \multirow[t]{2}{*}{ هั } & 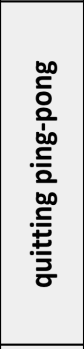 & 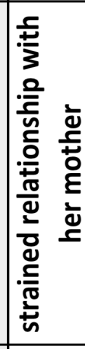 & 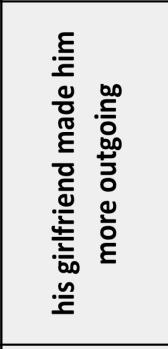 & 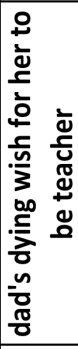 & 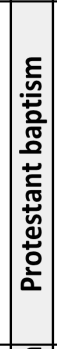 & 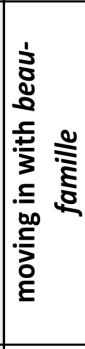 & 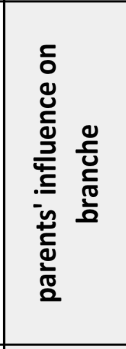 & 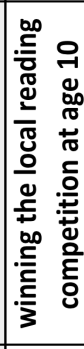 & 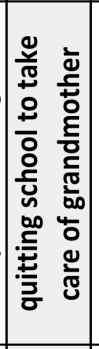 & 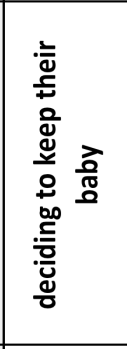 & 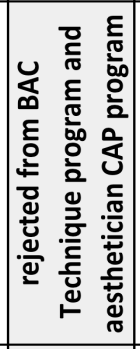 & 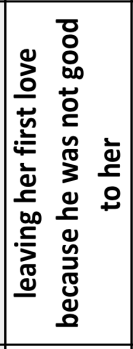 & 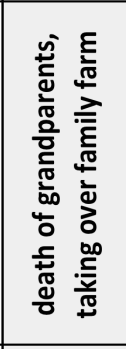 & 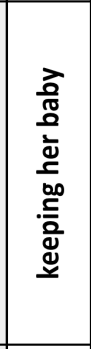 & 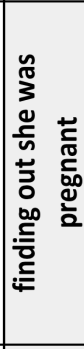 & 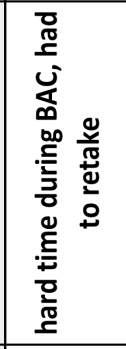 \\
\hline & 음 & 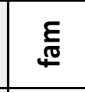 & $\bar{\Phi}$ & $\underset{\coprod}{\Xi}$ & 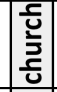 & $\underset{\Phi}{E}$ & $\underset{\varpi}{\Xi}$ & ర & 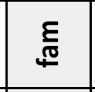 & $\underset{\Xi}{\Xi}$ & రृ & $\bar{\Phi}$ & 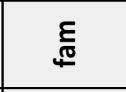 & $\frac{\overrightarrow{0}}{\frac{0}{8}}$ & 龸 & ర \\
\hline 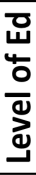 & 產 & 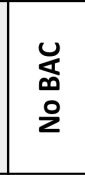 & $\begin{array}{l}\text { U⿳亠口冋 } \\
\text { o } \\
\text { z }\end{array}$ & 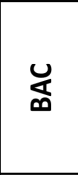 & 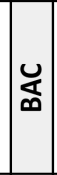 & $\begin{array}{l}\text { U⿺乚 } \\
\text { O } \\
\text { O }\end{array}$ & $\begin{array}{l}\text { Ũ } \\
\text { o } \\
\text { o }\end{array}$ & 䒽 & 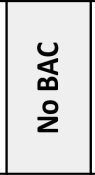 & 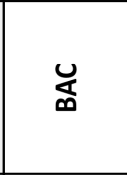 & $\begin{array}{l}\text { Ũ } \\
\text { o } \\
\text { o }\end{array}$ & $\begin{array}{l}\text { U̦ } \\
\text { O } \\
\text { o }\end{array}$ & $\stackrel{\breve{s}}{\infty}$ & $\begin{array}{l}\text { U̦ } \\
\text { o } \\
\text { o }\end{array}$ & $\boldsymbol{Y}$ & 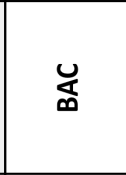 \\
\hline 总 & $\begin{array}{l}\vec{T} \\
\text { d } \\
-1\end{array}$ & $\stackrel{\sim}{\mathbf{N}}$ & $\begin{array}{l}\vec{N} \\
\stackrel{1}{-1}\end{array}$ & $\begin{array}{l}\stackrel{\sim}{\mathbf{N}} \\
\stackrel{\mathbf{N}}{\mathbf{n}}\end{array}$ & $\mid \begin{array}{l}\mathfrak{N} \\
\mathbf{N} \\
\end{array}$ & $\begin{array}{l}\stackrel{\sim}{N} \\
\mathbf{N}\end{array}$ & $\stackrel{\stackrel{\sim}{\sim}}{\mathbf{N}}$ & $\begin{array}{l}\text { ஜे } \\
\text { ஸे }\end{array}$ & $\begin{array}{l}\stackrel{N}{\sim} \\
\stackrel{\sim}{N}\end{array}$ & 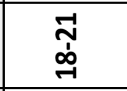 & $\stackrel{\stackrel{\sim}{\sim}}{\mathbf{N}}$ & $\stackrel{\sim}{\mathbf{N}}$ & $\begin{array}{l}\stackrel{\sim}{N} \\
\stackrel{\sim}{N}\end{array}$ & $\begin{array}{l}\stackrel{\sim}{\mathbf{N}} \\
\stackrel{\mathbf{N}}{\mathbf{n}}\end{array}$ & $\begin{array}{l}\text { ஜ్⿳亠丷厂 } \\
\text { ஸे }\end{array}$ & $\begin{array}{l}\vec{N} \\
\stackrel{0}{+}\end{array}$ \\
\hline$\sum_{0}^{5}$ & $\begin{array}{l}\overline{\overline{0}} \\
\overline{\mathrm{d}} \\
\stackrel{0}{\Sigma}\end{array}$ & $\begin{array}{l}\bar{\pi} \\
\overline{0} \\
\bar{\Sigma} \\
\Sigma\end{array}$ & 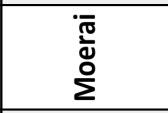 & ষ & ख & 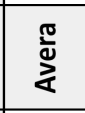 & $\begin{array}{l}\bar{\pi} \\
\overline{0} \\
\bar{\Sigma} \\
\Sigma\end{array}$ & 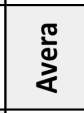 & $\begin{array}{l}\frac{\pi}{0} \\
\frac{5}{\alpha}\end{array}$ & $\begin{array}{l}\overline{\bar{\pi}} \\
\overline{0} \\
\frac{0}{\Sigma}\end{array}$ & $\begin{array}{l}\bar{\pi} \\
\bar{\Xi} \\
\bar{\Sigma} \\
\Sigma\end{array}$ & $\stackrel{\frac{\pi}{0}}{\stackrel{2}{\alpha}}$ & $\stackrel{\frac{\pi}{\pi}}{\stackrel{\square}{\alpha}}$ & $\begin{array}{l}\overline{\bar{\pi}} \\
\overline{\mathrm{J}} \\
\dot{\Sigma}\end{array}$ & $\begin{array}{l}\overline{\bar{\pi}} \\
\bar{\Xi} \\
\Sigma \\
\Sigma\end{array}$ & 坖 \\
\hline $\begin{array}{l}\stackrel{\mathscr{J}}{\frac{\pi}{\pi}} \\
\frac{\pi}{2}\end{array}$ & 宽 & 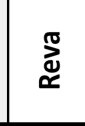 & 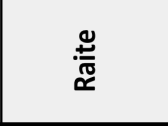 & ஃ̊ & 㺃 & 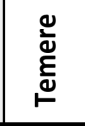 & $\stackrel{\Xi}{\overline{5}}$ & 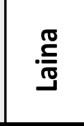 & گ్ర & $\begin{array}{l}\text { 로 } \\
\text { 오 }\end{array}$ & 离 & : & 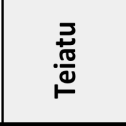 & $\begin{array}{l}\frac{\pi}{5} \\
\frac{10}{20} \\
\sum\end{array}$ & 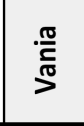 & 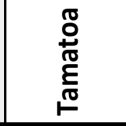 \\
\hline
\end{tabular}




\section{BIBLIOGRAPHY}

Alexeyeff, K., \& Taylor, J. 2016. Touring Pacific Cultures. Canberra, Australia: Australian National University Press.

Allison, A. 2012. Ordinary Refugees: Social Precarity and Soul in 21st Century Japan. Anthropological Quarterly, 85 (2), 345-370.

Altheide, D., 2000. Identity an Definition of the Situation in Mass Mediated Context. Symbolic Interaction, 23(1), 1-27.

Amit, V. 2011. "Before I Settle Down": Youth Travel and Enduring Life Course Paradigms. Anthropologica , 53 (1), 79-88.

Amit, V., \& Knowles, C. 2017. Improvising and Navigating Mobilities: Tacking in Everyday Life. Theory Culture \& Society, 34 (7-8), 165-179.

Amit-Talai, V., \& Wulff, H. 1995. Youth Cultures: A Cross-Cultural Perspective. New York, NY: Routledge.

Anayo, J. F. Transnational Identities in a Digital Age: A Case Study of Niue (Thesis). Melbourne, Australia: RMIT Univerisity.

Appadurai, A. 1996. Modernity at Large: Cultural Dimensions of Globalization. Mineapolis: University of Minnesota Press.

Arnett, J. J. 2000. Emerging Adulthood: A Theory of Development from the Late Teens Through the Twenties. American Psychologist , 55, 469-480.

Arnett, J. J. 2016. Life Stage Concepts across History and Cultures: Proposal for a New Field on Indigenous Life Stages. Human Development, 59, 290-316.

Basso, K., 1996. Wisdom Sits in Places: Landscape and Language among th Western Apache. Santa Fe: University of New Mexico Press.

Berry, J., Phinney, J., \& Vedder, P. 2006. Immigrant Youth in Cultural Transition: Acculturation, Identity, and Adaptation Across National Contexts. Mahwah, NJ, US: Lawrence Erlbaum Associates Publishers. 
Besnier, N. 2011. On the Edge of Global: Modern Anxieties in a Pacific Island Nation.

Stanford, CA: Stanford University Press.

Bhabha, H. 1994. The Location of Culture. New York, NY: Routledge.

Biehl, J., Good, B., \& Kleinman, A. 2007. Subjectivity: Ethnographic Investigations. Berkeley, CA: University of California Press.

Biehl, J. \& Locke, P. 2010. Deleuze and the Anthropology of Becoming. Current Anthropology, 51(3) 317-351.

Bjarnesen, J. 2009. A Mobile Life Story: Tracing Hopefulness in the Life and Dreams of a Young Ivorian Migrant. Migration Letters , 6 (2), 119-129.

Brison, K. J. 2003. Imagining Modernity in Rural Fiji. Ethnology, 42 (4), 335-348.

Brown, R. A., Hruschka, D. J., \& Worthman, C. M. 2009. Cultural Models and Fertility Timing among Cherokee and White Youth in Appalachia: Beyong the Mode. American Anthropologist , 111 (4), 420-431.

Brown, R. A., Rehkopf, D. H., Copeland, W. E., Costello, E. J., \& Worthman, C. M. 2009. Lifecourse Priorities Among Appalacian Emerging Adults: Revisiting Wallace's Organization of Diversity. Ethos , 37 (2), 225-242.

Buckholtz, M. 2002. Youth and Cultural Practice. Annual Review of Anthropology, 31, 525552.

Butler, J. 2004. Giving an Account of Oneself. New York: Fordham University Press.

Bynner, J. 2001. British Youth Transitions in Comparative Perspective. Journal of Youth Studies , 4 (1), 5-23.

Bynner, J. 2005. Rethinking the Youth Phase of the Live-course: The Case for Emerging Adulthood? Journal of Youth Studies , 8 (4), 367-384.

Calves, A.-E., Kobiane, J.-F., \& Martel, E. 2007. Changing Transition to Adulthood in Urban Burkina Faso. Journal of Comparative Family Studies , 38 (2), 265-281.

Camfield, L. 2011. Editorial: Young Lives in Transition: From School to Adulthood? European Journal of Development and Research , 23, 669-678.

Celentano, A. B. 2002. La jeuness à Tahiti: renouveau identitaire et réveil culturel. Cultures Devenirs , 32 (4), 647-661.

Césaire, A. 1972. Discourse on Colonialism. New York, NY: Monthly Review Press.

Chochinov, HM, Hack, T, McClement, S, Kristjansson, L, Harlos, M. 2002. Dignity in the Terminally Ill: A Developing Empirical Model. Social Science \& Medicine 54 (3), 433-443. 
Clark, S. S. 1993. Anxiety, Cultural Identity, and Solidarity:A Tahitian Ethnomedical Encounter. Ethos , 21 (2), 180-204.

Clark, S. S. 1994. Ethnicity Embodied: Evidence from Tahiti. Ethnology, 33 (3), 211-227.

Cohen, A. 2009. Dek Inter and the "Other": Thai Youth Subcultures in Urban Chiang Mai. Sojourn: Journal of Social Issues in Southeast Asia , 24 (2), 161-185.

Cohen, A. K. 1955. Delinquent Boys: The Culture of the Gang. Chicago: Free Press.

Cole, J. 2008. Fashioning Distinction: Youth and Consumerism in Urban Madagascar. In J. D. Cole, Figuring the Future: Globalization and the Temporalities of Children and Youth (pp. 99-124). Santa Fe, NM: School for Advanced Research Press.

Cole, J., \& Durham, D. 2008. Figuring the Future: Globalization and the Temporalities of Children and Youth. Santa Fe, NM: School for Advanced Research Press.

Cole, J., \& Durham, D. 2008. Introduction: Globalization and the Temporality of Children and Youth. In J. Cole, \& D. Durham, Figuring the Future: Globalization and the Temporalities of Children and Youth (pp. 3-24). Santa Fe, NM: School for Advanced Research Press.

Condon, R. G. 1990. The Rise of Adolescence: Social Change and Life Stage Dilemmas in the Central Canadian Arctic. Human Organization, 49 (3), 266-279.

Condon, R. G. 1995. The Rise of the Leisure Class: Adolescence and Recreational Acculturation in the Canadian Arctic. Ethos, 23 (1), 47-68.

Cook, E. E. 2016. Adulthood as Action: Changing Meanings of Adulthood for Male Part-Time Workers in Contemporary Japan. Asian Journal of Social Science , 44 (3), 317-337.

Cote, J., \& Bynner, J. M. 2008. Changes in the Transition to Adulthood in the UK and Canada: The Role of Structure and Agency in Emerging Adulthood. Journal of Youth Studies , 11 (3), 251-268.

Csordas, T. J. 2012. Psychoanalysis and Phenomenology. Ethos , 40 (1), 54-74.

Dedios, M.C. and Anderson, E. 2014. "Top of the Heap: Sarah Willen” Somatosphere (blog), September 12, 2014. http://somatosphere.net/2014/09/top-of-the-heap-sarah-willen.html

Demerath, P. 2003. Negotiating Individualist and Collectivist Futures: Emerging Subjectivities and Social Forms in Papua New Guinea High Schools. Anthropology \& Education Quarterly, 34 (2), 136-157.

Demerath, P. W. 1997. The Social Cost of Acting "Extra": Dilemmas of Student Identity and Academic Success in Post-Colonial Papua New Guinea. Ann Arbor, MI: UMI .

Dijk, R. v., de Bruijn, M., Cardoso, C., \& Butter, I. 2011. Introduction: Ideologies of Youth. African Development , 36 (3\&4), 1-17. 
Dole, C. \& Csordas, T. J., 2003. Trials of Navajo Youth: Identity, Healing, and the Struggle for Maturity. Ethos, 31 (3), 357-384.

Douglas, B. 2002. Christian Citizens: Women and Negotiations of Modernity in Vanuatu. The Contemporary Pacific, 14 (1), 1-38.

Durham, D. 2008. Apathy and Agency: The Romance of Agency and Youth in Botswana. In J. D. Cole, Figuring the Future: Globalization and the Temporalities of Children and Youth (pp. 151-178). Santa Fe, NM: School for Advanced Research Press.

Durham, D. 2004. Disappearing Youth: Youth as a Social Shifter in Botswana. American Ethnologist , 31 (4), 589-605.

Durham, D. 2000. Youth and the Social Imagination in Africa: Introduction to Parts $1 \& 2$. Anthropological Quarterly, 73 (3), 113-120.

Dyson, J. 2008. Harvesting Identities: Youth, Work, and Gender in the Indian Himalayas. Annals of the Association of American Geographers , 89 (1), 2008.

Elliston, D. A. 2004. A Passion for the Nation: Masculinity, Modernity, and Nationalist Struggle. American Ethnologist, 31 (4), 606-630.

Esson, J. 2013. A Body and a Dream at a Vital Conjuncture: Ghanaian Youth, Uncertainty and the Allure of Football. Geoforum , 47, 84-92.

Evans, K. 2007. Concepts of Bounded Agency in Education, Work, and the Personal Lives of Young Adults. International Journal of Psychology , 42 (2), 85-93.

Evans, R. 2014. Parental Death as a Vital Conjuncture? Intergenerational Care and Responsibility Following Bereavement in Senegal. Social and Cultural Geography , 15 (5), 547-570.

Finn, B., \& Oldfield, S. 2015. Straining: Young Men Working through Waithood in Freetown, Sierra Leone. Africa Spectrum , 50 (3), 29-48.

Finney, B. 2000. The Sin of Awarua. In D. Hanlon, \& G. M. White, Voyaging Through the Contemporary Pacific. New York, NY: Rowman \& Littlefield Publishers, Inc. .

Flanagan, C. A. 2008. Private Anxieties and Public Hopes: The Perils of Promise of Youth in the Context of Globalization. In J. D. Cole, Figuring the Future: Globalization and the Temporalities of Children and Youth (pp. 125-150). Santa Fe, NM: School for Advanced Research Press.

Fogel-Chance, N. 1993. Living in Both Worlds: "Modernity" and "Tradition" among North Slope Iñupiaq Women in Anchorage. Arctic Anthropology, 30 (1), 94-108.

Fokwang, J. T. 2008. Being Young in Old Town: Youth Subjectivities and Associational Life in Bamenda. Toronto: Library and Archives Canada. 
Gable, E. 2000. The Culture Development Club: Youth, Neo-Tradition, and the Construction of Society in Guinnea-Bissau. Anthropological Quaterly, 73 (4), 195-203.

George, J. R., \& Rodriguez, L. 2009. Hybrid Youth Identity in the Maori/Pacific Island Diaspora in Australia: A Study of Young Urban Polynesian Men in Sydney. New Zealand Sociology , 24 (1), 1-21.

Giddens, A. 1984. The Constitution of Society: Outline of the Theory of Structuration. Malden, MA: Blackwell Publishing.

Giddens, A. 1991. Modernity and Self-identity: Self and Society in the Late Modern Age. Stanford, CA: Stanford University Press.

Gonschor, L. 2008. French Polynesia. The Contemporary Pacific , 20 (1), 222-232.

Gonschor, L. 2009. French Polynesia. The Contemporary Pacific , 21 (1), 151-162.

Gonschor, L. 2010. French Polynesia. The Contemporary Pacific , 22 (1), 168-179.

Gonschor, L. 2011. French Polynesia. The Contemporary Pacific , 23 (1), 215-227.

Gonschor, L. 2012. French Polynesia. The Contemporary Pacific , 24 (1), 171-184.

Gonschor, L. 2013. French Polynesia. The Contemporary Pacific , 25 (1), 151-165.

Gonschor, L. 2014. French Polynesia. The Contemporary Pacific , 26 (1), 192-208.

Gonschor, L. 2015. French Polynesia. The Contemporary Pacific , 27 (1), 257-273.

Good, B. J. 2012. Phenomenology, Psychoanalysis, and Subjectivity in Java. Ethos , 40 (1), 2436.

Good, M.D., Hyde, S. T., Pinto, S., Good, B. J. 2008. Postcolonial Disorders: Reflections on Subjectivity in the Contemporary World. Los Angeles, CA: UC Press.

Good, M. K. 2012. Modern Moralities, Moral Modernities: Ambivalence and Change Among Youth in Tonga. Ann Arbor, MI: ProQuest.

Guano, E. 2002. Spectacles of Modernity: Transnational Imagination and Local Hegemonies in Neoliberal Buenos Aires. Cultural Anthropology, 17 (2), 181-209.

Hall, G. S. 1907. Adolescence : its psychology and its relations to physiology, anthropology, sociology, sex, crime, religion and education (Vol. 1). New York, NY: Appleton.

Hegarty, D., \& Tryon, D. 2013. Politics, Development, and Security in Oceania. Canberra, Australia: Australian National University E Press.

Herdt, G. H., \& Leavitt, S. C., 1998. Adolescence in Pacific Island Societies. Pittsburgh, PA: University of Pittsburgh Press. 
Hoey, B. A., \& Fricke, T. 2007. "From Sweet Potatoes to God Almighty" Roy Rappaport on Being a Hedgehog. American Ethnologist, 34 (3), 581-599.

Holland, D., Lachicotte, W., Skinner, D., \& Cain, C. 1998. Identity and Agency in Cultural Worlds. Cambridge, MA: Harvard University Press.

Holland, D. \& Lave, J. 2001. History in Person: Enduring Struggles, Contentious Practice, Intimate Identities. Ann Arbor, MI: School of American Research Press.

Institute de la Statistique de la Polynesie Français. 2017. "Répartition de le Population en Polynésie Française en 2017”. http://www.ispf.pf/docs/defaultsource/rp2017/repart_poplegale_iles_2017_v3.pdf?sfvrsn=2

Jacobson, N., 2012. Dignity and Health. Nashville, TN: Vanderbilt University Press.

Janssen, D. F. 2009. Life Course Staging as Cultural and Subjective Practice: Review, Critique, and Theoretical Possibilities. Culture \& Psychology , 15, 541-559.

Jeffrey, C. 2008. 'Generation Nowhere': Rethinking Youth Through the Lens of Unemployed Young Men. Progress in Human Geography, 32 (6), 739-758.

Jeffrey, C. 2010. Geographies of Children and Youth I: Eroding Maps of Life. Progress in Human Geography, 34 (4), 496-505.

Jeffrey, C. 2010. Timepass: Youth, Class, and Time Among Unemployed Young Men in India. American Ethnologist, 37 (3), 465-481.

Jeffrey, C., \& McDowell, L. 2004. Youth in a Comparative Perspective: Global Change, Local Lives. Youth \& Society, 36, 131-142.

Jeffrey, C., Jeffery, P., \& Jeffery, R. 2004. "A Useless Thing!" or "Nectar of the Gods?": The Cultural Production of Education and Young Men's Struggles for Respect in Liveralizing North India. Annals of the Association of American Geographers , 94 (4), 961-981.

Johnson-Hanks, J. A., Bachrach, C. A., Morgan, S. P., \& Kohler, H.-P. 2011. Understanding Family Change and Variation: Toward a Theory of Conjunctural Action. New York, NY: Springer.

Johnson-Hanks, J. 2002. On the Limits of Life Stages in Ethnography: Toward a Theory of Vital Conjunctures. American Anthropologist, 104 (3), 865-880.

Johnson-Hanks, J. 2005. When the Future Decides: Unvertainty and Intentional Action in Contemporary Cameroon. Current Anthropology , 46 (3), 363-385.

Jourdan, C. 2007. Masta Liu. In V. Amit-Talai, \& H. Wulff Youth Cultures: A Cross-Cultural Perspective. New York, NY: Routledge. 
Juarez, F., \& Gayet, C. 2014. Transitions to Adulthood in Developing Countries. Annual Review of Sociology , 40, 521-538.

Kahn, M. 2011. Tahiti Beyond the Postcard: Power, Place, and Everyday Life. Seattle, WA: University of Washington Press.

Kahn, M. 2000. Tahiti Intertwined: Ancestral Land, Tourist Postcard, and Nuclear Test Site. American Anthropologist , 102 (1), 7-26.

Kirkpatrick, J. 1987. Taure'are'a. Ethos , 15 (4), 382-405.

Kleinman, A., \& Fitz-Henry, E. 2007. The Experiential Basis of Subjectivity: How Individuals Change in the Context of Societal Transformation. In J. Biehl, B. Good, \& A. Kleinman, Subjectivity: Ethnographic Investigations (pp. 52-65). Berkeley, CA: University of California Press.

Kuwahara, M. 2006. Dancing and Tattooing the Imagined Territory: Identity Formation at Heiva and the Festival of Pacific Arts (Vol. 9). Papeete: JCAS Area Studies Research Report.

Langevang, T. 2008. 'We are Managing!' Uncertain Paths to Respectable Adulthoods in Accra, Ghana. Geoforum , 39, 2039-2047.

LeBlanc, M. N. 2007. Imaniya and Young Muslim Women in Cote D'Ivoire. Anthropologica, $49(1), 35-50$.

Leenhardt, M. 1979. Do Kamo: Person and Myth in the Melanesian World. Chicago, IL: University of Chicago Press.

Leichty, M. 1995. Media, Markets and Modernization: Youth Identities and the Exerience of Modernity in Kathmandu, Nepal. In V. Amit-Talai, \& H. Wulff, Youth Cultures: A CrossCultural Perspective. New York, NY: Routledge.

Liechty, M. 2006. "Learning to be Modern": Mass Media and Identity in Kathmandu. Studies in Nepali History and Society, 11 (1), 3-29.

Levin, P. F. 2005. Changing Childhood in Polynesia: The Impact of Robert Levy's Tahitians on Psychological Anthropology in Oceania. Ethos , 33 (4), 467-474.

Levine, R. A. 2011. Tradition in Transition: Adolescents Remaking Culture. Ethos , 39 (4), 426431.

Levy, R. I. 2005. Ethnography, Comparison, and Changing Times. Ethos , 33 (4), 435-458.

Levy, R. I. 1973. Tahitians: Mind and Experience in the Society Islands. Chicago: University of Chicago Press. 
Linnekin, J. S. 1983. Defining Tradition: Variations on the Hawaiian Identity. American Ethnologist , 10 (2), 241-251.

Liversage, A. 2009. Vital Conjunctures, Shifting Horizons: High-Skilled Female Immigrants Looking for Work. Work, Employment, \& Society, 23 (1), 120-141.

Lock, C., \& Te Lintelo, D. J. 2012. Young Zambians 'Waiting' for Opportunities and 'Working Towards' Living Well: Lifecourse and Asipiration in Youth Transitions. Journal of International Development , 24 (6), 777-794.

Lockwood, V. 2002. Poverty in Paradise: Development and Relative Income Poverty in Rural Tahitian Society. Human Organization, 61 (3), 210-225.

Lockwood, V. 1993. Tahitian Transformations: Gender and Capitalist Development in a Rural Society. Boulder, CO: Lynn Reinner Publishers.

Lockwood, V. S. 1990. Development and Return Migration to Rural French Polynesia. International Migration Review, 24 (2), 347-371.

Lowe, E. D. 2003. Identity, Activity, and the Well-Being of Adolescents and Youths: Lessons from Young People in a Micronesian Society. Culture, Medicine, and Psychiatry, 27, 187219.

Madan, T.N. 1992. Dying with Dignity. Social Science \& Medicine. 35 (4), 425-432.

Maira, S. 1999. Identity Dub: The Paradoxes of an Indian American Youth Subculture. Cultural Anthropology, 14 (1), 29-60.

Maira, S., \& Soep, E. 2005. Youthscapes: The Popular, the National, the Global. Philadelphia, PA: University of Pennsylvania Press.

Masquelier, A. 2005. The Scorpion's Sting: Youth, Marriage, and the Struggle for Social Maturity in Niger. The Journal of the Royal Anthropological Institute , 11 (1), 59-83.

Maynes, M., Pierce, J. L., \& Laslett, B. 2008. Telling Stories: The Use of Personal Narratives in the Social Sciences and History. Ithaca, NY: Cornell University Press.

McDade, T. W. 2001. Lifestyle Incongruity, Social Integration, and Immune Function in Samoan Adolescents. Social Science \& Medicine , 53, 1351-1362.

McDade, T. W., \& Worthman, C. M. 2004. Socialization Ambiguity in Samoan Adolescents: A Model for Human Development and Stress in the Context of Culture Change. Journal of Research on Adolescence, 14 (1), 49-72.

McGrath, B. 2001. "A Problem of Resources": Defining Rural Youth Encounters in Education, Work, and Housing. Journal of Rural Studies , 17, 481-495.

McRobbie, A. 1994. Postmodernism and Popular Culture. New York, NY: Routledge. 
Mead, M. 1928. Coming of Age in Samoa. New York: William Morrow \& Company.

Medicine, N. R. Growing Up Global: The Changing Transitions to Adulthood in Developing Countries. (C. B. Lloyd, Ed.) Washington, DC: The National Academies Press.

Mendoza-Denton, N. 2002. "Language and Identity." In The Handbook of Language Variation and Change, edited by J. K. Chambers, P. Trudgill, and N. Schilling,

Mendoza-Denton, N., \& Boum, A. 2015. Breached Innitiations: Sociopolitical Resources and Conflicts in Emergent Adulthood. Annual Review of Anthropology, 44, 295-310.

Miles, A. 2000. Poor Adolescent Girls and Social Transformations in Cuenca, Ecuador. Ethos, $28(1), 54-74$.

Miles, S. 2000. Youth Lifestyles in a Changing World. Philadelphia, PA: Open University Press.

Morarji, K. 2014. Subjects of Development: Teachers, Parents, and Youth Negotiating Education in Rural North India. European Journal of Development Research, 26 (2), 175185

Morrow, V. 2013. Troubling Transitions? Young People's Experiences of Growing up in Poverty in Rural Andhra Pradesh, India. Journal of Youth Studies , 16 (1), 86-100.

Nakano, L. Y. 2000. Volunteering as a Lifestyle Choice: Negotiating Self-Identities in Japan. Ethnology, 39 (2), 93-107.

Orta, A. 1999. Syncretic Subjects and Body Politics: Doubleness, Personhood, and Aymara Catechists. American Ethnologist , 26 (4), 864-889.

Osella, F., \& Osella, C. 2009. Muslim Entrepreneurs in Public Life Between India and the Gulf: Making Good and Doing Good. Journal of the Royal Anthropological Institute, S202-S221.

Pike, I., Mojola, S. A., \& Kabiru, C. W. 2018. Meking Sense of Marriage: Gender and the Transition to Adulthood in Nairobi, Kenya. Journal of Marriage and Family, 80 (5), 12981313.

Poirine, B. 2010. The Economy of French Polynesia: Past, Present, Future. Pacific Economic Bulletin , 25 (1), 24-34.

Powis, R., 2016. Enduring Precarity: Emergent Masculinities and Rethinking Couvade in Dakar, Senegal. Proceedings from the African Futures Conference, 1 (1), 197-202.

Punch, S. 2002. Youth Transitions and Interdependent Adult-Child Relations in Rural Bolivia. Journal of Rural Studies , 18, 123-133

Riley, K. C. 2007. To Tangle or not to Tangle: Shifting Language Ideologies and the Socialization of Charabia in the Marquesas, French Polynesia. In M. Makihara, \& B. B. 
Shieffellin, Consequences of Contact: Language Ideologies and Sociocultural Transformations in Pacific Societies (pp. 70-95). Oxford, UK: Oxford University Press.

Riley, K. C. 2013. Fêtes traditionnelles et festivals glocalisés aux Marquises : Utilisation des systèmes alimentaires syncrétiques pour forger des identités hybrides. Anthropologie et Sociétés, 37 (2), 91-111.

Roche, S. 2014. Domesticating Youth: Youth Bulges and their Socio-political Implications in Tajikistan. New York, NY: Berghahn Books.

Roth-Gordon, J., \& Woronov, T. E. 2009. Youthful Concerns: Movement, Belonging and Modernity. Pragmatics , 19 (1), 129-143.

Saris, A. 1995. Telling Stories: Life Histories, Illness Narratives, and Institutional Landscapes. Culture, Medicine, and Psychiatry. 19 (1), 39-72.

Saura, B. 2015. Histoire et Mémoire des Temps Coloniaux en Polynésie Française. Pirae: Au Vent des Îles.

Schlegel, A. 1995. A Cross-Cultural Approach to Adolescence. Ethos , 23 (1), 15-32.

Schlegel, A., \& Barry, H. 1991. Adolescence: An Anthropological Inquiry. New York, NY: Free Press.

Sennott, C., \& Mojola, S. A. 2017. "Behaving Well": The Transition to Respectable Womanhood in Rural South Africa. Culture Health \& Sexuality, 19 (7), 781-795.

Sennott, C., \& Yeatman, S. 2018. Conceptualizing Childbearing Ambivalence: A Social Dynamic Perspective. Journal of Marriage and Family, 80 (4), 888-901.

Smith-Morris, C. 2007. Social Capital In A Mexican-American Community In Dallas, Texas. Urban Anthropology and Studies of Cultural Systems and World Economic Development 36 (4), 425-456.

Snellinger, A. 2016. "Let's See What Happens": Hope, Contingency, and Speculation in Nepali Student Activism. Critial Asian Studies , 48 (1), 27-49.

Somers, M. R. 1994. The Narrative Constitution of Identity: A Relational and Network Approach. Theory and Society, 23 (5), 605-649.

Sulmasy D.P. 2007. Human Dignity and Human Worth. In Perspectives on Human Dignity: A Conversation edited by J. Malpas and N. Lickiss N. Springer, Dordrecht

Tetiarahi, G. 2005. French Nuclear Testing in the South Pacific, or When France Makes Light of its Duty to Remember. The Contemporary Pacific , 17 (2), 378-381.

Thaman, K. H. 2003. Decolonizing Pacific Studies: Indigenous Perspectives, Knowledge, and Wisdom in Higher Education. The Contemporary Pacific, 15 (1), 1-17. 
Thompson, V.M.L \& Adloff, R., 1971. French Pacific Islands: French Polynesia and New Caledonia. Berkeley, CA: University of California Press.

Tsing, A. 2005. Friction: An Ethnography of Global Connection. Princeton and Oxford: Princeton University Press.

Vigh, H. 2009. Motion Squared: A Second Look at the Concept of Social Navigation. Anthropological Theory, 9 (4), 419-438.

Vleet, K. E. 2003. Adolescent Ambiguities and the Negotiation of Belonging in the Andes. Ethnology, 42 (4), 349-363.

Walker, T. P. 2002. Rurutu, Memoires d'Avenir d'Une Ile Australe. Papeete: Haere Po.

Weisner, T. S., \& Lowe, E. D. 2005. Chapter 17. Globalization, Childhood, and Psychological Anthropology. In C. Casey, \& R. B. Edgerton, A Companion to Psychological Anthropology: Modernity and Psychocultural Change (pp. 315-336). Oxford, UK: Blackwell Publishing Ltd.

Willis, P. 1977. Learning to Labor: How Working Class Kids Get Working Class Jobs. New York, NY: Columbia University Press.

Wohlmann A. 2014. Illness Narrative and Self-Help Culture: Self Help Writing on Age-Related Infertility. European Journal of Life Writing, Vol III.

Worthman, C. M. 2011. Inside-Out and Outside-In? Global Development Theory, Policy, and Youth. Ethos , 39 (4), 432-451.

Zhau, S., Grasmuck, S., and Martin, J. 2014. "Identity Construction on Facebook: Digital Empowerment in Anchored Relationships." Computers in Human Behavior, 24, 1816-1836.

Zigon, J. 2010. Moral and Ethical Assemblages. Anthropological Theory, 10 (1-2), 3-15. 